Florida International University FIU Digital Commons

$4-5-2012$

\title{
The Examination of the Relationships Among Secondary Principals' Leadership Behaviors, School Climate, and Student Achievement in an Urban Context
}

Valmarie Rhoden

Florida International University, valmarier@bellsouth.net

DOI: $10.25148 /$ etd.FI12050245

Follow this and additional works at: https://digitalcommons.fiu.edu/etd

\section{Recommended Citation}

Rhoden, Valmarie, "The Examination of the Relationships Among Secondary Principals' Leadership Behaviors, School Climate, and Student Achievement in an Urban Context" (2012). FIU Electronic Theses and Dissertations. 635.

https://digitalcommons.fiu.edu/etd/635 


\title{
FLORIDA INTERNATIONAL UNIVERSITY
}

Miami, Florida

THE EXAMINATION OF THE RELATIONSHIPS AMONG SECONDARY

PRINCIPALS' LEADERSHIP BEHAVIORS, SCHOOL CLIMATE, AND STUDENT

ACHIEVEMENT IN AN URBAN CONTEXT

\author{
A dissertation submitted in partial fulfillment of the \\ requirements for the degree of \\ DOCTOR OF EDUCATION \\ in \\ EDUCATIONAL LEADERSHIP AND PROFESSIONAL STUDIES \\ by \\ Valmarie Rhoden
}

2012 
To: Dean Delia C. Garcia

College of Education

This dissertation, written by Valmarie Rhoden, and entitled The Examination of the Relationships Among Secondary Principals' Leadership Behaviors, School Climate, and Student Achievement in an Urban Context, having been approved in respect to style and intellectual content, is referred to you for judgment.

We have read this dissertation and recommend that it be approved.

Delia Garcia

$\begin{array}{r}\text { Joyce Fine } \\ \hline \text { Erskine Dottin }\end{array}$

\author{
Thomas G. Reio Jr., Major Professor
}

Date of Defense: April 5, 2012

The dissertation of Valmarie Rhoden is approved.

Dean Delia C. Garcia

College of Education

Dean Lakshmi N. Reddi

University Graduate School

Florida International University, 2012 
(C) Copyright 2012 by Valmarie Rhoden

All rights reserved. 


\section{DEDICATION}

To Dr. Dominic Mohamed

This accomplishment would not have been possible without your guidance and belief.

I am very grateful for your extensive knowledge, leadership, and personal support.

You left a great and lasting legacy and inspiring example for others to follow, and you are greatly missed. 


\section{ACKNOWLEDGMENTS}

My dissertation journey took me down five distinct metaphorical streets, all replete with potholes. These streets looked suspiciously like the five dissertation chapters. On the first four streets, I naively stumbled into the potholes because I failed to see the impending perils or was concentrating too much on arriving at my destination. However, I learned a great lesson on this journey from these first four trips and decided to take a different route on the fifth. This last trip was much more productive and pleasurable and had many less stumblings.

Several professional associates deserve great thanks for guiding me in arriving at my destination - the completion of my dissertation. First, special gratitude goes to Dr. Thomas G. Reio, Jr., my major professor and dissertation chair. He agreed and bolstered me throughout that I would complete this journey with grace, and I never doubted him or my ability to do it. Very special thank yous to Dr. Delia Garcia, Dr. Joyce Fine, and Dr. Erskine Dottin, who accompanied me on this journey as my dissertation committee. I will be forever grateful for your feedback, guidance, and words of encouragement over these past years.

Now, to my sons Edward and Christopher, you have always been the wind beneath my wings. I have so wanted to be an example of excellence and perseverance for you and the entire family. Mama and Daddy, as you rest in the Master's Arms, know that you were ministering and protecting angels for me as I traversed through this journey. I pray you are proud of me. Thank you to my sisters, Willie Mae, Shirley, and Bernice, and my brother Larry. I learned how to be the best me through your love, guidance, and examples. To my friends, pastors, and church families, who prayed with me and for me, 
thank you. You helped me see more clearly that all things are possible through Christ Who strengthens me.

To my heavenly Father, I thank you for prospering me in mind, body, and soul. Your means of prosperity empowered me to succeed and your blessings allowed me to do just that. Thank you for never leaving or forsaking me. To You I give all the glory for all that I am and all that I ever hope to be. 


\section{ABSTRACT OF THE DISSERTATION \\ EXAMINATION OF THE RELATIONSHIPS AMONG SECONDARY PRINCIPALS' \\ LEADERSHIP BEHAVIORS, SCHOOL CLIMATE, AND STUDENT \\ ACHIEVEMENT IN AN URBAN CONTEXT}

by

Valmarie Rhoden

Florida International University, 2012

Miami, Florida

Professor Thomas G. Reio, Jr., Major Professor

School principals' leadership is key to successful school reform, as is increased student achievement. This nonexperimental ex post facto study tested relationships among secondary school principals' leadership behaviors, school climate, and student achievement.

Of 165 secondary school principals from the three largest school districts in South Florida, 58 completed three online survey instruments: the Leadership Practices Inventory, School Climate Inventory-Revised, and researcher-designed Demographic Questionnaire. Student achievement was measured by students' scores on the reading and mathematics Florida Comprehensive Assessment Tests. Three null hypotheses tested relationships among (a) five principals' leadership behaviors and seven domains of school climate; (b) principals' leadership behaviors and student achievement; and (c) principals' leadership behaviors, school climate, and student achievement.

Multiple linear regressions were used to determine the degree to which the independent variables predicted the dependent variables for the first two hypotheses. 
ANOVAs tested possible group differences between the demographic and research variables as controls for the third hypothesis. Partial correlational analyses tested the strength and direction of relationships among leadership behaviors, climate, and achievement.

Results revealed partial support of the hypotheses. None of the leadership variables significantly predicted school climate. No significant relationships were found among the five leadership behaviors and student achievement. Demographic group differences in school climate and student achievement were marginally significant. The leadership behaviors of Inspiring a Shared Vision and Enabling Others to Act were positively linked to reading achievement. Partial correlations were found ( $r .27$ to -.35$)$ among school climate variables of Order, Involvement, and Expectation and achievement variables. The Modeling the Way leadership variable was negatively associated with reading achievement.

After controlling for gender, years at current school, and years in the district, partial positive correlations were found among leadership, school climate, and student achievement. Inspiring a Shared Vision, Enabling Others to Act, Encouraging the Heart, and Challenging the Process leadership variables were partially correlated to Order, Leadership (Instructional), and Expectation climate variables. Study results should provide policymakers and educators with a leadership profile for school leaders challenging the status quo who can create schools for enhanced student learning and relevance to the needs of students, families, and society. 


\section{TABLE OF CONTENTS}

CHAPTER

PAGE

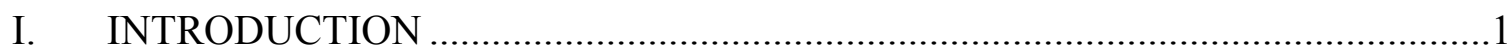

Background to the Problem …………….........................................................

The Principal as Leader..................................................................................5

Principal Leadership and School Climate .........................................................

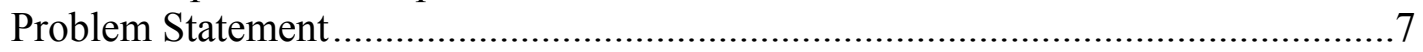

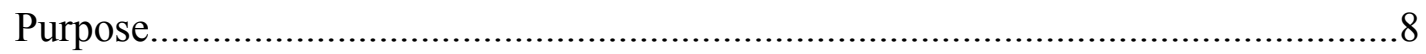

Research Questions and Hypotheses ……………...............................................

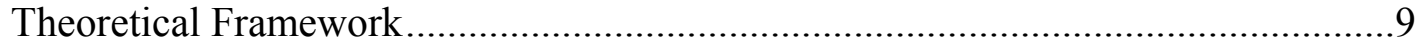

Transformational Leadership .....................................................................

Transformational vs. Transactional Leadership .............................................10

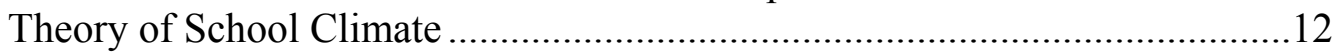

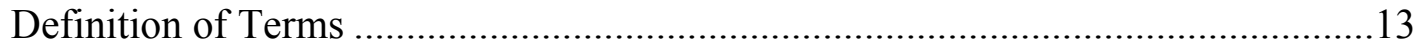

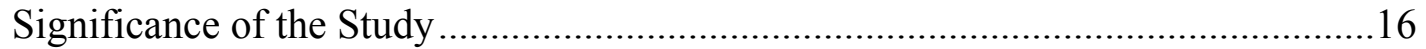

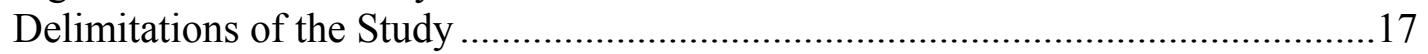

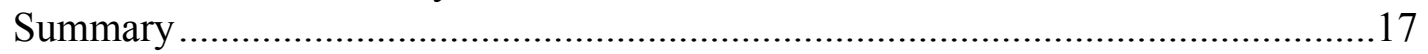

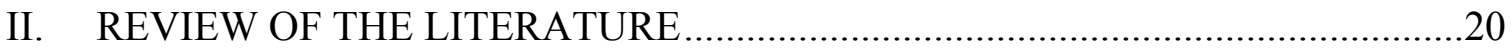

Transformational Leadership ......................................................................22

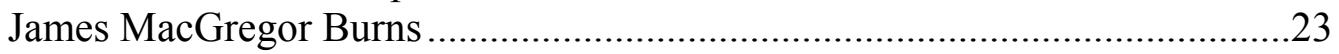

Bernard M. Bass and Colleagues ...................................................................24

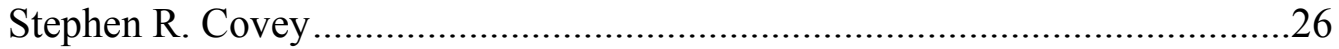

James Kouzes and Barry Posner .................................................................... 31

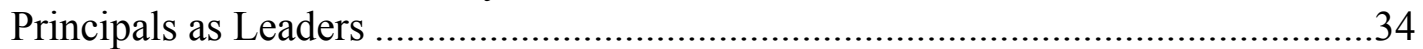

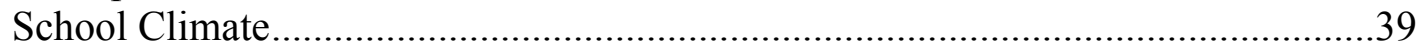

School Climate and Student Achievement .............................................................

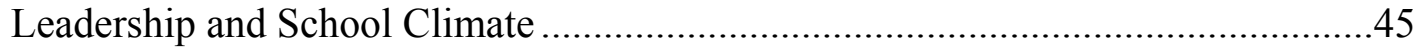

Leadership and Student Achievement ………………......................................48

Leadership, School Climate, and Student Achievement............................................51

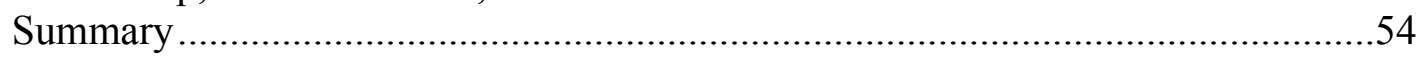

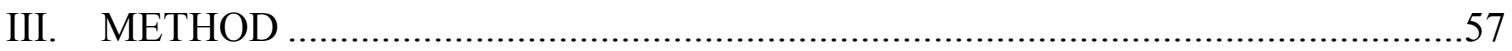

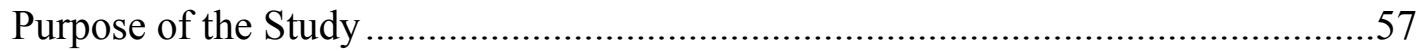

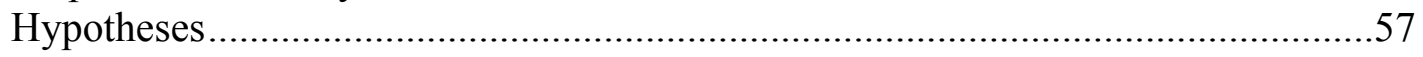

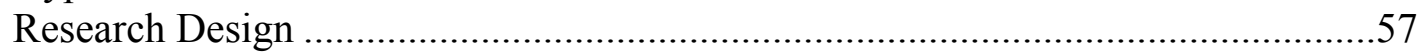

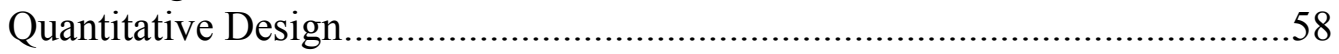

Nonexperimental Ex Post Facto Design ......................................................58

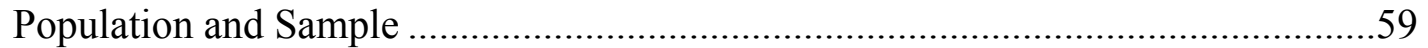

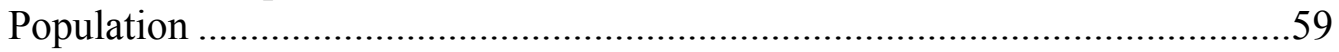

Sample

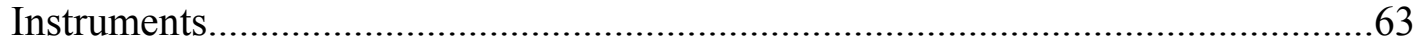

Demographic Questionnaire ......................................................................63 
Leadership Practices Inventory ....................................................................64

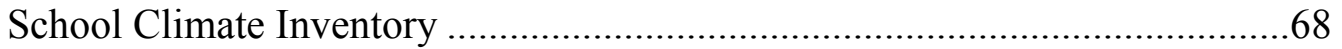

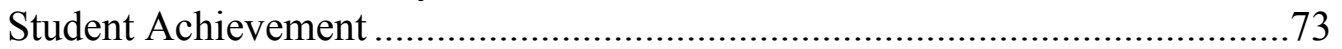

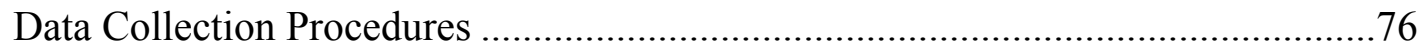

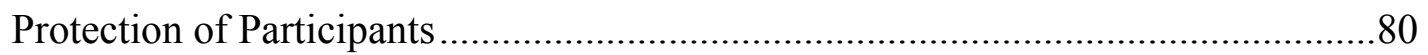

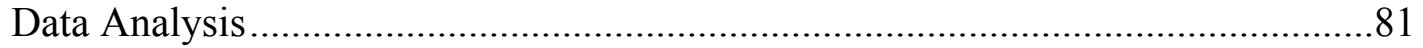

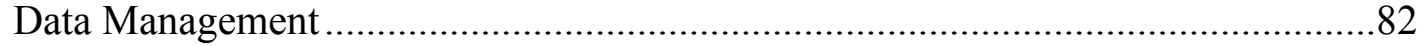

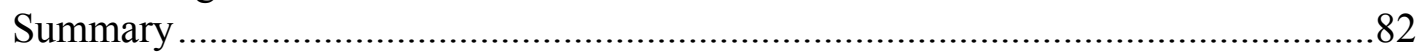

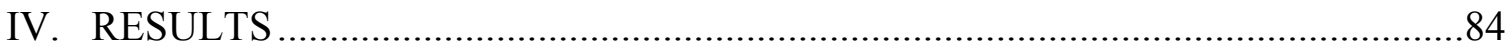

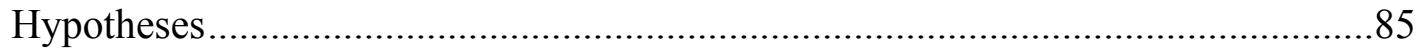

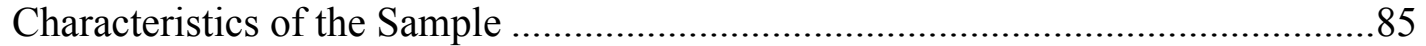

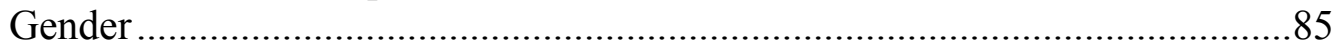

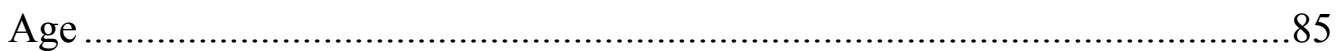

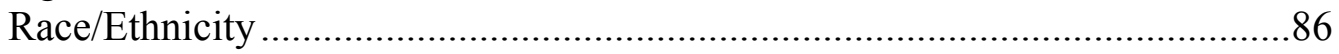

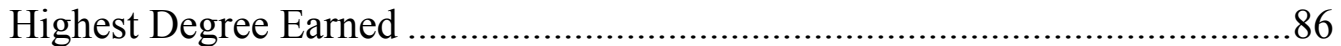

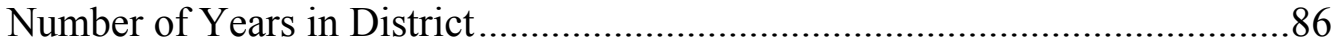

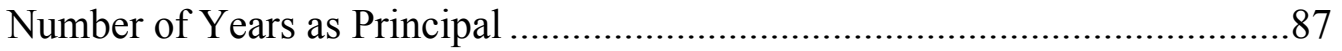

Number of Years as Principal at Current School ...............................................8

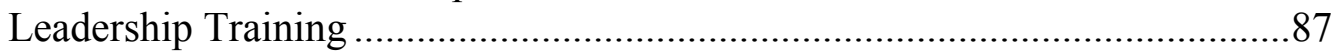

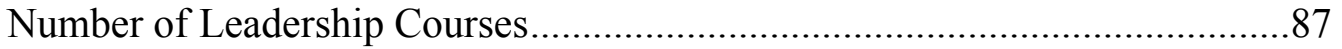

Cross Tabulations of Background Demographic Variables...............................89

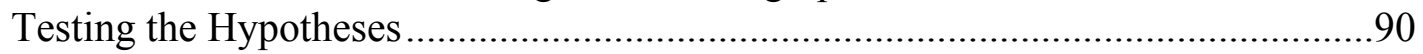

Testing Hypothesis 1: Correlational Analysis.................................................92

Testing Hypothesis 2: Correlational Analysis.................................................95

Testing Hypothesis 3: Group Differences.....................................................98

Testing Hypothesis 3: Among Leadership Behaviors, Climate, and

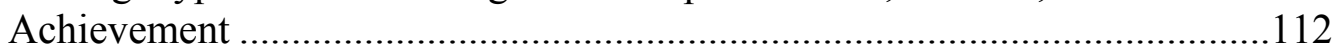

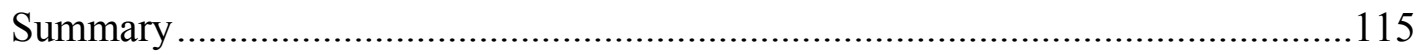

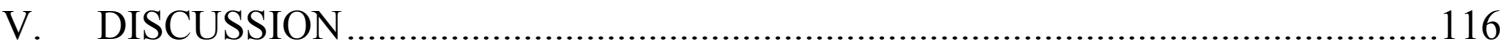

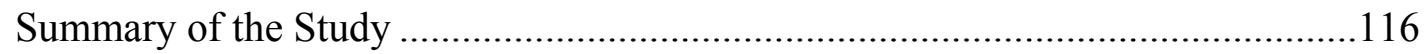

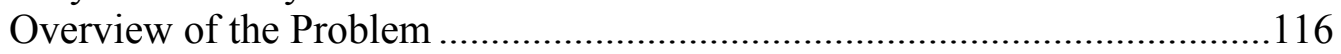

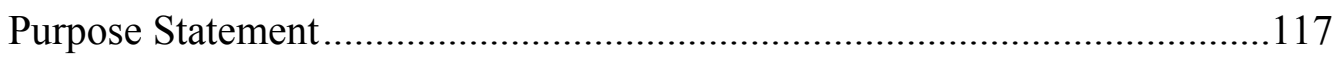

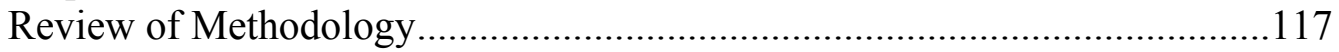

Discussion of the Results and Relationship to Previous Literature .........................119

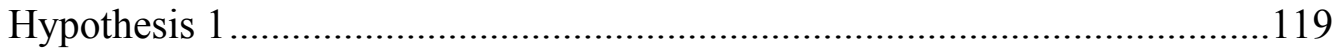

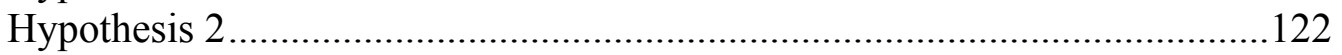

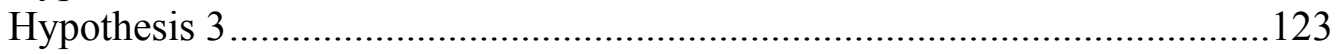

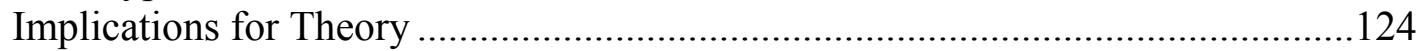

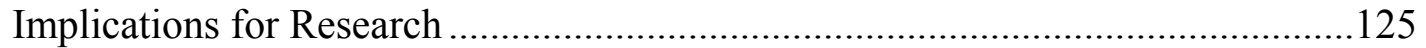

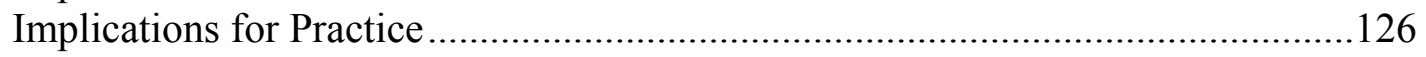

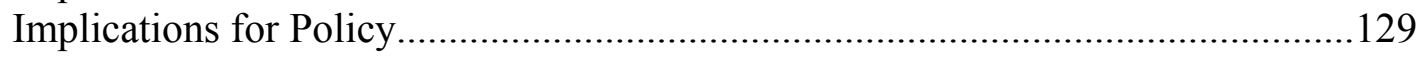

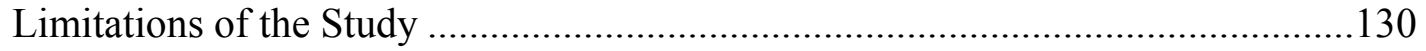

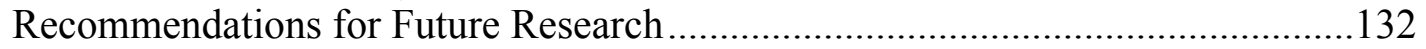


Conclusion .....

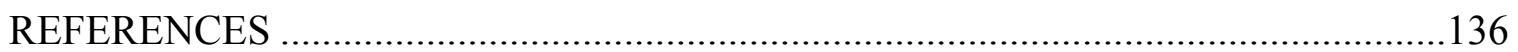

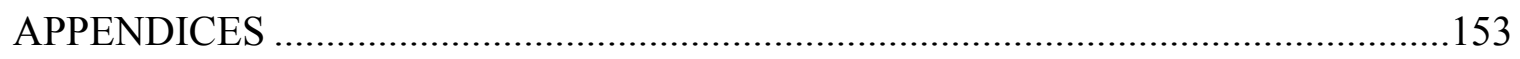

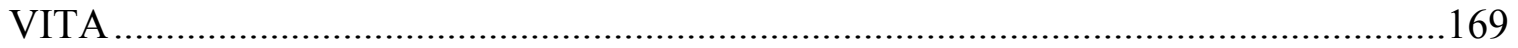




\section{LIST OF TABLES}

TABLE

PAGE

1. Gender and Racial/Ethnic Demographic Characteristics of Secondary Principals in the Three Counties by Percentage .61

2. Distribution of Middle and High School Principals in the Tri-County Area

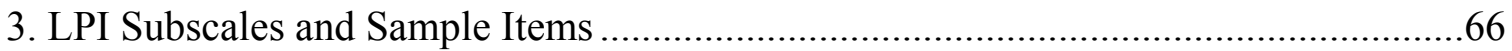

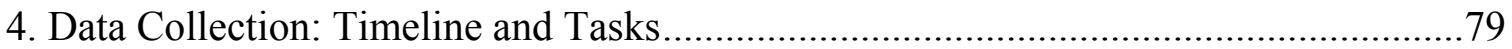

5. Frequencies and Percentages of Demographic Characteristics of the Sample $(N=58)$ .88

6. Cross Tabulations of Demographic Variables. .91

7. Multiple Regression Analyses Predicting Order, Leadership, and Environment Climate Variables

8. Multiple Regression Analyses Predicting Instruction, Involvement, and Expectation Climate Variables

9. Multiple Regression Analysis Predicting Collaboration Climate Variable

10. Multiple Regression Analyses With Leadership Behaviors Predicting Percentage Passing in Reading

11. Multiple Regression Analyses With Leadership Behaviors Predicting Percentage Passing in Mathematics.

12. Multiple Regression Analyses With Leadership Behaviors Predicting Mean Passing in Reading.

13. Multiple Regression Analyses With Leadership Behaviors Predicting Mean Passing in Mathematics.

14. Demographic Group Mean Differences: Student Percentage Passed in Reading

15. Demographic Group Mean Differences: Student Percentage Passed in Mathematics 
16. Demographic Group Mean Differences: Student Mean Gains in Reading

17. Demographic Group Mean Differences: Student Mean Gains in Mathematics

18. Demographic Group Mean Differences: Leadership and Gender 104

19. Demographic Group Mean Differences: Leadership and Age

20. Demographic Group Mean Differences: Leadership and Ethnicity .105

21. Demographic Group Mean Differences: Leadership and Education....... .106

22. Demographic Group Mean Differences: Leadership and Years in District .106

23. Demographic Group Mean Differences: Leadership and Years as Principal

24. Demographic Group Mean Differences: Leadership and Years in Current School

25. Demographic Group Mean Differences: Leadership and Number of Leadership Courses. .108

26. Demographic Group Mean Differences: Climate and Gender 108

27. Demographic Group Mean Differences: Climate and Age. 109

28. Demographic Group Mean Differences: Climate and Ethnicity 109

29. Demographic Group Mean Differences: Climate and Education 110

30. Demographic Group Mean Differences: Climate and Years in District 110

31. Demographic Group Mean Differences: Climate and Years as Principal 111

32. Demographic Group Mean Differences: Climate and Years at Current School

33. Demographic Group Mean Differences: Climate and Number of Leadership Courses. 
34. Partial Correlation Analysis of Relationships Among Leadership Behavior, Climate, and Student Achievement....................................................................114 


\section{CHAPTER I}

\section{INTRODUCTION}

The purpose of this nonexperimental ex post facto study was to test the relationships among leadership behaviors, school climate, and student achievement. This chapter provides the introduction to the study. First, the background to the problem is described, followed by the problem statement, purpose, and hypotheses. Next, the theoretical framework and definition of terms are described. Finally, the significance of the study to the field and delimitations are discussed. The chapter concludes with a summary and advanced synopsis of the remainder of the study.

\section{Background to the Problem}

All students deserve the intellectual development, motivation, and skills that equip them for successful work and lifelong learning. A primary predictor of whether students will become successful adults is whether they graduate from high school (America's Promise, 2008). Few institutions have a greater impact on the quality of American life than the public secondary schools, the foundation for adult participation in society and the workplace (Miami-Dade County Public Schools Secondary School Reform Plan, 2005). One of the great challenges facing American public schools is the improvement of urban education (Harvey \& Housman, 2004; Pingle \& Cox, 2007). In the U.S., one in five students missed 3 or more days of school monthly, making the national attendance 25th of 45 countries studied (Lifson, 2008). Moreover, 10\% of high schools are "dropout factories," from which only $60 \%$ of students graduate (Zuckerman, 2007).

Even more astounding, approximately 2,000 American high schools produce more than half of the nation's dropouts. In these "dropout factories," nearly $60 \%$ of 
students drop out within 3 years. In addition, these schools include $69 \%$ of all Black dropouts and $63 \%$ of all Hispanic dropouts, compared to $30 \%$ of all White dropouts. Each year, nearly 1.2 million students fail to graduate from high school, and more than half are from racial/ethnic minority groups. Nationally, only $71 \%$ of all students graduate from high school on time with a regular diploma, and only half of Black and Hispanic students earn diplomas in 4 years. In many states, the difference between White and minority graduation rates is as high as $40 \%$ or $50 \%$. These statistics diminish, significantly, students' chances of securing steady employment and becoming contributing members of society (Alliance for Excellent Education, 2009).

The Nation's Report Card, a national measure of the effectiveness of reform efforts, showed that in 2005 the reading and mathematics scores of over 21,000 high school seniors from 900 schools across the country were lower than scores in 1992 (National Center for Education Statistics, 2007). In recent years, public officials, researchers, and national leadership organizations have recognized the critical importance of redesigning programs and options for secondary school youth to provide them with equitable and excellent education (Harvey \& Housman, 2004).

In 1983, an education commission created by then-President Ronald Reagan released the report, A Nation at Risk. This report focused national attention on the nation's failing public education system, a focus similar to that precipitated by Russia's first entrance into space in 1957. However, in 1995, Berliner and Biddle questioned the statistics documenting educational failure and pointed to the lack of citations for these statistics used as evidence that U.S. schools were of low quality. Berliner and Biddle also alleged that politicians had used the report to implement misdirected reforms. In 
response, education scholar John I. Goodlad (2003) observed that the Nation at Risk report gained media attention but the attention rarely focused on the recommendations. Rather, the report instead summarized the disappointing statistics and problems that existed in schools. Goodlad argued further that the link between student achievement and the nation's economy was overstated. Other criticisms of the report noted its emphasis on high schools and ignoring of kindergarten through eighth grade education as contributing factors to low student achievement (Peterson, 2003). Dr. Gerald W. Bracey (2003), a professor and independent scholar who wrote a monthly column for Phi Delta Kappan, commented that $A$ Nation at Risk was propadanda.

Nevertheless, The Secretary's Commission on Achieving Necessary Skills (SCANS) of 1992 followed A Nation at Risk. The SCANS report showed that schools were not failing, However, this second report did not attract the same attention as $A$ Nation at Risk (Bell, 1993). In 1998, the federal government established the Comprehensive School Reform (CSR) program to stem the popularly perceived downward spiral of achievement in American schools. The CSR program was developed to help high-poverty and low-achieving schools address common obstacles to improving student achievement. Improvement was to take place through effective whole-school reform, especially in the areas of curriculum changes, sustained professional development for teaching and administrative staff, and enhanced parental involvement (Borman, Hews, Overman, \& Brown, 2002). CSR was reauthorized in 2001 through Title I, Part F, of the No Child Left Behind Act (U.S. Department of Education [USDOE], 2007). The No Child Left Behind Act (NCLB) of 2001 was signed into law on January 8, 2002. The Act contains four basic education reform principles: stronger accountability for 
results, increased flexibility and local control, expanded options for parents, and an emphasis on teaching methods that have been proven to work. The original major purpose of the Act was to ensure that all students perform at grade level in reading and mathematics by 2014 (Spellings, 2007). However, with recognition that such a mandate may be unrealistic to achieve, President Obama announced the granting of waivers to states for meeting this deadline. Students will continue to be tested annually and accountability and high standards will be retained. But schools in the opting out states will no longer face the same prescriptive actions and deadline spelled out with NCLB (Bruce, 2011).

Nevertheless, under NCLB, schools are increasingly being asked to use student achievement data from state assessments, such as the Florida Comprehensive Assessment Test (FCAT), to improve instruction and professional development through researchbased practices (Miami-Dade County Public Schools Secondary School Reform Plan, 2005). NCLB has increased pressures for school improvement and student achievement. Accountability pressures and ambitious educational goals have placed districts and schools in the position of requiring rapid change to meet the new demands of secondary school reform. Principals are at the center of this process, and their leadership is the key to the successful implementation of change (Kelley, Thornton, \& Daugherty, 2005). Studies have supported the relationship between strong leadership and improvement in student achievement in reading, writing, and mathematics (Cotton, 2003; Kiper, 2007; Leithwood, Seashore, Anderson, \& Wahlstrom, 2004; O’Donnell \& White, 2005). 


\section{The Principal as Leader}

Leadership has been a crucial component of school change for over 25 years (Murphy, 2005). In school reform, leadership may be the most important determinant of a principal's success and an effective learning environment. Leaders must understand the procedures and processes that create the conditions necessary for improvement in the school. "Skilled leaders precisely envision future needs and empower others to share and implement that vision. "School principals must be able to assess and evaluate the impact and perceptions of their leadership styles" (Kelley et al., 2005, p. 17).

In the present complex and rapidly changing environment, the role of the principal has changed dramatically from the past as a result of legislative and educational reforms and increasingly high expectations and complex problems teachers and parents bring to principals (Miami-Dade County Public Schools Superintendent's Urban Principal Initiative, 2006, p. 1). Principals must deal with building leadership capacity of both faculty and staff (Fullan, 2002; Murphy, 2005). To meet these challenging demands, the concept of a strong principal has shifted from the traditional one of an isolated authority focused on discipline and record keeping to that of an instructional leader and team player with vision for reform (Janc \& Appelbaum, 2004).

\section{Principal Leadership and School Climate}

Under this new vision of leadership, principals guide school planning and decision-making based on various types of data, such as student attendance, standardized test scores, and school climate surveys. Principals must be keenly aware of the nature of instructional practice taking place in their schools and are expected to transform schools by having a firm understanding of the change process. This understanding involves 
interpreting data, investigating instructional strategies, and selecting appropriate approaches (Janc \& Appelbaum, 2004). The effect of leadership on a school "frequently emerges as a key component in achieving significant school reform" (Pingle \& Cox (2007, p. 2). In addition, effective school leadership is often associated with improved student achievement, quality instruction, and school climate (Waters, Marzano, \& McNulty, 2004). Principals' leadership behavior can be an early indicator of school climate and student achievement (Bulach, Boothe, \& Pickett, 2006).

How principals affect school climate is an important part of both their leadership and reform efforts (Kelley et al., 2005). School climate encompasses many characteristics and qualities of a school, including physical and psychological environments, leadership qualities of staff, and community relations. School climate is a set of internal characteristics distinguishing schools and influencing members' behaviors and their shared values, and interpretations of social activities (Hoy \& Miskel, 2005; Kelley et al., 2005). Effective leadership is critical for improving school climate, which is shaped by the actions and behaviors of the principal (Bulach, Boothe, \& Pickett, 1998; Bulach \& Malone, 1994; Sergiovanni \& Starratt, 1998). A sustainable, positive school climate fosters student development and learning necessary for a productive, contributing, and satisfying life (National School Climate Center, 2007). Positive learning in urban schools has been linked to school climate through caring connections, positive behavioral support, and social and emotional learning (Osher \& Fleischman, 2005). Principals' leadership practices have also been linked to school climate and student achievement (Sims, 2005). Therefore, it would seem that school climate is a salient factor and should be considered in the goal of raising student achievement. 


\section{Problem Statement}

Schools in many parts of the country are falling short in terms of student achievement. Despite the mandates of NCLB and improvements in educational quality, the issue of low student achievement has persisted across the U.S., particularly in Texas, New York, and Illinois. In Texas, only $50 \%$ of students in Grade 10 met proficiency on all 2007 assessments in English language arts, mathematics, social studies, and science. In New York in 2007, 46\% of middle grade students met proficiency in mathematics and $42 \%$ in language arts. Statistics from Illinois revealed only a 50\% proficiency rating on state assessments in 2007 (U.S. Department of Education, 2007). In Florida in 2010, statistics showed that $55 \%$ of eighth-grade students were at or above grade level in reading, and $68 \%$ were at or above grade level in mathematics. For 10th-grade students, $39 \%$ scored at or above grade level in reading, and $73 \%$ scored at or above grade level in mathematics (Florida Office of Economic and Demographic Research [FOEDR], 2010).

The gravity of the problem is compounded by conflicting data on the relationships among school leadership, school climate, and student achievement (Bulach \& Malone, 1994; Glover \& Coleman, 2005; Kelley et al., 2005). In light of these conflicting data, more research is needed to clarify whether school climate is indeed related to student achievement. If so, further studies should provide empirical evidence on the relationship of school climate to student achievement. Data from this study provide policy makers with a template for qualifying, training, and certifying effective school leaders. The data could also help current principals to improve their leadership practices by engaging in reflection and implementation of leadership behaviors that have been widely tested in urban school settings. 


\section{Purpose}

The purpose of this nonexperimental ex post facto study was to test the relationships among secondary school principals' leadership behaviors, school climate, and student achievement, as measured by the Leadership Practice Inventory (LPI), School Climate Inventory (SCI), and the Florida Comprehensive Achievement Test (FCAT).

\section{Research Questions and Hypotheses}

Three research questions guided this study. These were as follows:

1. What is the relationship between the two independent variables of principals' leadership behaviors and school climate?

2. What is the relationship between the independent variable of principals' leadership behaviors and the outcome variable of student achievement?

3. What are the relationships among leadership behaviors, school climate, and student achievement?

Three null hypotheses were tested to examine these research questions;

1. There is not a positive relationship between principals' leadership behaviors and school climate.

2. There is not a positive relationship between principals' leadership behaviors and student achievement.

3. After controlling for gender, years at current school, and years in the district, there are not positive relationships among principals' leadership behaviors, school climate, and student achievement. 


\section{Theoretical Framework}

The theoretical frameworks that guided this study were the transformational leadership framework that is based on Kouzes and Posner's (2007) five practices of exemplary leadership, and the school climate framework that is based on Sheridan and Gutkin's (2000) theoretical grounding for school climate.

\section{Transformational Leadership}

The term "transformational leadership" was first used by Burns (1978), whose definition remains among the most comprehensive:

Transforming leadership ... occurs when one or more persons engage with others in such a way that leaders and followers raise one another to higher levels of motivation and morality. Their purposes, which might have started out as separate but related, as in the case of transactional leadership, become fused. Power bases are linked not as counterweights but as mutual support for common purpose. Various names are used for such leadership . . . elevating, mobilizing, inspiring, exalting, uplifting, preaching, exhorting, evangelizing. [Transformational leadership] ultimately becomes moral in that it raises the level of human conduct and ethical aspiration of both leader and led, and thus it has a transforming effect on both. (p. 20)

Transformational leaders espouse and offer purposes that transcend short-term goals and focus on higher-order intrinsic needs. In turn, followers identify with the needs of the leader, who desires to improve the performance of followers and develop followers to their fullest potential (Avolio, 1999; Bass, 1998; Bass \& Avolio, 1997). People who exhibit transformational leadership often have a strong set of internal values and ideals, 
and are effective at motivating followers to act in ways that support the greater good rather than their own self-interests (Covey, 1990; Kouzes \& Posner, 2007; Kuhnert, 1994).

\section{Transformational versus Transactional Leadership}

Transformational leadership has been linked to improved school climate and student achievement (Howell \& Avolio, 1993). Transformational leadership contrasts with transactional leadership, in which followers agree with, accept, or comply with the leader's directives in exchange for praise, rewards, and resources, or the avoidance of disciplinary action (Podsakoff, Todor, \& Skov, 1982). In transformational leadership, the leader seeks to envision and create the future by synthesizing and extending the aspirations of members of the organizational community. In transactional leadership, the leadership focuses on management of existing relationships and maintenance of the status quo (Northouse, 2007). With regard to this study, instructional leadership is explicitly focused on school improvement and would thus be characterized as transactional in the sense that it seeks to manage and control organizational members to move toward a predetermined set of goals. Nevertheless, for effective school improvement, the leadership must transmit a vision of the improvement and involve the organizational community. Therefore, effective leadership requires both transactional and transformational elements (Hallinger \& Heck, 1996).

Similar to the concept of transformational leadership (see Burns, 1978), visionary or exemplary leadership posits that outstanding leaders use specific behavioral practices to facilitate employees in achievement of organizational goals (Chen \& Baron, 2007). Kouzes and Posner (2007) defined exemplary leadership as the "fundamental practices 
that enable leaders to get extraordinary things done" (pp. 8-9) and developed their Leadership Practices Inventory (LPI) around five fundamental practices. These are (a) challenging the process, (b) inspiring a shared vision, (c) enabling others to act, (d) modeling the way, and (e) encouraging the heart. They posited that a transformational leadership approach, through these five fundamental leadership practices, is one that is needed for change (Devereaux, 2000). Kouzes and Posner suggested that when transformational leadership exists, individuals "raise each other to higher levels of motivation and morality" (p. 153).

Other scholars have conjectured the transformational nature of their five practices. Sandbakken (2004) pointed out that the salient traits of transformational leadership have been operationalized by Kouzes and Posner (2003) in their Leadership Practices Inventory. Carless (2001) noted that the LPI "describes five key transformational leadership behaviours" (p. 233). Pursley (2002) quoted Kouzes and Posner's observation that "transformational leaders are those who inspire others to excel" and commented, "Current thought about organizations and leadership supports the transformational aspects of leadership and views the leader as an agent of change within the organization" (pp. 25-26). Northouse (2007) summarized Kouzes and Posner's leadership model and practices in his chapter on transformational leadership and noted that their work has "contributed in unique ways to our understanding of the nature of transformational leadership" (p. 186).

In a discussion of transformational leadership, Pennings (2007) examined the development of transformational leadership skills in terms of Kouzes and Posner's research and five practices. The five fundamental transformational leadership practices 
delineated by Kouzes and Posner, Pennings (2007) suggested, may hold the key to addressing the problem of how school leadership in secondary schools can improve school climate and student achievement.

\section{Theory of School Climate}

The theoretical foundation of school climate is based on the concept of ecological grounding, which considers students within the contexts of classrooms, schools, and communities (Sheridan \& Gutkin, 2000). In this theory, four assumptions are made: (a) each student is "an inseparable part of a small social system"; (b) disturbance is viewed as discordance ("lack of balance") in the system rather than the individual student; (c) discordance is seen as a disparity between the student's abilities and the environmental demands or expectations; (d) "the goal of any intervention is to make the system work" (Sheridan \& Gutkin, p. 489).

Principals' positive leadership has been theorized to improve school climate and enhance student achievement, specifically through the concept of academic optimism (McGuigan \& Hoy, 2006). Moreover, the principal's role should be seen in "a conceptual framework that places the principal's leadership behavior in the context of the school organization and its environment and that assesses leadership effects on student achievement" (Hallinger, Bickman, \& Davis, 1996, p. 527). In this framework, school context variables such as parental involvement and instructional climate, encompassing school mission, opportunity to learn, and teachers' expectations, should be taken into account in relationship to the principal's instructional leadership (Hallinger et al.). Teachers' perceptions of principals' behaviors that focused on improving school climate 
have been hypothesized and shown to be predictors of student achievement (O'Donnell \& White, 2005).

\section{Definition of Terms}

For the purpose of this study, the following terms are defined as follows:

Challenging the process. This term refers to the leader's searching out challenging opportunities to change grow, innovate, and improve, as well as experiment by taking risks and learn from possible mistakes. Challenging the process is one of the five exemplary leadership practices operationalized in the LPI (Kouzes \& Posner, 2007).

Enabling others to act. This term refers to the fostering of collaboration with followers by the leader in promoting cooperative goals and building trust. Enabling others to act is one of the five exemplary leadership practices operationalized in the LPI (Kouzes \& Posner, 2007).

Encouraging the heart. This term refers to the leader's recognition of individual followers' contributions in every project's success and the leader initiating regular celebrations of team accomplishments. Encouraging the heart is one of the five exemplary leadership practices operationalized in the LPI (Kouzes \& Posner, 2007).

Exemplary leadership practices. These are the five practices identified by Kouzes and Posner (2007) and listed above as pivotal for transformational leaders to effect positive change in their organizations among followers (Leadership Challenge, 2007).

Extraneous variables. These are independent variables that are recognized as variables that might influence the relationships among the study variables and may affect the outcomes (Creswell, 2008; Hoy \& Miskell, 2005). 
Inspiring a shared vision. This term includes the leader's characteristic of envisioning an uplifting and ennobling future and enlisting others in this common cause. Inspiring a shared vision is one of the five exemplary leadership practices operationalized in the LPI (Kouzes \& Posner, 2007).

Leadership. This is the process whereby an individual influences a group of individuals to achieve a common goal (Northouse, 2007).

Learning environments. This term includes but is not limited to academic classrooms, computer laboratories, sports facilities, and off-campus or universitysanctioned events (Finnan, Schnepel, \& Anderson, 2003).

Learning styles. This term refers to the preferred ways by which people learn. Common learning styles include visual, auditory, and tactile (hands-on) modes (Kolb, 1984).

Modeling the way. This term relates to the leader's setting the example of exemplary leadership and true caring through behavior consistent with shared values. Modeling the way is one of the five exemplary leadership practices operationalized in the LPI (Kouzes \& Posner, 2007).

Secondary principal. This is a school leader who has authority and responsibility for the entire school at the middle school or high school level.

School climate. Although no single definition exists (Glover \& Coleman, 2005), this is the pervasive quality of a school environment experienced by students and staff and which affects their behavior (Roach \& Kratochwill, 2004). The environment can include physical attributes, such as orderliness and cleanliness of the school; behavioral attributes, such as positive teaching and learning attitudes of teachers and students; and 
community attributes, such as parental involvement and cooperation with community agencies (Kelley et al., 2005; Roach \& Kratochwill, 2004).

School climate was measured in this study with the SCI-R (CREP, 2002). This instrument has seven domains. They are order, the extent to which the environment is ordered and appropriate student behaviors are present; leadership, the extent to which the administration provides instructional leadership; environment, the extent to which positive learning environments exist; involvement, the extent to which parents and the community are involved in the school; instruction, the extent to which the instructional program is well developed and implemented; expectations, the extent to which students are expected to learn and be responsible; and collaboration, the extent to which the administration, faculty, and students cooperate and participate in problem solving (CREP, 2002).

Student achievement. Student achievement is defined in this study by secondary students' reading and mathematics scores on the 2009-2010 FCAT, specifically 8th- and 10th-grade students. Generally, students' writing scores would be included. However, in 2007, multiple-choice questions were added to the writing portion of the FCAT. Therefore, students' progress in writing from 2009 to 2010 was not computed in the study. For the reading and mathematics scores, students demonstrated annual learning gains in any one of the following three ways: (a) Improved achievement levels from 1-2, 2-3, 3-4, or 4-5. (b) Maintained within the high levels of 3, 4, or 5.

(c) Demonstrated more than 1 year's growth in achievement levels 1 or 2 (Florida Department of Education, 2008a). 
Transformational leadership. This is the form of leadership that motivates followers to do more than the expected by (a) raising followers' levels of consciousness about the importance and value of specified and idealized goals, (b) motivating followers to transcend their own self-interest for the sake of the team or organization, and (c) moving followers to address higher-level needs (Northouse, 2007). Transformational leadership was measured in this study by the LPI (Kouzes \& Posner, 2002). This instrument has five domains: Challenging the Process, Inspiring a Shared Vision, Enabling Others to Act, Modeling the Way, and Encouraging the Heart.

\section{Significance of the Study}

This study has significance in several areas, especially theory, research, practice, and policy. Regarding theory, this study tested Kouzes and Posner's (2007) leadership theory in an understudied context, urban high schools, and informed other theories on school climate, student achievement, and their association to leadership. Regarding research, the growing body of research related to effective leadership attests to its importance to educational researchers and practitioners such as school principals, other administrators, teachers, students, parents, and management professionals. The empirical findings derived from this study added new information to understanding of the relevance of principal leadership practices and their relationship to school climate and student achievement.

Effective leadership has a great impact where it is greatly needed—in the nation's challenged schools (Center for Comprehensive School Reform and Improvement, 2005). Regarding practice, this study provided principals in struggling urban districts with valuable information about the critical elements needed for effective leadership toward 
the goal of school reform. In addition, the study presented more empirical research related to leadership and school climate. More immediately, the findings may prompt Boards of Education to create a set of transformational leadership characteristics for school principals to assist in their ongoing development and evaluation. This set of characteristics could enable Boards to identify principal candidates for employment who have the most potential to act as transformational leaders.

Regarding policy, the results of this study could inform districts to include leadership practices in leadership training and professional development programs. Such programs could also provide practitioners with a practical framework for effective leadership that ultimately could lead to improved student achievement. The empirical data from this study could allow principals to maximize their personal potential and that of their teachers, staff, and students. Finally, study findings could lead to implementation of educational policy requiring the development of training and licensure programs in higher education, business, and industry to train and certify leaders.

\section{Delimitations of the Study}

This study was delimited to secondary school principals in three large urban school districts in South Florida. Student achievement was delimited to the FCAT scores for 8th- and 10th-grade students during the 2009-2010 school year. Specifically, their scores were confined to their reading and mathematics portions of the FCAT for the school year specified.

\section{Summary}

Urban education in the U.S. is in great need of improvement. Student achievement has been consistently low, as measured by state-mandated standardized 
testing. With the implementation of NCLB, school leadership has been increasingly recognized as a crucial component of school change. The role of the principal has changed dramatically from the past, and principals are called upon to deal with complex and challenging issues as they implement school improvement and work toward raising their students' scores on standardized tests. Principals' leadership is central to effective change, and their positive leadership styles govern positive school reform and improved school climate (Murphy, 2005). Although studies have been conducted on these factors, no studies were found that investigated the relationships among principals' leadership styles, school climate, and student achievement.

The purpose of this study was to test these relationships with three hypotheses. The study was grounded in the theoretical framework of transformational leadership, especially as represented by Kouzes and Posner's (2007) five exemplary leadership practices, and the principles of excellent school climate, as delineated by Sheridan and Gutkin (2000). The study was delimited to secondary school principals in three large urban school districts in South Florida. Three instruments were used, Kouzes and Posner's (2003) LPI, CREP's (2002) SCI-R, and a researcher-designed Demographic Questionnaire. Student achievement was determined by 8th- and 10th-grade students' scores on the reading and mathematics portions of the FCAT for the 2009-2010 school year. The study is significant for ascertaining leadership practices in urban secondary schools, aiding principals to implement more effective leadership and motivate their staffs toward greater improvement, provide evidence for Boards of Education to create and deliver leadership training programs for school leaders. 
This introductory chapter identified the specific purpose of the study as well as its significance, hypotheses, theoretical framework, significance of the study, definitions of key terms, and limitations. In Chapter II, a review of the literature relevant to the study is provided. In Chapter III, the study methodology, including design, population, and instruments are described. In Chapter IV, the results of the study are presented, and in Chapter V, the study conclusions, implications, and recommendations for future research are discussed. 


\section{CHAPTER II}

\section{REVIEW OF THE LITERATURE}

Schools in many parts of the country are falling short in terms of student achievement (Spellings, 2007). Despite the mandates of NCLB and improvements in educational quality, the issue of low student achievement has persisted across the U.S., particularly in Texas, New York, and Illinois (Spellings). Nationwide in 2005, only 23\% of 12th-grade students performed at or above proficiency in mathematics on the National Assessment of Educational Progress (NAEP). Reading scores decreased dramatically from $40 \%$ to $35 \%$ (U.S. Department of Education, 2007). The 2005 NAEP, however, incorporated a new framework to reflect changes in high school standards and course work (U.S. Department of Education, 2007).

However, in 2007, little progress was demonstrated in larger states. In Texas, only $50 \%$ of students in Grade 10 met proficiency on all 2007 assessments in English language arts, mathematics, social studies, and science (U. S. Department of Education, 2007). In New York in 2007, 46\% of middle grade students met proficiency in mathematics and $42 \%$ in language arts. Statistics from Illinois revealed only a $50 \%$ proficiency rating on state assessments in 2007 (U.S. Department of Education, 2007).

In smaller states, such as Kentucky and North Carolina, eighth-grade students showed similar scores on the 2007 administration of the NAEP. In Kentucky, only $27 \%$ of students scored at or above proficiency in mathematics and 33\% in reading. In North Carolina, the results were similar, with only $34.5 \%$ of eighth-grade students scoring at or above proficiency in mathematics and $28 \%$ in reading. 
NCLB has significantly increased the pressure on school leaders to improve student achievement. Bolman and Deal (2008) contend that the most effective leadership is that which views an organization, such as a school, as a living organism and applies a range of strategies and processes to an ever-changing fluid environment. The gravity of the problem to quantify leadership is compounded by conflicting data on the relationships of school leadership, school climate, and student achievement (Bulach \& Malone, 1994;

Glover \& Coleman, 2005; Kelley et al., 2005). Leadership researchers from 1988 to 1995 have believed that leadership will continue to be a major focus in the era of school accountability and school restructuring for many years to come (Heck \& Hallinger, 1999).

Top scholars in educational administration, such as Fullan (2002) and Northhouse (2007) also suggest that the study of school leadership would become increasingly more eclectic, both philosophically and methodologically. In addition, leading and managing effective schools to respond to the more complex demands of society will take the knowledge and technical skills of committed and competent leaders, with a continued focus on the development of teachers' knowledge and skills, professional community, program coherence, and technical resources (Fullan, 2002). Fullan further claimed that effective leadership is "in short supply," and that "leadership development initiatives" will dominate the scene over the next decade" (p. xii).

In view of the conflicting data, the purpose of this nonexperimental ex post facto study was to test the relationships among secondary school principals' leadership behaviors, school climate, and student achievement. 
Data from this study may provide policy makers with a template for qualifying, training, and certifying effective school leaders. The data should also help current principals improve their leadership practices by engaging in reflection and implementation of leadership behaviors that have been widely tested in urban school settings. In this chapter, literature pertinent to this purpose is reviewed. The literature is organized on the following topics: (a) transformational leadership; (b) several major researchers in transformational theory, such as Burns, Bass and colleagues, Covey, and Kouzes and Posner; (c) principals as leaders; (d) school climate; (e) school climate and student achievement; (f) leadership and school climate; (g) leadership and student achievement; and (h) leadership, school climate, and student achievement. A summary ends this chapter.

\section{Transformational Leadership}

Transformational leadership is the primary model reflecting the relatively new attention to leadership models that are more consistent with evolving trends in educational reform, such as empowerment, shared leadership, and organizational learning, rather than hierarchical or dictatorial leadership models (Howard, 2004; Northouse, 2007). This evolution of educational leadership roles has been labeled as reflecting "second order" changes (Leithwood, 1992, p. 8) because researchers have moved beyond defining the qualities of effective leadership to determining the impact of leadership on school operations and student achievement. For a full conceptualization and understanding of the theory of transformational leadership, an examination of its inception and development is needed, as well as an investigation into the research and literature provided by leading scholars. The scholars most closely associated with 
transformational leadership are James MacGregor Burns, Bernard M. Bass and his colleagues, Steven Covey, and James Kouzes and Barry Posner. The contributions of these scholars are discussed in the following sections.

\section{James MacGregor Burns}

In Burns' (1978) groundbreaking book Leadership; he noted that although leadership literature was abundant, no central concept of leadership had emerged because scholars were working in separate disciplines to answer questions unique to their specialties. Because of his work in humanistic psychology, Burns was able to make generalizations about leadership across cultures and time. In this book, Burns set the stage for the evolution of the concept of transformational leadership.

Burns (1978) posited that leadership must align with a collective purpose and that effective leaders should be judged by their ability to affect social change. He further suggested that the role of the leader and follower be united conceptually through a process of interplay of conflict and power. Burns proposed two basic types of leadership: transactional and transformational. Transactional leaders approach followers with the intent to exchange one thing for another. An example is a leader rewarding a hardworking teacher with an increase in budget allowance. Conversely, the transforming leader looks for potential motives in followers, seeks to satisfy higher needs, and engages the full potential of the follower. Burns' position was that leaders are neither born nor made; instead, leaders evolve from a structure of motivation, values, and goals.

In an analysis of the leadership styles of world leaders, Burns (2003) in his latest book entitled Transforming Leadership: A New Pursuit of Happiness suggested ways that transactional leaders can learn to become transformational. These methods include 
elevating followers' motivation and performance to higher levels of accomplishment and building personal and social identification among followers with the leader's mission and goals. Followers' feelings of involvement, cohesiveness, commitment, potency, and performance are enhanced. Burns also examined people he considered to be "breakthrough leaders," such as Gandhi, Gorbachev, Eleanor Roosevelt, Washington, and Jefferson (p. 45) and found several common characteristics. These include effective communication, goal orientation, organized work around shared vision, and building of capacity. A major conclusion of this work was Burns' contention that leadership is a moral undertaking and a response to human wants as they are expressed in human values. Burns' (1978) work was instrumental in defining two seminal conceptualizations of the terms "transactional leadership" and "transformational leadership." However, his work lacked empirical evidence to support his theory. The work of Bass and his colleagues, such as Avolio (1999), Avolio and Bass (2002a, 200b), and Bass and Avolio $(1990,1997)$ was a response to some of Burns' (1978) limitations and omissions.

\section{Bernard M. Bass and Colleagues}

Most of Bass' research arose from the deficiencies and inadequacies of Burns' (1978) earlier work. Bass (1998) concentrated his research on military, business, and educational organizations and found evidence that transformational leadership was a powerful means to move followers beyond what was traditionally expected. He believed that transformational leaders behave in ways that raise the level of commitment from followers. Bass (1998; Bass et al., 2003) found that previous research relied heavily on the use of survey instruments and that many studies tested the same hypotheses. As a result, a scarcity of theory existed, as well as a lack of practical application of these 
limited findings (Bass, 1998). Bass's purpose, therefore, was to develop new ways of identifying successful and effective leaders. His work used an empirically confirmed and logically supported factor analytic framework of transformational and transactional leadership.

To fulfill this purpose, Bass and his colleagues (Bass \& Avolio, 1990, 1997) developed the Multifactor Leadership Questionnaire (MLQ) to identify the components of transformational leadership. The MLQ contains 141 statements developed and classified by trained judges as either transformational or transactional leadership. In development, the questionnaire was administered to U. S. Army officers who rated their superior officers on a scale from 0 (not observed) to 4 (behavior observed frequently). This study was the foundation for many other studies to analyze the frequencies of behaviors observed by subordinates in business, agencies, and the military (Bass, 1998). From this study, Bass and colleagues (Bass \& Avolio, 1997) developed four overarching components of transformational leadership:

1. Charismatic leadership or idealized influence. In this style of leadership, transformational leaders have a clear vision and a sense of purpose and are willing to take risks. They are respected and admired by followers. Followers identify with leaders and want to emulate them (Bass et al., 2003).

2. Motivation. Transformational leaders behave in ways that motivate others, generate enthusiasm, and challenge people. These leaders clearly communicate expectations, and they demonstrate a commitment to goals and a shared vision (Bass et al., 2003). 
3. Intellectual stimulation. Transformational leaders actively solicit new ideas and new ways of doing things. They stimulate others to be creative and never publicly correct or criticize others (Bass \& et al., 2003).

4. Individual consideration. Transformational leaders pay attention to the needs of others and the potential for developing others. These leaders establish a supportive climate in which individual differences are respected. Interactions with followers are encouraged, and the leaders are aware of individual concerns (Bass, 1998).

In addition to these components of transformational leadership, Bass' (1998; 2003) model of leadership also includes three dimensions of transactional leadership: contingent reward, management-by-exception, and laissez-faire styles. In contingent reward, the leader assigns work and then rewards followers for carrying out the assignment. In management-by-exception (MBE), the leader monitors followers and then corrects them if necessary. MBE can be either passive (MBE-P) or active (MBE-A). In laissez-faire leadership, the leader is passive, either waiting for problems to arise before taking action or taking no action at all (Bass et al., 2003).

\section{Stephen R. Covey}

Covey's (1990) theory of principle-centered leadership is based on his development of "Seven Habits" necessary to establish effectiveness in one's life. Covey defined a habit as "the intersection of knowledge, skill, and desire" (p. 10). Knowledge is the theoretical paradigm, the what to do and the why. Skill is the how to do, and desire is the motivation, the want to do. To make an action a habit, an individual must develop and maintain all three characteristics. The Seven Habits are not a set of separate or piecemeal formulas. In harmony with the natural laws of growth, they provide an incremental, 
sequential, highly integrated approach to the development of personal and interpersonal effectiveness (Covey, 1990).

The seven habits evolved from Covey's 25 years of working with people in business, university, and marriage and family settings. In these settings, he came in contact with individuals who achieved outward success but struggled with a need for personal congruency and healthy relationships with other people. Personally, Covey and his wife struggled to help their son, who was doing poorly academically and was socially immature. During this time Covey was involved in leadership development for IBM and prepared bimonthly presentations on communication and perceptions. These presentations led to his studying the expectancy theory and self-fulfilling prophecies. As a result, he realized that if individuals want to change situations, they must first change their perceptions (Covey, 1990).

In addition to Covey's research on perceptions, he studied success literature published in the United States since 1776. However, he found the success literature of the past 50 years to be superficial and filled with quick fixes. In contrast, he found the literature in the first 150 years focused on character ethic as the foundation for success. Character ethic taught that such concepts as integrity, humility, fidelity, temperance, and modesty are basic principles for success and enduring happiness (Covey, 1990).

Shortly after World War I, the accepted basic view of success shifted from character ethic to personality ethic. Success became more a function of public image, attitude, behaviors skills, and techniques than an internally-driven ethic of moral principles. Covey's experience with his son, in which he and his wife realized they were perceiving their son as a failing student rather than seeing his success potential, in 
conjunction with his study of perceptions and success literature, converged. From his realizations in personal life and business, Covey created The Seven Habits of Highly Effective People (Covey, 1990).

As Covey (1990) pointed out, because the Seven Habits are based on ethically sound principles, they bring the maximum long-term beneficial results. They become the basis of a person's character, creating an empowering center of correct maps from which an individual can effectively solve problems, maximize opportunities, and continually learn and integrate other principles in an upward spiral growth. Covey's components of the Seven Habits Paradigm are as follows:

1. Be proactive. Proactivity means taking responsibility for one's own life. Behavior is a function of decisions, not conditions. Feelings can be subordinated to values, but humans have the initiative and the responsibility to make things happen (Covey, 1990).

2. Begin with the end in mind. This habit and principle means starting with a clear understanding of one's destination and knowing where one is going to better understand where one is now. With this understanding, the steps one takes are always in the right direction (Covey, 1990).

3. Put first things first. This precept means practicing effective self-management rather than focusing on things and time, one should focus on preserving and enhancing relationships and on accomplishing results (Covey, 1990).

4. Think win/win. This is a frame of mind and heart that constantly seeks mutual benefit in all human interactions. Win/Win means that agreements or solutions are 
mutually beneficial and mutual satisfying. All parties feel good about decisions made and feel committed to the action plan (Covey, 1990).

5. Seek first to understand, then to be understood. This principle means the use of empathetic listening. Empathic listening is listening with the intent to understand feelings and meaning. This type of listening is powerful because it gives one data to work with that directly relate to the individual speaking. Instead of projecting one's own autobiography and assumptions of thoughts, feelings, motives and interpretation, the listener deals with the reality within the other person's head and heart (Covey, 1990).

6. Synergize. This concept means the practice of "creative cooperation" (p. 14). Synergy means an understanding that the whole is greater than the sum of its parts. Synergy establishes a safe environment that enables people to be open to learn and listen to each other's ideas. This openness leads to brainstorming, in which the spirit of evaluation is subordinate to the spirit of creativity, imagining, and intellectual networking. Within this environment, transformation takes place that leads to new direction, new thrust, and new ideas (Covey, 1990).

7. Sharpen the saw. This principle makes the other six habits possible. Sharpening the saw mean expressing the four interrelated dimensions of one's nature: physical, spiritual, mental, and social/emotional. Investment in sharpening the saw is the single most powerful investment one can make - the investment and commitment to deal with life and to contribute to it (Covey, 1990).

Each dimension of sharpening the saw carries responsibilities and actions. The physical dimension involves eating the right kinds of food, getting sufficient rest and relaxation, and exercising on a regular basis. The spiritual dimensions relates to values 
clarification and commitment to study and meditation. The mental dimension concerns self-discipline in reading, visualizing, planning, and writing. The social/emotional dimension encompasses service, empathy, synergy, and intrinsic security (Covey, 1990)

These Seven Habits are integral to both individual growth and the practice of transformational leadership. These principles extend from changed personal habits and modes of living to application in social settings. Workshops, training, and seminars have been developed for teaching these principles, and Covey's (1990) work has been adopted in many venues with both individuals and groups in institutions for teaching and learning of these habits (Covey, 1990). Covey's Seven Habits provide a unique means to demonstrate the predictive power of the Performance-based Interview Process. Moreover, it offers users a guide for becoming a better team member, partner, collaborator, and leader. According to Schmidt and Hunter (2004) in a massive study of selection methods in personnel research, past performance rather than past behaviors was found to be a better predictor of future performance. Therefore, using a performance profile, such as Covey's, in a structured interview for assessing candidates' abilities and motivation to perform the work strengthens the process (Schmidt \& Hunter, 2004).

Moscoso and Salgado (2001) studied the psychometric properties of a structured interview used to hire private security personnel. Reliability was estimated using interrater coefficients. Two independent interviewers were used to rate each interviewee. Results show a reliability coefficient of $.81(N=43)$ and .89 with Spearman-Brown correction for two raters. Validity was estimated using the content validity approach. The interview consisted of seven questions, and each was rated by 11 experts in the job. 
Results showed a significant content validity ratio (CVR) for majority of the questions in the interview and content validity index (CVI) of .89.

\section{James Kouzes and Barry Posner}

Kouzes and Posner began studying leadership practices in 1983 and started from the assumption that they did not have to interview and survey star performers to discover best practices. Instead, they assumed that asking ordinary people to describe extraordinary experiences would lead to synthesis of the patterns of success. The results of their initial study and further research conducted over two decades enabled them to refute the stereotypes of leaders (Kouzes \& Posner, 2003). Leaders, they found, exhibit certain distinct practices when they are doing their best. This pattern of behavior is consistent across industries, professions, communities, and countries.

In 1995, with the use of many groups in various fields, Kouzes and Posner explored the dynamic process of effective leadership and its components through case analyses and multiple survey questionnaires. Through years of development (Kouzes \& Posner, 2007), the researchers distilled five fundamental practices of exemplary leaders that enable leaders "to get extraordinary things done" (p. 14). Kouzes and Posner developed these five practices into behavioral statements in a quantitative instrument that has been used extensively in educational research (Kouzes \& Posner, 2007).

The LPI was developed through a triangulation of qualitative and quantitative research methods and studies. In-depth interviews and written case studies from personalbest leadership experiences generated the conceptual framework that led to the final LPI instrument (Kouzes \& Posner, 2007). The five practices of exemplary leaders and their characteristics of transformational leadership are as follows: 
1. Challenging the Process. This aspect involves the leader's searching out challenging opportunities to change, grow, innovate, and improve, as well as experiment by taking risks and learn from possible resulting mistakes (Kouzes \& Posner, 2007).

2. Inspiring a Shared Vision. This aspect includes the leader envisioning an uplifting and ennobling future and enlisting others in this common vision. The leader appeals to their values, interests, hopes, and dreams in portraying the vision (Kouzes \& Posner, 2007).

3. Enabling Others to Act. This aspect fosters collaboration with followers by the leader promoting cooperative goals and building trust. The leader is not afraid to strengthen others by surrendering power, providing choices, developing competence, assigning crucial tasks, and offering visible support (Kouzes \& Posner, 2007).

4. Modeling the Way. This aspect relates to the leader's setting the example of exemplary leadership and true caring through behavior consistent with shared values. The leader also publicizes followers' small victories that promote consistent progress and build others' commitment (Kouzes \& Posner, 2007).

5. Encouraging the Heart. This aspect entails the leader's recognition of individual followers' contributions in every project's success and regularly celebrating team accomplishments (Kouzes \& Posner, 2007)

The LPI has been administered to over 350,000 managers and non managers across a variety of organizations, disciplines, and demographic backgrounds. The 1995 version of the LPI has gone through several iterative psychometric processes, and the resulting instrument was used for this study (LPI, 2003). A version of the LPI was also developed for specific use with high school and college students. 
Validation studies by Kouzes and Posner, as well as other researchers, were conducted over a 15 -year period to confirm the reliability and validity of the Leadership Practice Inventory. Many organizations and educational institutions use the five practices of exemplary leadership and the LPI in assessments, workshops, seminars, and trainings to measure and improve their leaders' abilities and skills (Kouzes \& Posner, 2007). As a well-known, highly accepted, and proven instrument to measure the salient and vital aspects of transformational leadership, the LPI was used to measure principals' leadership characteristics. Internal reliability, as measured by Cronbach's alpha continues to be strong with all scales above the .75 level. Results of leaders using the LPI-Self form for each leadership behavior were: Challenge .80; Inspire .87; Enable .75; Model .77; and Encourage .87 (Kouzes \& Posner, 2000).

A five-factor solution for the LPI-Self form was generated by a factor analysis using principal component analysis with Varimax rotation and Kaiser normalization. While some statements loaded on more than one factor, their highest loading was generally with the other statements conceptualized as compromising that factor (scale). These results provided empirical support for these various leadership behaviors to be conceptualized within five practices (Kouzes \& Posner, 2000). The LPI is described in more detail in Chapter III.

This brief review of characteristics and aspects of transformational leadership, with development of tools such as the MLQ and LPI, indicates the importance of transformational leadership in the current social climate. This type of leadership is equally important in the educational sphere, especially in building the collective confidence required of school leaders and teachers so they may responsibly and effectively deal with 
difficult challenges such as improving student achievement. Lezotte (1999) noted, for example, that the role of the school principal has changed since earlier decades toward greater collaboration and co-learning with school staff, parents, and other stakeholders. The next section reviews literature on school principals as leaders.

\section{Principals as Leaders}

Starting in the mid-1980s, the public became increasingly more demanding of school systems to raise standards and improve student academic performance (Adams \& Kirst, 1999). Scholars began to study school leadership and observed the link between leadership and school effectiveness (Adams \& Kirst, 1999). Leithwood, Jantzi, and Steinbach (2002) studied large-scale school reform, accountability initiatives, and the pressure placed on principals to improve student achievement in light of the NCLB mandates. Many accountability initiatives were based on high-stakes standardized testing, which is typically incongruent with what most educators recognize as effective ways of measuring quality teaching and learning (Adams \& Kirst).

The move toward greater accountability was simultaneous with the increasing number of research studies attempting to measure the impact of school leadership (Hallinger, 2003). Leithwood (1992) noted the "move toward transformational leadership" and predicted that many leaders will believe in creating the conditions that enable staffs to find their own directions" (p. 8). New terms began to emerge in the literature, such as "shared leadership," "teacher leadership," "distributed leadership," and “transformational leadership" (Hallinger, 2003). As Hallinger (2003) observed, “The emergence of these models was an indication of the broader dissatisfaction with the instructional leadership model that focused too much on the principal as the center of 
expertise, power, and authority" (p. 330). The new examination of principals' styles of leadership was the beginning of the trend toward transformational leadership in education.

School and district leaders have been the focus of intense scrutiny in recent years as researchers have attempted to define the qualities of effective leadership and the impact on operation of schools and student achievement (Center for Comprehensive School Reform and Improvement, 2005). Leithwood, Seashore-Louis, Anderson, and Wahlstrom (2004) made two important claims. First, "Leadership is second only to classroom instruction among all school-related factors that contribute to what students learn at school" (p. 7). Second, "leadership effects are usually largest where and when they are needed most" (p. 7). Without a powerful leader, troubled schools are unlikely to be turned around toward greater student achievement. Leithwood et al. (2004) stressed that "many other factors may contribute to such turnarounds, but leadership is the catalyst" (p. 7).

Leithwood and his colleagues have been instrumental in extending the work of Burns and Bass into the field of educational administration (Steward, 2006). Leithwood and colleagues used the following seven dimensions to describe transformational leadership: (a) building school vision and establishing school goals, (b) providing intellectual stimulation, (c) offering individualized support, (d) modeling best practices and important organizational values, (e) demonstrating high performance expectations, (f) creating a productive school culture, and (g) developing structures to foster participation in school decision (Leithwood, Seashore-Louis, Anderson, \& Wahlstrom, 2004; Mulford, Silins, \& Leithwood, (2005). They believed that the earlier models of 
transformational leadership neglected to include necessary transactional components which were fundamental to the stability of the organization. Therefore, they added the following management dimensions: staffing, instructional support, monitoring school activities, and community focus. This model assumed that the principal shares leadership with teachers. The model is grounded in providing individual support, not in controlling or coordinating others (Mulford et al.; Leithwood, Aitken, \& Jantzi, 2006; Leithwood \& Harris, 2010).

Leithwood (1992) reported on three studies he completed with colleagues that pinpointed the transformational leadership characteristics of school leaders. In the schools studied, in which principals initiated their own reforms as well as responded to district- and state-level initiatives, the leaders pursued "three fundamental goals" (p. 9). They maintained a collaborative culture, fostered teacher development, and improved group problem solving. Leithwood et al. (2004) further described successful educational leaders in transformational leadership terms. Principals are purposeful about turning their schools into effective organizations. They accomplish this purpose by developing and counting on contributions from many others in their organizations to strengthen the culture, modify the organizational structure, and build collaborative processes. Leithwood and Jantzi (1999) highlighted "people effects' as a cornerstone of the transformational leadership model. Leithwood and Lantzi found that principal efforts are apparent in the school climate that produces changes in people rather than promoting specific instructional practices. Together, transformational leadership and school climate explained $17 \%$ of the variation in classroom conditions. Further, principals strengthen school culture when they clearly and consistently articulate high expectations for all 
students, including subgroups that are too often marginalized and blamed for schools not making adequate yearly progress in student achievement. Principals can modify organizational structures by changing schedules to make certain that teachers share common planning time and use that time to discuss improving instruction. This kind of restructuring reinforces the use of collaborative processes among teachers. Teachers learn to trust their colleagues and are more willing to share best practices and challenges. Thus, through effective leadership, principals can foster cooperation and collaboration through all spheres of the school organization (Leithwood et al., 2004; Leithwood et al., 2006). During the past two decades, different recommendations have been made in response to the need to improve America's schools (Pingle \& Cox, 2007). Pingle and Cox asserted that the principalship has become a uniquely challenging job with increasing demands made each year:

Principals today must serve as leaders for student learning. They must know and understand academic content and pedagogical techniques. They must be able to work with teachers to strengthen their instructional skills. They must collect, analyze and use data to improve test scores. They must seek to rally students, teachers, parents, local health and family service agencies, youth development groups, local businesses and other community members around the common goal of improving student performance. They must also develop the leadership skills and knowledge necessary to effectively exercise autonomy and pursue successful academic strategies. (p. 2)

The multifaceted and complex demands of principals have increased (Orr et al., 2005). The pace is rapid, frequent interruptions take place, and decisions are sometimes 
made without accurate or complete information (Greenfield, 1995). As the roles of principals have changed dramatically, the need for exemplary leadership has become more apparent (Pingle \& Cox, 2007).

In Florida, for example, the Miami-Dade County Public Schools system recognized that a shortfall of qualified principals was taking place. Principals were needed to serve the nation's fourth-largest school district of over 360,000 students. In 2004, a program was initiated, the Superintendent's Urban Principal Initiative, to help stem the growing leadership gap (Miami-Dade County Public Schools Superintendent's Urban Principal Initiative, 2006). This program has become a multifaceted comprehensive leadership training program for principals, assistant principals, and teacher leaders.

The effort of New Leaders for New Schools, a national non-profit organization that trains principals in Chicago, New York, and Washington D.C. is noteworthy (NGA Center for Best Practices, 2003). These programs are relatively new, and provide ongoing support and professional development and mentoring for candidates on the job. For example, the New Model for Principal Preparation in Massachusetts with support from the Massachusetts Department of Education, the Springfield Public Schools (SPS) developed a new "Leadership University" to house all training and professional development activities for principals and district staff. As a part of this "Leadership University," SPS now offers its own preparation and licensure programs. District staff members collaborate with seven local colleges and universities to teach the coursework. Candidates are selected from the program through a rigorous application process 
managed by SPS. The program is expected to produce 150 new administrators for SPS and other local districts during the next 5 years.

Training and producing effective school leaders cannot be limited to instilling outstanding traits in people (Leithwood \& Harris, 2010). Organizations and schools must support the collective form of leadership in which individuals feel safe, supported, and free to think creatively (Stewart, 2006). Huber and West (2002) stated, "The school leader is the key figure in school's development by either blocking or promoting changes, acting as the internal change agent, overseeing the process of growth and renewal" (p. 1072). School leaders are in the position to foster strong community support for public education and to provide learning opportunities for all children, regardless of their previous negative or neglected experiences.

\section{School Climate}

School leadership has increasingly been recognized as important in combination with school climate and quality instruction for effective schools and student achievement (Kelly, Thornton, \& Daughtery, 2005). The National School Climate Center (2007) stated more directly, "Educators have recognized the importance of school climate for a hundred years" (p. 5). However, systemic study of school climate began only in the 1950s. The systematic study of school climate grew out of organizational research and studies in school effectiveness (Creemers \& Reezigt, 1999; Miller \& Fredericks, 1990). Research by Brookover (1979), Edmonds (1979), and Rutter, Maugh, Mortimore, and Ouston (1979) found that correlates of effective schools included strong leadership, a climate of expectation, an orderly but not rigid atmosphere, and effective communication. 
Many educational leaders and researchers (Frieberg, 1998; Levine \& Lezotte, 1990; Phillips \& Wagner 1996; Sizer, 1998; Wagner, 2006) have pointed out that school climate is an important and often overlooked component of the school reform movement. Although there is no commonly accepted definition of school climate, most researchers and scholars have recognized that school climate reflects subjective experience in school (Cohen, 2006). Kottkamp (1984) suggested that climate consists of shared values, interpretation of social activities, and commonly held definitions of purpose. Bulach et al. (1998) linked the behaviors of building level principals to the climate of the school. Hoy and Miskell (2005) defined school climate as "the set of internal characteristics that distinguish one school from another and influence the behaviors of each school's members" (p. 185).

In addition, 10 essential dimensions have been suggested that shape subjective experience in schools, and these were examined in this study. These dimensions are environment, structure, safety, teaching and learning, school community, morale, peer norms, school-home-community partnerships, and learning community (Cohen, 2006; Freiberg, 1999). The National School Climate Center (2007) elaborated with a comprehensive description:

School climate refers to the quality and character of school life. It is based on patterns of school life experiences and reflects norms, goals, values, interpersonal relationships, teaching, learning and leadership practices, and organizational structures. A sustainable, positive school climate fosters youth development and learning necessary for a productive, contributing and satisfying life in a democratic society. (p. 5) 
Principals have the power, authority, and position to impact the climate of the school but sometimes lack the feedback to improve (Kelly, Thornton, \& Daugherty, 2005). If principals are highly skilled, they can develop in their staff feelings of trust, open communication, collegiality, and promote effective feedback. Leaders must be able to correctly envision the needs of their teachers, students, and school community and empower all groups to share the leader's vision of school improvement and excellence in order to create an effective school climate (Glover \& Coleman, 2005).

\section{School Climate and Student Achievement}

School climate has also been shown to promote meaningful student learning. When activities such as community service and debates are presented in a supportive, collaborative environment, they encourage students to construct their own knowledge and enhance learning (Wentzel \& Watkins, 2002). When students feel safe, cared for, supported, and gently "pushed" to learn, their academic progress should increase. Studies have found that a positive school climate promotes cooperative learning, group cohesion, respect, and mutual trust (Finnan et al., 2003; Ghaith, 2004). Urban (1999) stated, "Unless students experience a positive and supportive climate, some may never achieve the most minimum standards or realize their full potential" (p. 69).

Several studies have examined the relationship between school climate and student achievement using the Tennessee School Climate Inventory (TSCI). For example, with 20 schools, Bulach, Malone, and Castleman (1995), using regression analysis, found a strong positive correlation $(r=.52 ; p<.05)$ between student achievement and school climate, concluding that school climate may be a significant factor in successful school reform. Hoy, Tarter, and Bliss (1990) found that long-term improvement in academic 
achievement was related to schools with strong academic emphasis within the context of healthy and open climates.

Blanchard, Hambleton, Zigarmi, and Forsyth (1991) developed the Leadership Behavior Analysis II (LBAII) to assess leadership styles. Respondents chose from four leadership styles for each of 20 leadership scenarios. Using two forms of the LBAII, principals self-rated their leadership style and teachers rated their perception of their principal's style. The LBAII provided two primary scores: Leader Effectiveness and Flexibility. Zigarmi, Edeburn, and Blanchard (1995) reported reliability coefficients for the four leadership style scales from six research studies ranging from .54 to .86 , with a median value of .74 .

In the same study, school climate was assessed using the Staff Development and School Climate Assessment Questionnaire (SDSCAQ; Zigarmi \& Edeburn, 1980). The SDSCAQ is a Likert-like instrument that provides six scale scores: (a) Communications, (b) Innovativeness, (c) Advocacy, (d) Decision-Making, (e) Evaluation, and (f) Attitudes toward Staff Development. The SDSCAQ scale scores were found to be reliable using the Cronbach's alphas above .80 (Zigarmi \& Edeburn, 1980).

In a study on school climate and students' reading scores, Cunningham (2003), a principal in Orange County, Florida, surveyed 61 Florida elementary schools and found a significant relationship between a measure of school culture (the School Culture Triage Survey, Masden-Copas \& Wagner, 2002) and FCAT student reading scores. School culture was defined as professional collaboration, affiliative and collegial relationships, and efficacy or self-determination. The results showed that the healthier the school culture, as defined by the presence of these factors, the higher the reading scores. The 
researchers posited that, conversely, when the school culture factors are absent, the school climate is more toxic, and the reading scores will be lower. These results showed that when effective school leaders implement best practices of classroom management, curriculum and instruction, and assessment to meet the needs of all students and engage in shared leadership, they produce maximum efficiency and achievement (Cunningham, 2003).

Better understanding of the level of school climate within a building allows school principals and faculty to identify areas of strength and focus on those that might need to be improved. To identify the factors associated with school climate, Springfield Public School (SPS) in collaboration with Missouri State University's Institute for School Improvement (ISI; 2006) developed a study to examine the Missouri School Improvement Plan (MSIP) Advance Questionnaires completed by teachers, parents, and students in order to develop an index of school climate. Using this index, the relationship between school climate and student achievement was examined using spring 2005 SPS Missouri Assessment Program (MAP) communication arts, mathematics and science scores.

The research team conducted an exploratory factor analysis of the faculty MSIP Advance Questionnaire to establish an index of school climate. The Advance Questionnaire included 96 items. Using principle axis factoring, 12 factors were initially extracted. The first five factors were considered "prime" indicators associated with school climate. The factors included: (1) School Environment, (2) Parent Involvement, (3) Curriculum, (4) Community Support, and (5) Technology Support. The same steps were followed for the extracting climate factors from the parent and student MSIP 
Advance Questionnaires. The six "prime factors from the parent questionnaires were: (1) School Environment, (2) School/District Structure, (3) Communication, (4) Positive Performance Expectations, (5) Belonging, and (6) Learning Environment. Data from the elementary student surveys yielded two "prime" climate factors: (1) Teacher/School Quality, and (2) School Environment. Secondary student "prime" factors were (1) Teacher Quality, (2) School Environment, (3) Positive Performance Expectations, (4) Counselor Quality, (5) School Bonding, and (6) Teen Substance Use.

Once these factors were obtained and determined to be valid indictors of school climate, multivariate analyses of covariance (MANCOVA) were conducted for each factor set (Teacher, Parent, Student). Mean school climate factors scores were used as the dependent variables, and MAP proficiency levels (Progressing, Nearing Proficiency, Proficient, and Advanced) were used as the independent variables. Significant MANCOVA results were found for all five Teacher Climate factor scores on both Mathematics and Communication Arts MAP levels. Student achieving at higher levels on the MAP assessments were attending schools with more positive school climate mean factor scores, as perceived by teachers. Elementary and secondary students' results were the same.

Educators have become increasingly convinced that the climate of schools is an important determinant of academic achievement (Roach \& Kratochwill, 2004). An orderly, safe climate conducive to teaching and learning is an important characteristic of an effective school (Edmonds, 1982; Roach \& Kratochwil; Ross et al., 2005). The climate of an effective school encourages every student to become disciplined, creative, and well-motivated as a learner. Principals and teachers must be committed to serving the 
whole child and acknowledging that a student's physical, social, and emotional well being are also related to learning. Thus, beyond a solid academic program, the school climate should provide basic health and counseling services for students, referrals for families, and enrichment programs for extended learning (Boyer, 1995; Cho, 2003;

Glover \& Coleman, 2005).

\section{Leadership and School Climate}

To create and maintain a positive school climate, principals must demonstrate strong leadership based on positive values (Osher \& Dwyer, 2005). Urban schools often face challenges such as high student poverty, mobility rates, large numbers of English language learners, and unsafe neighborhoods (Orr, Byrne-Jimenez, McFarlane, \& Brown, 2005). Yet in spite of these challenges, principals are accountable for providing highquality education in a supportive, positive learning environment (Osher \& Fleischman, 2005). Caring connections, positive behavioral supports, and social and emotional learning are essential to student success and student motivation to learn (National School Climate Center, 2007).

School-based research and national surveys have documented the importance of students believing that their teachers and principals care about them (McNeely, Nonnemaker, \& Blum, 2002). Students with strong connections with teachers and peers are more likely to resist the pull of gangs that offer an alternative form of connection for alienated students (Goldstein \& Soriano, 1994). When school principals and staff are explicit about behavioral expectation, provide support to help students meet expectations, monitor individual and school-wide behavior, and provide frequent positive 
reinforcement, student discipline problems can be reduced and instructional time recovered (Sugai et al., 2000).

Successful principals also nurture the internal assets that help students regulate their own behavior and deal with the many social and academic challenges they face. Principals must make certain that teachers transmit to students social and emotional skills, such as relationship building, self-awareness, self-management, and responsible decision-making. Teaching these skills can prevent problem behaviors and promote academic success and positive school climate. Students who develop these skills are less likely to participate in high-risk behaviors and are more able to persevere through academic challenges (Solomon, Battistich, Watson, Schaps, \& Lewis, 2000). Although studies of school climate are often combined with other variables, such as teacher effectiveness and student learning (Deal \& Peterson, 1990; Maehr, 1990; Water et al., 2004), several recent empirical studies, primarily dissertations, have investigated the relationship between principals' leadership and school climate.

Remondini (2001) studied the relationship between school climate and the leadership style of female public school principals in New Mexico. A total of 19 principals and 298 teachers completed the LPI and the Organizational Climate Description Questionnaire (Halpin \& Croft, 1962). Principals were considered "transformative" if their LPI scores were above the 70th percentile. Remondini found a statistically significant relationship between leadership styles and organizational climate for supportive principal behavior, but no statistically significant relationship for directive or restrictive principal behavior. 
A case study by Blatt (2002) investigated the relationship between transformational leadership and school climate as perceived by teachers in Ohio secondary schools. The Multifactor Leadership Questionnaire 5x and the CFK School Climate Profile were used to measure the variables. Analysis of the data revealed a statistically significant positive relationship between transformational leadership and school climate. However, no statistically positive relationship was identified between transactional leadership and school climate. The study collected data from $345(N=201)$ career technical teachers selected randomly from the 3,343 career technical teachers employed in joint vocational school districts during the 2001-2002 school year. The Pearson product moment correlation coefficient was used to determine the strength and direction of the relationship between transformational leadership and school climate. The result $(r=.569)$ indicated a moderate relationship, significant at alpha level $p<0.01$.

Teachers' perceptions of principals' leadership behaviors and the relationship to school culture were studied by Stone (2003) in Mississipi public schools. Respondents were comprised of 68 teachers from 11 elementary, middle, and high schools. Using the LPI-Observer (Kouzes \& Posner, 2005) and Instructional Climate Inventory (Braskamp \& Maehr, 1986), Stone found statistically significant relationships among all principals’ practices of all five of the exemplary leadership practices and the schools' culture, based on teachers' perceptions. When school level was tested, no significant differences were found.

Principals in rural schools were studied for the relationship of leadership and school climate. Kelley, Thornton, and Daugherty (2004) studied principals from 31 elementary schools and 155 teachers, with the Leader Behavior Analysis instrument 
(Blanchard, Hambleton, Zigarmi, \& Forsyth, 1991) and the Staff Development and School Climate Assessment Questionnaire (Zigarmi \& Edeburn, 1980). Correlation analysis revealed statistically significant positive relationships between teachers' perceptions of the principals' effectiveness scores and all size domains of the school climate instrument (communication, decision-making, innovation, advocacy, evaluation, and staff development). The researchers concluded that for this sample, school climate was directly connected to teachers' perceptions of their principals' effectiveness, as defined by leadership behavior.

These studies indicated that principals possess the power, authority, and position to impact a school's climate, but many principals may not recognize the specific areas needing improvement and may require appropriate feedback to implement improvements (Kelley, et al., 2005).

\section{Leadership and Student Achievement}

Research has indicated the inextricable link between school leadership and school success, and the public is growing more appreciative of the importance of effective leadership (Sergiovanni, 1991). The roles of the principal have undergone dramatic changes (Casavant \& Cherkowski, 2001; Pingle \& Cox, 2007). Legislation and educational reforms have consistently pointed to the importance of responsible, assertive, and visible school leadership with regard to school success (Sergiovanni, 1991; Waters, Marzano, \& McNulty, 2004; Zepeda, 2007). Moreover, school leadership has become an educational priority throughout the world (Pont, Nusche, \& Moorman, 2008).

Researchers in education have long recognized that educational leaders, especially school principals, influence school effectiveness (Levine \& Lezotte, 1990; Pashiardis, 
2004; Reynolds \& Cuttance, 1992). However, findings of earlier studies were mixed concerning the effects of leadership on student achievement. Some studies found no influence and others identified some effects (Heck, 1992; Witziers, Bosker, \& Kruger, 2003). Murphy (2005) pointed out that as principals can have a positive impact on achievement; they can also have a marginal or negative impact as well. When principals concentrate on the wrong school and classroom practices, or miscalculate the magnitude of change they are implementing, they can negatively impact student achievement.

Nevertheless, 30 years of research have demonstrated a substantial relationship between leadership and student achievement (Marzano, 2004; Waters et al., 2004). In a study commissioned by the National Governors' Association, Elmore (2003) concluded that the appropriate focus of change is key to improving schools and increasing student achievement:

Knowing the right things to do is the central problem of school improvement. Holding schools accountable for their performance depends on having people in schools with the knowledge, skill, and judgment to make the improvements that will increase student performance. (p. 9)

Recent studies on principals' leadership and student achievement further corroborate the importance of leadership to achievement.

Middle school teachers and principals from the Hempfield School District in Pennsylvania were surveyed to identify the relationship between instructional leadership behaviors and student achievement with school socioeconomic status (SES) as a secondary variable (O'Donnell \& White, 2005). Both teachers and principals completed the Hallinger's (1987) Principal Instructional Management Rating Scale, a 50-item scale 
measuring effective behaviors identified by research in schools. Student test scores on the Pennsylvania System of School Assessment were also analyzed. The findings indicated that when teachers perceived their principals' behaviors were focused on improving the school climate, these perceptions predicted student achievement. The study also found that in schools with high SES, principals who perceived themselves as frequently exhibiting behaviors associated with their schools' missions were related to higher student reading scores.

Kiper (2007) studied the correlation between transformational leadership and student state-mandated proficiency scores in reading and mathematics at seven suburban Minnesota schools. Through a stratified random sample, 59 teachers in these schools completed the LPI, Observer version, to rate their principals in the five exemplary leadership practices of Kouzes and Posner (2005). Results of this study showed all five leadership practices of the Leadership Practices Inventory (Kouzes \& Posner, 2007) were positively correlated with the Minnesota Comprehensive Assessment (MCA) scores in mathematics, with Modeling, Enabling, and Encouraging reaching statistical significance. MCA scores in reading were all positively correlated but did not reach statistical significance with the five leadership practices. Kiper reported that study results that were significant "showed strong, positive relationship between transformational leadership practices and mathematics test scores when leaders model desired behaviors, enabled teachers to act by creating opportunities for them to take risks, and encouraged them through positive recognition" (p. iii).

School educational leaders play an invaluable role in guiding the instructional process, which in turn is an important factor in student achievement (Borman, Hewes, 
Overman, \& Brown, 2002). Schools that help students achieve are led by principals who make a significant contribution to teachers' effectiveness and to the learning of the students taught (Edmonds, 1979; Murphy, 2005; Ross et al., 2005). Principals may impact teaching and classroom practices through decisions they make regarding the formulation of school goals, the setting and communicating of expectations, allocation of resources, supervision of teachers' performance, and promotion of an orderly, positive environment of learning (Hallinger \& Leithwood, 1994; Center for Comprehensive School Reform and Improvement, 2005).

\section{Leadership, School Climate, and Student Achievement}

As the studies reviewed indicated, principals' leadership, especially transformational leadership practice, is strongly related to school climate. Studies reviewed above also showed the positive effects of leadership on student achievement. Several studies have investigated the three variables together, principals' leadership, school climate, and student achievement.

Hallinger, Bickman, and Davis (1996) explored the extent of the principal's effect on reading achievement in a sample of 87 elementary schools in the United States. Data were collected from principal and teacher questionnaires and student test scores. Results indicated a direct effect of leadership on the existence of a clear school mission, which in turn influenced students' opportunities to learn and teachers' expectations for student achievement.

Principal leadership, school climate, and student achievement were also studied by Sims (2005) with 213 teachers in 13 Title I elementary schools in large urban district in western Tennessee. Teachers completed the Kouzes and Posner (2005) LPI-Observer 
Questionnaire and the School Climate Inventory (Center for Research in Educational Policy, 2002). Sims used reading and mathematics scores from the state assessment to measure student achievement.

Findings of the Sims (2005) study showed the most frequent leadership practice as Encouraging the Heart, followed closely by Challenging and Inspiring, Modeling and Enabling least frequent. With regression analysis, principals' leadership practices accounted for over $76.6 \%$ of the variability in overall school climate. For the school climate dimensions, the five leadership practices accounted for $88.7 \%$ of the variation in Leadership, 86.4\% in Collaboration, 81.5\% in Environment, and 80.5\% in Instruction. Further, principals' leadership practices had no significant effect on student achievement in reading and mathematics. Although no statistically significant relationship was found, based on the regression analysis results, Sims (2005) observed that principals should continue to exhibit exemplary leadership behaviors to positively impact school climate. As studies have indicated, school climate can in turn positively affect student achievement (Bulach et al., 1995; Cunningham, 2003; Institute for School Improvement, 2006).

Hill (2007) examined servant leadership to determine a possible correlation with this leadership style and school climate and student achievement. Servant leadership is the understanding and practice of leadership that places the good of those led over the leader's self-interest. The characteristics overlap with those of transformational leadership and include valuing others, developing their potentials, building community, displaying authenticity, providing leadership, and sharing leadership (Block, 1996). 
Secondary principals and teachers from Minnesota schools were surveyed by Hill (2007), with consideration of student academic performance.

A significant relationship was found between the perceptions of servant leadership behaviors reported by both principals and teachers. A stronger relationship was found between school leader attributes and overall school climate, as well as the relationship between servant leadership behaviors and the school's organizational climate. However, no significant relationship was found for either variable with student achievement (Hill, 2007).

The impact of transformational leadership and school climate on student achievement was analyzed by Mees (2008) in communication arts in 79 Missouri middle schools. The Principal Leadership Questionnaire (PLQ) by Jantzi and Leithwood (1997) was used to provide data on transformational leadership. The PLQ measures six factors: Vision Identification, Modeling, Goal Acceptance, Individualized Support, Intellectual Stimulation, and High Performance Expectations. School climate was measured by the School Culture Survey (Gruenert \& Valentine, 1998), with six factors: Collaborative Leadership, Teacher Collaboration, Professional Development, Unity of Purpose, Collegial Support, and Learning Partnership. The percentage of students scoring proficient on the Grade 8 Missouri Assessment Program (MAP) was used to measure student achievement. In addition, the percentage of students eligible for free and reduced lunch and school enrollment were used in stepwise regression to account for their effect on the dependent variable, student achievement.

The findings of Mees (2008) indicated that several transformational leadership factors and other school factors predicted school culture. Mees conducted a regression 
analysis of the factors of the Principal Leadership Questionnaire in conjunction with the factors of the School Culture Survey. Information was also collected on the demographic variables of the percentage of students eligible for free and reduced lunch and school enrollment. Results indicated that three transformational leadership factors were significant predictors for the cultural factor of collaborative leadership. The factors of goal acceptance, individualized support, and modeling accounted for $72.5 \%$ of the variance. Goal acceptance was the primary factor impacting collaborative leadership, accounting for $67.9 \%$ of the variance, followed by individualized support (3.3\% of variance), and modeling (1.3\% of variance).

It is evident that few studies have been conducted on the three variables of principals' leadership behaviors, school climate, and student achievement. More studies have focused on two of these three variables, and results have been mixed for studies of the three variables. This study was undertaken to help fill this gap.

\section{Summary}

Schools in many parts of the country are falling short in terms of student achievement (Spellings, 2007). NCLB has significantly increased the pressure on school leaders to improve student achievement. The purpose of this nonexperimental ex post facto study was to test the relationships among secondary school principals' leadership behaviors, school climate, and student achievement.

Transformational leadership is the primary model reflecting the relatively new attention to leadership models that are more consistent with evolving trends in educational reform, such as empowerment, shared leadership, and organizational learning, rather than hierarchical or dictatorial leadership models (Howard, 2004; 
Northouse, 2007). The scholars most closely associated with transformational leadership and description and refinement of its principles are Burns (1978), Bass (1998) and colleagues (Bass \& Avolio, 1990, 1997; Bass et al., 2003), Covey (1990), and Kouzes and Posner $(2002,2007)$. As the roles of principals have changed dramatically, the need for exemplary leadership has become more apparent (Pingle \& Cox, 2007). School leadership has increasingly been recognized as important in combination with school climate and quality instruction for effective schools and student achievement (Kelly, Thornton, \& Daughtery, 2005; National School Climate Center, 2007).

Studies examining school climate and student achievement have generally found significant relationships (Bulach et al., 1995; Cunningham, 2003). Results for tests of leadership and school climate have also been found significant (Stone, 2003; Remondini, 2001; Kelley et al., 2004), although with both sets of variables, significant relationships have not always resulted. Findings for the relationship between school leadership and student achievement have been mixed (Heck, 1992; Johnson, 1993; Witziers et al., 2003). However, more recent studies have indicated significant relationships (Kiper, 2007; Mees, 2008; O'Donnell \& White, 2005).

For the three variables of principal leadership, school climate, and student achievement, those to be examined in this research, fewer studies have been conducted. The results have been mixed, generally with significant relationships between leadership and school climate but not student achievement (Hallinger et al., 1996; Hill, 2007; Sims, 2005; Mees, 2008). In light of such results and the scarcity of studies, this study was undertaken to examine the relationships among these variables, aid understanding of 
leadership, school climate, and student achievement among principals and teachers, and provide guidance for principals' school reform practices. 


\section{CHAPTER III}

\section{METHOD}

This chapter begins with the purpose of the study, research questions, and hypotheses, as outlined in Chapter I. Next, the research design is discussed, followed by a description of the population and sample, instruments, procedures for data collection, data analysis, data management. The limitations and a summary conclude the chapter.

\section{Purpose of the Study}

The purpose of this nonexperimental ex post facto study was to test the relationships among secondary school principals' leadership behaviors, school climate, and student achievement.

\section{Hypotheses}

Three null hypotheses were formulated for this study. They are as follows:

1. There is not a positive relationship between principals' leadership behaviors and school climate.

2. There is not a positive relationship between principals' leadership behaviors and student achievement.

3. After controlling for gender, years at current school, and years in the district, there are not positive relationships among principals' leadership behaviors, school climate, and student achievement.

\section{Research Design}

The framework for this study was derived from the Kouzes and Posner's theory of exemplary leadership practices and Sheridan and Gutkin's (2000) theoretical foundation of school climate. A quantitative research design was chosen for this study because of the 
nature of the hypotheses and the fact that a large number of participants were surveyed (Hoy \& Miskell, 2005). This quantitative study used a nonexperimental ex post facto design to test the hypotheses.

\section{Quantitative Design}

In a quantitative study, the research questions are relatively narrow and specific. Hypotheses are formulated from the research questions, with particular variables identified (McMillan \& Schumacher, 2009). Instruments, such as surveys and questionnaires that have been demonstrated to have good reliability and validity estimates, are used to collect the data necessary to answer the questions and test the hypotheses with the sample. The questions are preset, specific, and close-ended (Creswell, 2008).

As many participants as possible are sought; and they are identified as the sample to test the hypotheses with inferential questions. This type of research involves the collection and analysis of quantitative data to develop a precise description of a sample's behavior or personal characteristics. Researchers may describe a sample at a single point in time, over a period of time, or over several successive points in time (Creswell, 2008; Gall, Gall, \& Borg, 2005).

\section{Nonexperimental Ex Post Facto Design}

In nonexperimental research, random assignment to groups is not possible and the researcher does not manipulate an independent variable (Johnson \& Christensen, 2007). Further, because of the lack of manipulation of research conditions, generalizations about cause and effect cannot, and should not be made. In ex post facto research, the aim is to determine how one factor, characteristic, or item (an independent variable), which is 
preexisting, affects another (a dependent variable) in a population (Creswell, 2008;

McMillan \& Schumacher, 2009). The purpose, then, is "to investigate whether one or more preexisting conditions have possibly caused subsequent differences in the groups of subjects" (Creswell, 2008, p. 303).

Results indicate not only whether relationships between variables exist, but also the strength of the relationships (Johnson \& Christensen, 2007). Use of a statistical tool, correlational analysis, also makes it possible to analyze the relationships between two or more variables at a time. Therefore, this type of quantitative design enables researchers to investigate how several variables, either singly or in combination, might affect a particular pattern of behavior (Gall et al., 2005). For the purposes of this study, correlational coefficients were computed among six independent variables, five leadership behaviors and school climate, and one dependent variable, student achievement, as measured by the FCAT.

\section{Population and Sample}

A description of the population and sample is presented first. This is followed by a description of the instruments used. Then data management and analysis are discussed. Population

The population was selected from secondary school principals in the tri-county area of Miami-Dade, Broward, and Palm Beach counties, Florida. The tri-county area was selected because these were the three most populous counties in the state, respectively, and because of general similarities in student demographics, student achievement data (as noted in Chapter I), and county economic demographics. For example, the overall populations were generally similar (Miami-Dade 2.2 million, 
Broward 1.6 million, Palm Beach 1.3 million). Although Miami-Dade had a greater proportion of Hispanics (60\%), all three counties have similar proportions of Blacks (Miami-Dade 19\%, Broward 20\%, Palm Beach 16\%), and Broward and Palm Beach had similar proportions of Hispanics (16\%, 16\%, respectively). In addition, according to the most recent statistics, the proportions of residents living below the poverty line were approximately similar in the three counties. For Miami-Dade County, the percentage was 18\%; for Broward County, 11\%; and for Palm Beach County, 10\% (Florida Office of Economic and Demographic Research [FOEDR], 2008).

The population of secondary school principals in the three counties included those from the middle schools and high schools. The gender and racial/ethnic characteristics of the principals are shown in Table 1 . The total number of secondary school principals in the tri-county area was 235 (Broward County Public Schools, 2010; Miami-Dade County Public Schools, 2010; Palm Beach County Public Schools, 2010). The distribution of the total population is displayed in Table 2 .

\section{Sample}

For this study, a total of 235 secondary school principals from the tri-county area of Miami-Dade County, Broward County, and Palm Beach County were originally anticipated as participants. The three urban counties are among the largest in the state of Florida. Notwithstanding, the researcher was afforded access to but five of the principals in one county. Thus, surveys could only be sent to 165 secondary school principals in the tri-county area. 
Table 1

Gender and Racial/Ethnic Demographic Characteristics of Secondary Principals in the Three Counties

\begin{tabular}{lccc}
\hline Characteristic & Miami-Dade & Broward & Palm Beach \\
\hline Gender & 53 & 33 & 29 \\
Male & 54 & 39 & 27 \\
Female & & & \\
Race/Ethnicity & 36 & 35 & 30 \\
White & 22 & 32 & 20 \\
Black & 49 & 5 & 6 \\
Hispanic & 107 & 72 & 56 \\
Total & & & \\
\hline
\end{tabular}

Note. From Broward County Public Schools (2010), Miami-Dade County Public Schools (2010), Palm Beach County Public Schools (2010). 
Table 2

Distribution of Middle and High School Principals in the Tri-County Area

\begin{tabular}{lccc} 
County & Middle Schools & High Schools & Totals \\
\hline Miami-Dade & 61 & 46 & 107 \\
Broward & 41 & 31 & 72 \\
Palm Beach & 33 & 23 & 56 \\
Totals & 132 & 96 & 235 \\
\hline
\end{tabular}

Note. From Broward County Public Schools (2010), Miami-Dade County Public Schools (2010), Palm Beach County Public Schools (2010).

These are the variables that were examined in this study: the five LPI exemplary leadership behaviors, school climate, student achievement, gender, years at current school, and years in the district. To determine the minimum acceptable number of participants, an a priori power analysis was performed. For one-tailed (unidirectional) bivariate correlation analysis, the power was set at $80 \%$, the effect size selected was medium $(r=.30)$, and $a=.05$. These are values widely used in educational studies (Creswell, 2008). The results of the power analysis with the $\mathrm{G}^{*}$ Power analysis program (Faul, Erdfelder, Lang, \& Buchner, 2007) resulted in a required minimum sample size of 111. However, all secondary principals in the three counties were recruited to compensate for nonresponses or unusable data because of missing information on the instruments. This is the census approach, recommended for small populations of 200 or less (Israel, 1992). 


\section{Instruments}

Three instruments were used in this study. The Demographic Questionnaire was designed by the researcher, following the format of similar instruments used in educational studies. The Leadership Practices Inventory and School Climate Inventory were chosen for applicability to the variables studied and for the minimal time required and ease of administration. In addition, the instruments were chosen for their extensive testing with educational and other populations, and for their reliability and validity estimates (Bulach \& Malone, 1994; Kouzes \& Posner, 2007; Leadership Challenge, 2007; Sims, 2005; Stone, 2003). Both instruments are commercially available; the LPI was purchased by the researcher, and the SCI-R is made available free of charge for dissertation research with signing of the Instrument Usage Agreement Statement (Center for Research in Educational Policy [CREP], 2002; see Appendix A).

\section{Demographic Questionnaire}

A researcher-designed demographic questionnaire was used to collect descriptive data from the participants. The 13 items were drawn from similar studies in the literature (e.g., Cho, 2003; Sims, 2005; Stone, 2003) and requested demographic items were specific to secondary school principals. Items included gender, age, race/ethnicity, highest degree earned, years in school district, years as principal in current or another school, years as principal in current school, whether the principal had leadership training for one or more years, and the number of leadership courses (see Appendix B). The number of students receiving free or reduced lunch, race/ethnicity of students, and the number of teachers in the school will also be included for additional insight into the school community. 


\section{Leadership Practices Inventory}

Principals' leadership practices were measured in this study with the Leadership Practices Inventory (LPI; Kouzes \& Posner, 2007; see Appendix C). The purpose of this inventory is to assess the extent to which leaders report using the practices toward understanding and improvement in leadership behaviors. The LPI contains five subscales representing the five exemplary leadership practices: (a) Challenging the Process, (b) Inspiring a Shared Vision, (c) Enabling Others to Act, (d) Modeling the Way, and (e) Encouraging the Heart (Kouzes \& Posner, 2000, 2002, 2007).

Development. Over 20 years, Kouzes and Posner developed, tested, and refined the LPI. It was developed through a triangulation of qualitative and quantitative research methods and studies. In-depth interviews and written case studies from personal-best leadership experiences generated the conceptual framework, which yielded the five leadership practices. The LPI was created by developing a set of statements describing each of the leadership behaviors. Statements were modified, discarded, or included following lengthy discussions and iterative feedback sessions with respondents and subject matter experts, as well as empirical analyses of various sets of behaviorally-based statements (Kouzes \& Posner, 2002).

Description. The LPI is comprised of 30 items, with each of the five subscales measured by 6 items. The Challenging the Process subscale involves searching out challenging opportunities to change, grow, innovate, and improve, as well as experimenting by taking risks and learning from the resulting mistakes (items 1, 6, 11, 16, 21, 26). The Inspiring a Shared Vision subscale involves envisioning an uplifting and ennobling future and enlisting others in a common vision through appeal to their values, 
interests, hopes, and dreams (items 2, 7, 12, 17, 22, 27). The Enabling Others to Act subscale involves fostering collaboration by promoting cooperative goals and building trust, as well as strengthening others by surrendering power, providing choices, developing competence, assigning crucial tasks, and offering visible support (items 3,8 , $13,18,23,28)$. The Modeling the Way subscale involves setting the example through behavior consistent with shared values, as well as achieving small victories that promote consistent progress and build others' commitment (items 4, 9, 14, 19, 24, 29). The Encouraging the Heart subscale involves recognizing individual contributions to every project's success and regularly celebrating team accomplishments (items $5,10,15,20$, $25,30)$. The six items in each subscale were added to compute the total score (Kouzes \& Posner, 2007). Table 3 illustrates sample items for each subscale.

Research with the LPI. The response options on the LPI scores have been found to be unrelated to demographic characteristics (e.g. age, marital status, years at current school, and educational level) or organizational features (e.g. size, functional area, and line versus staff position). This finding extended across a wide variety of non-business settings as well as suggested research with school superintendents, principals, and administrators. In addition, no gender differences or differences in leadership practices based on racial/ethnic background were reported for studies involving school principals or superintendents (Kouzes \& Posner, 2002).

Several studies have used the LPI with principals with regard to school climate. Remondini (2001) studied the leadership styles and school climates of Hispanic and nonHispanic women principals. Findings showed that, although ethnicity did not determine leadership styles of principals, a statistically significant relationship was found between 
principals' leadership styles and school climate. Stone (2003) studied principals' leadership behaviors and school climate as perceived by teachers in elementary, middle, and high schools. Statistically significant relationships were found between principals' implementation of all five leadership practices of the LPI and school climate. Sims (2005) examined the effects of principals' leadership practices on school climate and student achievement in elementary schools. Results indicated that principals' leadership practices accounted for a high percentage (76.6\%) of the variance in overall school climate.

Table 3

LPI Subscales and Sample Items

Subscale Sample Item

Challenging the Process

26. I experiment and take risks with new approaches to my work even when there is a chance of failure.

Inspiring a Shared Vision

7. I appeal to others to share my dream of the future as their own.

Enabling Others to Act

18. I develop cooperative relationships with the people I work with.

Modeling the Way

24. I am consistent in practicing the values I espouse.

Encouraging the Heart

5. I take time to celebrate accomplishments when project milestones are reached.

The LPI is one of the most widely used leadership assessment instruments available. Over 350,000 leaders in a range of fields, including education, have completed 
the LPI. In addition, more than 250 master's theses and doctoral dissertations have used the LPI (Leadership Challenge, 2007).

Reliability and validity. Strong reliability and validity estimates of the LPI have been supported by Kouzes and Posner's research and independent studies. Validation studies conducted over 15 years have consistently supported the reliability and validity of the five practices of exemplary leaders and the LPI. Reliability coefficients (Cronbach's alpha) using the LPI for school principals were reported at .79, consistently above the acceptable criterion of .70 (Santos, 1999). Internal reliabilities for each of the five leadership practices were found as follows: Challenging the Process, .80; Inspiring a Shared Vision, .87; Enabling Others to Act, .75; Modeling the Way, .77; Encouraging the Heart, .87 (Kouzes \& Posner, 2000, 2002). In a study of managers and employees, managers' leadership behaviors internal reliability for the five leadership practices ranged from .88 to .95 (Bell-Roundtree, 2004). Test-retest reliabilities involving school administrators were reported at .86 for superintendents and .79 for school principals (Kouzes \& Posner, 2002).

Construct validity. Factor analysis, used to determine the extent to which instrument items measure content areas that are the same or different, was performed on the LPI by several researchers. A factor analysis was performed with LPI data in conjunction with a study of transformational and transactional leadership by Herold, Fields, and Hyatt (1993). The researchers concluded that the LPI items that had correlations with other items exceeding . 50 , resulted in a confirmatory model with acceptable fit $\left(\chi^{2}=399.9, d f=363, p<.09\right)$. In addition, all the hypothesized structural coefficients linking the observed variables to the five factors were highly significant with 
all $t$ values exceeding 7.0. These values suggest that when modeled appropriately the estimates confirmed the LPI factor Model.

Kouzes and Posner (2002) conducted a confirmatory factor analysis of the LPI. The analysis revealed that the LPI contained five factors, with eigenvalues greater than 1.0 and accounting for $60.5 \%$ of the variance. The 30 leadership behavior items were subjected to a principal factoring method. Five interpretable factors were obtained, consistent with the five subscales of the LPI. The stability of the five factors was tested by factor analysis of the data from different subsamples. In each case, the factor structure was essentially similar to the one involving the entire sample (Kouzes \& Posner, 2002).

Scoring. The LPI is comprised of 30 items on a 10-point Likert-type scale, refined for greater sensitivity in 1999 from a 5-point Likert-type scale. The values are as follows in application to practice of what is described in each statement: (1) Almost never, (2) Rarely, (3) Seldom, (4) Once in a while, (5) Occasionally, (6) Sometimes, (7) Fairly often, (8) Usually, (9) Very frequently, and (10) Almost always. The range for the LPI is 30 to 300 , with higher values representing more frequent and better use of a leadership behavior. Completion of the LPI takes approximately 10 minutes (Kouzes \& Posner, 2002).

\section{School Climate Inventory}

Principals' perceptions of their school climate were measured in this study with the School Climate Inventory-Revised (SCI-R; CREP, 2002; see Appendix C). The purpose of this inventory is to enable school leaders to assess their perceptions of school climate, encourage them to adopt behaviors likely to result in improved school climates, and to develop strategies to address those climate factors that may inhibit or limit school 
effectiveness. The data can assist and motivate staff to adopt behaviors likely to result in improved organizational climates and better support of student learning (CREP, 2002).

The SCI-R contains seven subscales, logically and empirically linked with factors associated with effective school organizational climates. These are (a) Order, the extent to which the environment is ordered and appropriate student behaviors are present; (b) Leadership, the extent to which the administration provides instructional leadership; (c) Environment, the extent to which positive learning environments exist; (d) Involvement, the extent to which parents and the community are involved in the school, (e) Instruction, the extent to which the instructional program is well developed and implemented; (f) Expectation, the extent to which students are expected to learn and be responsible; and (g) Collaboration, the extent to which the administration, faculty, and students cooperate and participate in problem solving (CREP, 2002).

Development. The School Climate Inventory-R (SCI-R) was developed by researchers at the Center for Research in Educational Policy (CREP) at the University of Memphis in 1989. The SCI-R was developed from the Tennessee School Climate Inventory (Butler \& Alberg, 1991) and was designed for administration with adult professionals in schools. The instrument has been used for school-based improvement planning and schools and state school districts (CREP, 2002).

Description. The SCI-R is comprised of 49 items, with each subscale measured by 7 items. The Order subscale represents the extent to which the environment is ordered and appropriate student behaviors are present (items 13, 23, 25, 30, 39, 44, 46). The Leadership subscale represents the extent to which the administration provides instructional leadership (items 8, 20, 34, 36, 42, 45, 47). The Environment subscale 
represents the extent to which positive learning environments exist (items 7, 9, 10, 14, 29, $38,49)$. The Involvement subscale represents the extent to which parents and the community are involved in the school (items 5, 11, 12, 18, 19, 32, 37). The Instruction subscale represents the extent to which the instructional program is well developed and implemented (items 4, 15, 24, 33, 35, 41, 48). The Expectation subscale represents the extent to which students are expected to learn and be responsible (items 2, 3, 17, 21, 22, 27, 43). The Collaboration subscale represents the extent to which the administration, faculty, and students cooperate and participate in problem solving (items 1, 6, 16, 26, 28, 31, 40; CREP, 2002).

Research with the SCI-R. The SCI-R has been used in a number of studies, reviewed below, and has been shown to be valuable for monitoring and managing school reform (CREP, 2002). Studies have used the SCI-R to measure school climate with regard to school leadership and student achievement. Ross and Nunnery (2005) investigated students in grades 3 through 8 attending one of 40 schools, matched for no school reform implementation or school reform, in 15 school districts in southern Mississippi. The majority of the students were of low socioeconomic status. Teachers' school climate results significantly favored the school reform schools on all dimensions of the SCI-R (effect sizes ranged from +0.20 , Involvement, to +0.54 , Collaboration), and the reform students scored significantly higher than comparison students on reading (median effect size estimates +0.11 for reading, +0.12 for language), writing ( $44.5 \%$ of reform group scored 3-4 on a 0-4 rubric versus $25.4 \%$ of comparison group), and mathematics (effect size estimates +.022 to +0.27 ) standardized tests. No tests were 
reported to determine whether the differences in the percentages were statistically significant.

Ross, McDonald, and Alberg (2005) studied a whole-school reform program at an inner-city school in a large high-poverty urban school district, with matched control and implementation groups of students. Results supported previous studies showing the crucial role of positive school climate on improvement of teacher effectiveness. The positive climate facilitated program implementation, improving teaching effectiveness and student achievement. As noted above under studies with the LPI, Sims (2005) found that elementary school principals' leadership practices were found to be significantly related to overall school climate and four domains of the SCI but not to student achievement. Multiple regression analysis showed that that principals' leadership practices accounted for $76.6 \%$ of variance in overall school climate, $88.7 \%$ in Leadership, 86.4\% in Collaboration, $81.5 \%$ in Environment, and 80.5\% in Instruction. However, principals' leadership practices were not significantly related to Order, Involvement, or Expectation or an effect on student scores in state-mandated reading and mathematics assessments.

McDonald, Ross, Bol, McSparrin-Gallagher (2007) studied three charter schools (elementary, middle, high school) with predominantly African American students in relation to matched noncharter school students. Qualitative and descriptive statistical analyses showed that for the charter schools strong positive school climate was a major factor related to success, including progress in program implementation, positive teacher and parent perceptions, and positive student achievement on state-mandated tests $(p<.05$ on 12 of $18 \times$ cohort $\mathrm{x}$ subtest comparisons). 
Reliability and validity. The team at CREP estimated the face validity of the school climate items and logical ordering of the items by scales during the development of the inventory. Later analysis of responses collected through administration of the inventory in various school sites has substantiated the validity of the items (CREP, 2002). The authors of the SCI reported, "The items and scales have appropriate discriminatory power (i.e., yield empirical indicators that differentiate schools on the variables assessed)" (CREP, 2002, p. 1). However, the statistical values were not clearly reported. Estimated reliability coefficients (Cronbach's alpha) for the seven subscales were all above the acceptable criterion of .70 (Santos, 1999), as follows: Order, .84; Leadership, .86; Environment, .85; Involvement, .78; Instruction, .76; Expectation, .75; Collaboration, .76 (CREP, 2002).

Construct and predictive validity. No studies of construct or predictive validity of the SCI-R were located by this researcher. In addition, in response to the researcher's inquiry to the originators at CREP as to studies of construct or predictive validity, she was informed that they knew of no such studies (S. Hurst, personal communication, July 2, 2008).

Scoring. The SCI-R is comprised of 49 items, with each subscale containing 7 items. Responses are scored on a 5-point Likert-type scale, with values as follows: (1) Strongly disagree, (2) Disagree, (3) Neutral, (4) Agree, (5) Strongly agree. The range for the SCI is 49-245, with higher scores indicating more positive assessment of school climate. Administration of the SCI-R takes approximately 15 minutes (CREP, 2002; see Appendix D). 


\section{Student Achievement}

Student achievement was measured in this study by the researcher's examination of 8th- and 10th-grade students' annual learning gains and percentage of passing the annual Reading and Mathematics FCAT. The FCAT is a criterion-referenced test that measures how well students meet the Florida State Standards in several basic subjects. These are reading, writing, mathematics, and science (Florida Department of Education, 2008a).

For this study, students' scores on the Reading and Mathematics portions only of the 2009-2010 FCAT were used. This was because according to Florida law, students must pass the Reading and Mathematics Grade 10 FCAT to graduate from high school. Only 8th- and 10th-grade students' scores were examined. Students are required to pass the 10th-grade examination in order to graduate.

Description. The FCAT measures student performance on selected benchmarks in reading, mathematics, writing, and science, as defined by the Florida State Sunshine Standards (SSS). The SSS articulates challenging content that Florida students are expected to know and be able to retain and apply. FCAT achievement levels describe the success a student has achieved and range from 1 (low) to 5 (high). The achievement level definitions are as follows:

Level 5: This student has success with the most challenging content of the SSS. A student scoring Level 5 answered most of the test questions correctly, including the most challenging. 
Level 4: This student has success with the challenging content of the SSS. A student scoring Level 4 answered most of the test questions correctly but may have only some success with questions that reflect the most challenging content.

Level 3: This student has partial success with the challenging content of the SSS. A student scoring Level 3 answered many of the test questions correctly but is generally less successful with questions that are the most challenging.

Level 2: This student had limited success with the challenging content of the SSS.

Level 1: This student had little success with the challenging content of the SSS (Florida Department of Education, 2008a).

Reliability and validity. In 2010, to further test the accuracy of the 2010 FCAT scores, the Florida Department of Education (FLDOE) commissioned the Buros Center for Testing to review all calibration and scaling procedures of tests selected by the FLDOE. Complex and classic statistical procedures were used, and the calibration sample size for the Grade 10 reading test was 14,927 (Chin, Shaw, Dwyer, McCormick, \& Geisinger, 2010). The FLDOE provided the FCAT 2010 Calibration and Equating Specifications document (FLDOE, 2010a) to serve as the guide for the Buros analysis. With regard to the accuracy of calibration and scaling, Chin et al. (2010) arrived at the following conclusions:

1. The FLDOE process was well organized.

2. The statistical analyses used to identify problematic items were adequate.

3. The organizations involved in the operational work were nationally recognized testing firms composed of high quality staff. 
4. The responsibilities of those organizations were clearly defined and ensured the accuracy of the scores on the 2010 FCAT. (p. 9)

Finally, Chin et al. (2010) observed that although equating is a highly quantitative procedure, considerable judgment is involved. The researchers believed that the FLDOE responsibly utilized the resources and expertise available to arrive at "reasonable and justifiable calibration, scaling and equating conclusions" (p. 9).

The FCAT has been tested for internal consistency reliability with Cronbach's alpha coefficients. The most recent estimate of reliability (2006) for the Grade 10 reading test was .85 and for the mathematics test was .88 (FLDOE, 2010a). The FLDOE asserted that its interpretation of test scores were valid. To promote validity, the following steps were implemented:

1. Educators and citizens judged the standards and skills as acceptable.

2. Item specifications were written.

3. Test items were written according to the guidelines provided by the item specifications.

4. The items were pilot tested using randomly selected groups of students at appropriate grade levels.

5. All items were reviewed for cultural, racial/ethnic, language, and gender bias.

6. Instructional specialists and practicing teachers reviewed the items.

7. The items were field tested to determine their psychometric properties. (FLDOE, 2010a)

Concurrent validity estimates for the FCAT were conducted with the correlation of scores on the criterion-referenced portion (SSS) with scores on the norm-referenced 
portion, the Stanford Achievement Test-Ninth Edition (SAT 9). The SAT 9 based standardization on stratified random samples from 450,000 students from 49 states and the District of Columbia and measured reading, language, spelling, study skills, listening, mathematics, science and social science (Cook, 2003). Both the SSS and SAT 9 were administered at the same time. Concurrent validity for FCAT in Grade 10 was .78 in reading and .76 in mathematics (FLDOE, 2010a).

Scoring. The total scores a student can receive in Reading and Mathematics range from 100 (low) to 500 (high). The reading and mathematics scores are also reported as developmental scale scores that range from 0 to 300 . These scores are used to track progress from year to year (FLDOE, 2010b).

In this study, however, individual students' FCAT mean scores were not used. Rather, mean FCAT scale scores in Reading and Mathematics, comprised of all students' scores, were used for each school to measure student achievement. These mean school scores are reported yearly. For example, in 2010 the mean scores in reading for these Broward County high schools were as follows: Boyd H. Anderson, 279; Nova, 326 (FOEDR, 2010). Whether a school met Adequate Yearly Progress (AYP) and school letter grade were analyzed as additional measures of overall school success.

\section{Data Collection Procedures}

First, approval for permission to conduct the study was sought and obtained from the Florida International University Institutional Review Board (IRB), the College of Education Office of Graduate Studies (OGS), and the University Graduate College (UGS). Next, upon these approvals, permission was sought and obtained from the Office of Program Evaluation in each county to contact principals (see Appendix E). Students' 
FCAT scores were available through the Florida Department of Education website (Florida Department of Education, 2008b).

Online methods were used for recruitment and data collection. Online survey methods have been used increasingly as the Internet has gained wider use and accessibility (Manfreda, Batagelj, \& Vehovar, 2002; Sue \& Ritter, 2007). Studies have proliferated not only on the feasibility of Internet use for surveys in many fields but also comparisons of Web-based and telephone and surface mail surveys (Sheehan \& Hoy, 1999; Sue \& Ritter). Although some online surveys have yielded fewer responses than more traditionally administered surveys (Leece et al., 2004; Wright, 2005), an increasing number have yielded excellent online response rates (e.g., 66\% reported by Lusk, Delclos, Bureau, Drawhorn, \& Aday, 2007) and researchers have increasingly recommended online data-gathering methods (Simsek \& Veiga, 2000; Wright).

The instruments were administered by means of a Web link to Survey Monkey®, a third-party provider of online survey software. A pilot study was conducted of 15 assistant principals and professional colleagues to test whether the online surveys and links were properly operative (Dillman, 2007). The pilot study not only tested the operation of the survey and links but also ascertained that the instruments were clear and easy to understand for participants' completion. The participants were given 2 weeks to return the online surveys and were asked to email the researcher with their feedback. Three assistant principals suggested having one link for all three instruments. However, this was not possible because of the structure of the SurveyMonkey program. No feedback was received suggesting improvements of the clarity of the instruments. 
Once the workability of the online surveys and links were ascertained, recruitment took place by email to 168 principals in the tri-county area, as well as the researcher's announcements in person to Miami-Dade County principals at various district-sponsored principals' meetings and social and professional development activities. Within these venues, Dillman's (2007) Tailored Design Method (TDM) was used to maximize the response rate. TDM emphasizes the application of social exchange theory and encouragement of respondent trust, as well as creating perceptions of increased rewards and reduced costs. TDM also takes into account specific aspects of the various survey situations to increase response, such as mixed-mode approaches including contact online, telephone, and face-to-face methods (Dillman, Smyth, \& Christian, 2008).

Potential participants were emailed a letter of prenotification (see Appendix F) introducing the researcher and study and describing the study's purpose and nature of participation. In a survey launch letter, they were informed of actual participation, with mention of the demographic questionnaire, the LPI, and the SCI-R, and instructions for completing the online survey (see Appendix G). The letter informed principals that the survey would take them no more than 30 minutes to complete and requested their voluntary participation. The letter also assured participants of anonymity (their names would not be divulged) and confidentiality of responses (their responses would not be linked with their names). In addition, the letter described their protection as participants, and indicated their participation constituted their informed consent (Gall et al., 2005; see Appendix G).

The survey launch letter included instructions for completion and a link to the instruments, through a World Wide Web URL and instructions for accessing it, so that 
participants could complete the instruments online immediately. Two weeks after initial emailing, the researcher sent follow-up email letters with the same information to those principals who had not responded the first time. This method was suggested by Creswell (2008) to increase responses. One week later, the researcher made the first of several follow-up reminder telephone calls to principals over a period of several weeks to optimize response rates. Table 4 shows the timeline and tasks for the steps in data collection.

Table 4

Data Collection: Timeline and Tasks

Time

Task

2nd week

4th week

6th week

7th and 8th weeks

Throughout study
Pilot study of online surveys and links.

Introductory letter emailed to principals who are potential participants; announcements by researcher at meetings. Surveys were sent out.

Follow-up letters reiterating information in first letter sent to principals who did not respond to first letter. Surveys were again sent out.

Follow-up telephone calls made by researcher to principals who had not responded.

Data log were kept by researcher on completed questionnaires returned, with assignment of identification numbers for all returned questionnaires. 


\section{Protection of Participants}

Participants' anonymity and confidentiality were protected by several means. The instruments were administered by means of a Web link to Survey Monkey®, a third-party provider of online survey software. The researcher set up a separate email account to receive completed instruments. When completed instruments were returned, the researcher coded each by a number so that no names were used, additionally protecting participants' confidentiality. Further, the Survey Monkey® provider stated its privacy policy:

We will not use the information collected from your surveys in any way, shape, or form. In addition, any other material you provide us (including images, email addresses, etc.) will be held in the strictest confidence. In addition, we do not collect personally identifiable information about you except when you specifically provide this information on a voluntary basis. We will make every effort to ensure that whatever information you provide will be maintained in a secure environment. (Survey Monkey, 2008, p.1)

The letter to participants contained information for their protection. The letter informed them that they could withdraw at any time and that their anonymity and confidentiality would be preserved. Participants were also informed that the information they supplied would be reported in group form only for research purposes and kept in the sole possession of the researcher. The letter further informed them of the possible benefits and risks of participating and that they could withdraw at any time without penalty. The letter supplied the researcher's contact information for any questions or 
concerns and offered to share study results with the participants if they so request (see Appendix G).

\section{Data Analysis}

Data were analyzed with use of the IBM SPSS 19 software package (IBM SPSS, 2010). This is frequently updated software that is used extensively in educational and social science research. Descriptive analysis was used to describe the sample and responses to the instruments with frequencies and percentages of responses to the Demographic Questionnaire, LPI, and SCI-R, and the means and ranges for the LPI, SCI$\mathrm{R}$, and the FCAT.

Nonexperimental ex post facto analysis (Gall et al., 2005) was used first to test the strength and direction of the relationships of the variables in Hypotheses 1 and 2: (a) whether a positive relationship existed between principals' leadership behaviors and school climate; (b) whether a positive relationship existed between principals' leadership' behaviors and student achievement. Multiple regressions were used subsequently to predict the dependent variables. Because the sample size was relatively modest for hierarchical regression analysis (10-1 to 15-1 participant-to-variable ratio rule-of-thumb; Tabachnick \& Fidell, 2007), partial correlational analysis was used instead to test Hypothesis 3 for examining the unique associations of each independent variable with student achievement. Partial correlation analysis has been shown to be a robust statistical tool for determining unique relationships among variables with smaller sample sizes as is the case in this research (Cohen \& Cohen, 1983). Thus, the researcher predicted that after controlling for gender, years at current school, and years in the district, null relationships 
would exist among principals' leadership behaviors, school climate, and student achievement.

\section{Data Management}

The researcher coded all instruments by number for anonymity of participants and then scored all instruments in accordance with the instructions in the manuals for the LPI and SCI-R. The researcher then entered all data into the SPSS program and conducted the data analysis. Instruments, resulting spreadsheets, and statistical analyses printouts were stored in a locked file in the researcher's office. Backup copies in hard copy, CDs, and flash drives were made of all files. These files, accessible only to the researcher, will be maintained for 6 years from completion of the study (Florida International University, 2007).

\section{Summary}

This chapter described the purpose of the study, research questions, and three hypotheses. These were followed by descriptions of the research design, population and sample, and instruments to be used. Next, procedures for data collection, analysis, and management were described, followed by study limitations.

This quantitative nonexperimental ex post facto study surveyed 165 secondary principals in the tri-county area of Miami-Dade, Broward, and Palm Beach counties, Florida. A total of 58 principals returned the completed instruments. The study investigated the relationships among principals' leadership behaviors, school climate, and student achievement. The independent variables were the five leadership behaviors (Kouzes \& Posner, 2007) and school climate; the dependent/criterion variable was the mean scores for 8th- and 10th-grade students' FCAT scores in Reading and Mathematics 
for the 2009-2010 school year. Participants completed a demographic questionnaire, the LPI, and the SCI-R to test the three hypotheses. The researcher examined and analyzed school gains and percentage passed of students' Reading and Mathematics for 8th- and 10th- grade scores from the 2009-2010 FCAT. Instruments were distributed and completed by email, with assurance by the researcher of anonymity and other protection of participants' human subjects rights. The data were analyzed with IBM SPSS 19 for descriptive and inferential statistics, and all data were stored in the researcher's locked office. The results of the data analysis are presented in Chapter IV and discussed in Chapter V. 


\section{CHAPTER IV}

\section{RESULTS}

The purpose of this quantitative study was to determine the relationships among secondary school principals' leadership behaviors, school climate, and student achievement. The study was conducted using the methods described in Chapter III and with a nonexperimental ex post facto quantitative research design. Data were collected using the Leadership Practice Inventory (LPI), the School Climate Inventory-Revised (SCI-R), and the Demographic Questionnaire. Three null hypotheses were tested.

This chapter presents the results of the study and is organized into three main sections: characteristics of the sample, examination of the hypotheses, and a brief summary of the chapter. The three hypotheses were examined using correlational and regression analyses to test the relationships among the research variables. First, zeroorder correlation analyses were conducted to preliminarily examine the strength and direction of relationships among the research variables. Second, multiple regressions were used to determine the degree to which the independent variables predicted the dependent variables in Hypotheses 1 and 2.

Third, a series of one-way ANOVAs were run to test for possible group differences between the demographic and research variables in line with supporting their use as statistical controls when testing Hypothesis 3. Fourth, partial correlation analyses were used subsequently to determine the strength and direction of relationships among the leadership, climate, and student achievement variables. 


\section{Hypotheses}

1. There is not a positive relationship between principals' leadership behaviors and school climate.

2. There is not a positive relationship between principals' leadership behaviors and student achievement.

3. After controlling for gender, years at current school, and years in the district, there are not positive relationships among principals' leadership behaviors, school climate, and student achievement.

\section{Characteristics of the Sample}

Fifty-eight respondents participated in this study, which represented $34.5 \%$ of the population of principals in the tri-county area. The demographic data collected, including gender, age, race/ethnicity, and highest degree earned, work experience, and leadership training are examined in the sections below.

\section{Gender}

Forty percent $(n=23)$ of the sample was male, and $60.3 \%(n=35)$ of the sample was female.

Age

A frequency analysis of age indicated that no respondents were 26 or between 26 and 30 years of age. Twenty-three percent $(n=13)$ of the respondents belonged to the 3140 group; $43.1 \%(n=25)$ to the $41-50$ group; $27 \%(n=16)$ to the $51-60$ group; and $6.9 \%$ $(n=4)$ to the 61 and over group. 


\section{Race/Ethnicity}

Analysis of ethnicity indicated that $25.9 \%(n=15)$ of the respondents were African American; 39.7\% $(n=23)$ Hispanic; and 32.8\% $(n=19)$ White. No respondents reported being Asian or Other, and one respondent did not complete this item. In addition, for the 58 principals in the sample, ethnicity per county indicated an especially high representation of Hispanics in Miami-Dade and low representation in Broward and Palm Beach counties.

For Miami-Dade the number of principals was as follows: 19 Hispanics, 11 African American, 15 White. For Broward, the number of principals was as follows: 1 Hispanic, 1 African American, and 2 White. For Palm Beach, the number of principals was as follows: 2 Hispanic, 2 African American, and 7 White.

\section{Highest Degree Earned}

Results of highest degree earned analysis indicated that no respondents reported having the highest degree earned as a BA, BS, or professional degrees (MD, JD). Sixtysix percent $(n=38)$ of the respondents earned a Master's degree; $22.4 \%(n=13)$ a Doctorate; $12.1 \%$ Other, meaning the Specialist degree. The Specialist degree is recognized in Miami-Dade County as 36 hours beyond the Master's degree (National Center for Education Statistics, 2010).

\section{Number of Years in District}

The number of years worked in the school district indicated that no respondents indicated they had worked in their district for less than 5 years or 5-10 years. Eleven percent $(n=6)$ of respondents had worked in their district $11-15$ years; $43.1 \%(n=25)$ for $16-20$ years; $46.6 \%(n=27)$ for 21 or more years. 


\section{Number of Years as Principal}

Analysis of the number of years as a school principal at this or another school indicated that $29.3 \%(n=17)$ of respondents had been a principal for less than 5 years; $56.9 \%(n=33)$ for $5-10$ years; $10.3 \%(n=6)$ for $11-15$ years; $3.4 \%(n=2)$ for $16-20$ years. No respondent indicated working as principal for 21 or more years.

\section{Number of Years as Principal at Current School}

Results of the analysis of the number of years as principal at current school indicated that $70.7 \%(n=41)$ of respondents were principal of their current school for less than 5 years; $24.1 \%(n=14)$ for $5-10$ years; and $5.2 \%(n=3)$ for $11-15$ years. No respondents indicated that they were principal at their current school for more than 15 years.

\section{Leadership Training}

Results of the analysis of the number of respondents having had leadership training indicated that $100 \%(n=58)$ had had leadership training. Of these respondents, $55.2 \%$ reported having leadership training in college-level coursework, and $93.1 \%$ reported training in professional (career) development coursework.

\section{Number of Leadership Courses}

Analysis of the number of leadership courses taken indicated that $1.7 \%(n=1)$ of the respondents had taken one course, $32.8 \%(n=19)$ had taken $2-5$ courses, $20.7 \%(n=$ 12) had taken $6-10$ courses, and $44.8 \%(n=26)$ had taken over 20 courses. Table 5 provides a summary of the frequencies and percentages for each of the demographic variables. 
Table 5

Frequencies and Percentages of Demographic Characteristics of the Sample $(N=58)$

\begin{tabular}{|c|c|c|c|}
\hline Category & Variable & Frequency & Percentage \\
\hline Gender & $\begin{array}{l}\text { Male } \\
\text { Female }\end{array}$ & $\begin{array}{l}23 \\
35\end{array}$ & $\begin{array}{l}37.9 \\
60.3\end{array}$ \\
\hline Age & $\begin{array}{l}26-30 \\
31-40 \\
41-50 \\
51-60 \\
61 \text { and Over }\end{array}$ & $\begin{array}{r}0 \\
13 \\
25 \\
16 \\
4\end{array}$ & $\begin{array}{c}0.0 \\
22.4 \\
43.1 \\
27.0 \\
6.9\end{array}$ \\
\hline Race/Ethnicity & $\begin{array}{l}\text { African American } \\
\text { Hispanic } \\
\text { White } \\
\text { No Designation }\end{array}$ & $\begin{array}{c}15 \\
23 \\
19 \\
1\end{array}$ & $\begin{array}{c}25.9 \\
39.7 \\
32.8 \\
1.7^{1}\end{array}$ \\
\hline $\begin{array}{l}\text { Highest Degree } \\
\text { Earned }\end{array}$ & $\begin{array}{l}\text { BA or BS } \\
\text { Master's } \\
\text { Doctorate } \\
\text { Professional (MD, } \\
\text { JD) } \\
\text { Other (Specialist) }\end{array}$ & $\begin{array}{r}0 \\
38 \\
13 \\
\\
0 \\
7\end{array}$ & $\begin{array}{r}0.0 \\
65.5 \\
22.4 \\
0.0 \\
12.1\end{array}$ \\
\hline $\begin{array}{l}\text { Years Worked in } \\
\text { District }\end{array}$ & $\begin{array}{l}\text { Less than } 5 \\
5-10 \\
11-15 \\
16-20 \\
21 \text { or More }\end{array}$ & $\begin{array}{r}0 \\
0 \\
6 \\
25 \\
27\end{array}$ & $\begin{array}{c}0.0 \\
0.0 \\
10.3 \\
43.1 \\
46.6\end{array}$ \\
\hline $\begin{array}{l}\text { Years as Principal at } \\
\text { Any School }\end{array}$ & $\begin{array}{l}\text { Less than } 5 \\
5-10 \\
11-15 \\
16-20 \\
21 \text { or More }\end{array}$ & $\begin{array}{c}17 \\
33 \\
6 \\
2 \\
0\end{array}$ & $\begin{array}{c}29.3 \\
56.9 \\
10.3 \\
3.4 \\
0.0^{\mathrm{a}}\end{array}$ \\
\hline
\end{tabular}

(continued) 


\begin{tabular}{llrr}
\hline \multirow{2}{*}{ Category } & Variable & Frequency & Percentage \\
\hline \multirow{2}{*}{ Years as Principal at } & Less than 5 & 41 & \\
Current School & $5-10$ & 14 & 70.7 \\
& $11-15$ & 3 & 5.1 \\
& $16-20$ & 0 & 0.0 \\
Leadership Training & Yes & 0 & $0.0^{\mathrm{a}}$ \\
& No & & 100.0 \\
Level of Training & College Level & 58 & 0.0 \\
& Professional & 0 & 55.2 \\
Number of Courses & 1 & 32 & 44.8 \\
& $2-5$ & 26 & 1.7 \\
& $6-10$ & & 32.8 \\
& Over 10 & 19 & 20.7 \\
& & 12 & 44.8 \\
\hline
\end{tabular}

${ }^{\mathrm{a}}$ Total varies from $100 \%$ because of rounding.

\section{Cross Tabulations of Background Demographic Variables}

Cross tabulation analyses of the demographic variables were examined to better understand the interrelationships of the responses in relation to the demographic variables. Descriptive statistical procedures such as a chi-square distribution help researchers make generalizations about the population and the generalizability of findings to a wider population. This is done through study of the population subset, the sample (Hinkle, Wiersma, \& Jurs, 2003). In the current study, demographic variables and experiential variables were used.

Cross tabulations of combinations of the demographic variables of gender, ethnicity, and education in combination with variables indicating experience are presented in Table 6. The experiential variables are years worked in district, years at 
current school, and number of leadership courses taken, As Table 6 indicates, the results of the chi-square analyses showed no statistically significant differences in frequencies between the demographic variables and experiential variables, $\chi^{2} \mathrm{~s}=.79-5.13, d f \mathrm{~s}=2-6$, $p \mathrm{~s}>.05$.

\section{Testing the Hypotheses}

After preliminary analysis by examination of the zero-order intercorrelations among the variables, a series of multiple regressions were conducted. These were conducted to test the first two hypotheses. Partial correlations were computed to test the third hypothesis.

Hypothesis 1 stated: There is not a positive relationship between principals' leadership behaviors and school climate. Hypothesis 2 stated: There is not a positive relationship between principals' leadership behaviors and student achievement.

Hypothesis 3 stated: After controlling for gender, years at current school, and years in the district, there are not positive relationships among principals' leadership behaviors, school climate, and student achievement.

In the multiple regressions, the standardized beta coefficients $(\beta)$ determined the magnitude of the relationship between leadership behaviors and climate variables. In addition, $t$ tests were performed to predict whether the mean scores in reading and mathematics were significantly related to leadership behaviors (Tabachnick \& Fidell, 2007). 
Table 6

Cross Tabulations of Demographic Variables

Variable

Combination

$\chi^{2}$ Value

$d f$

$p$

Gender and Years

Worked in District

5.018

2

.081

Gender and Years at

3.786

2

.151

Current School

Gender and Number

1.785

3

.618

of Leadership

Courses Taken

Ethnicity and Years

4.943

6

.551

Worked in District

4.206

6

.649

at Current School

Ethnicity and

5.128

9

.823

Number of

Leadership Courses

Taken

Education and Years

.785

4

.940

Worked in District

Education and Years

4

.502

at Current School

Education and

.956

6

.987

Number of

Leadership Courses

Taken

${ }^{*} p<.05$. Assumption of significance (2-tailed). 


\section{Testing Hypothesis 1: Correlational Analysis}

Hypothesis 1 stated there would not be a positive relationship between leadership behaviors and school climate. Zero-order correlations among the seven school climate variables and the five leadership behaviors revealed a pattern of low-moderate statistically significant positive correlations. Challenging the Process leadership was positively related to Expectation climate $(r=.27, p<.05)$; Inspiring a Shared Vision leadership was positively linked to Order climate $(r=.27, p<.05)$. Enabling Others to Act leadership was positively associated with both $\operatorname{Order}(r=.30, p<.05)$ and Expectation climates $(r=.28, p<.05)$. Encouraging the Heart leadership was positively linked to both Leadership $(r=.27, p<.05)$ and Instruction climates $(r=.31, p<.05)$. Finally, Modeling the Way leadership was not significantly associated with any of the climate variables.

A series of seven multiple regressions were run where each of the seven respective climate variables were regressed on the set of five leadership behaviors, entered simultaneously in the regression equations. Thus, there were seven regression models. When predicting the Order, Instruction, and Collaboration climate variables (see Tables 7-9), none of the leadership variables served as significant predictors.

Further, although Encouraging the Heart leadership behavior was detected as a significant predictor of Environment climate (see Table 7), the overall regression model was not statistically significant $\left(R^{2}=.099, p=.223\right)$. On the other hand, Encouraging the Heart was a positive predictor of Leadership (instructional), Involvement, and Expectation climate. Modeling the Way was a moderate negative predictor of Leadership, Involvement, and Expectation climate. 
Overall, leadership behaviors predicted Leadership (instructional), Involvement, and Expectation climate in the regression models. This explained $R^{2}=.202, p=.03 ; R^{2}=$ $.177, p<.05$; and $R^{2}=.178, p<.05$, of the variances, respectively. Because the Encouraging the Heart leadership behavior variable was a statistically significant positive predictor of Leadership, Involvement, and Expectation climates, Hypothesis 1 was partially rejected.

Table 7

Multiple Regression Analyses Predicting Order, Leadership, and Environment Climate Variables

\begin{tabular}{|c|c|c|c|c|c|c|}
\hline \multirow{2}{*}{$\begin{array}{l}\text { Leadership } \\
\text { Variable }\end{array}$} & \multicolumn{2}{|c|}{${\underline{\text { Order }^{\mathrm{a}}}}$} & \multicolumn{2}{|c|}{$\underline{\text { Leadership }}^{\text {b }}$} & \multicolumn{2}{|c|}{$\underline{\text { Environment }}^{\mathrm{c}}$} \\
\hline & $\beta$ & $t$ & $\beta$ & $t$ & $\beta$ & $t$ \\
\hline Challenging & 0.12 & 0.51 & -0.17 & -0.88 & 0.06 & 0.25 \\
\hline Inspiring & 0.04 & 0.16 & -0.22 & -0.89 & -0.12 & -0.46 \\
\hline Enabling & 0.19 & 0.75 & 0.36 & 1.53 & -0.02 & -0.06 \\
\hline Modeling & -0.19 & -0.84 & -0.39 & $-1.86^{*}$ & -0.30 & -1.32 \\
\hline Encouraging & 0.14 & 0.68 & 0.61 & $3.12 * * *$ & 0.44 & $2.09 *$ \\
\hline
\end{tabular}

Note. $N_{\mathrm{s}}=49-51$ because of listwise deletion; ${ }^{\mathrm{a}} R^{2}=.093 ; F(5,46)=0.95, p=.23 .{ }^{\mathrm{b}} R^{2}=$ $.202 ; F(5,46)=2.33, p=.03 .{ }^{c} R^{2}=.099 ; F(5,44)=0.972, p=.223$.

$* p<.05 . * * p<.01 . * * * p<.001$. 
Table 8

Multiple Regression Analyses Predicting Instruction, Involvement, and Expectation Climate Variables

$\underline{\text { Instruction }} \quad \underline{\text { Involvement }} \quad \underline{\text { Expectation }}$

Leadership

Variable

$\beta$

$\begin{array}{lllll}t & \beta & t & \beta\end{array}$

Challenging

Inspiring

Enabling

Modeling

Encouraging

$\begin{array}{rcccrc}0.31 & 1.39 & -0.09 & 0.43 & 0.31 & 1.40 \\ -0.03 & -0.13 & -0.09 & -0.34 & -0.17 & -0.65 \\ 0.00 & -0.00 & 0.241 & 0.98 & 0.28 & 1.15 \\ -0.28 & -1.28 & -0.48 & -2.20 * & -0.45 & -2.11^{*} \\ 0.32 & 1.61 & 0.41 & 2.04 * & 0.32 & 1.99^{*}\end{array}$

Note. $N \mathrm{~s}=49-51$ because of listwise deletion; ${ }^{\mathrm{a}} R^{2}=.137 ; F(4,46)=1.46, p=.11 .{ }^{\mathrm{b}} R^{2}=$ $.177 ; F(5,45)=1.98, p<.05 .{ }^{\mathrm{c}} R^{2}=.178 ; F(5,45)=1.99, p<.05$.

${ }^{*} p<.05 . * * p<.01 . * * * p<.001$.

Table 9

Multiple Regression Analyses Predicting Collaboration Climate Variable

\section{Collaboration}

Leadership

Variable

$\beta$

$t$

Challenging

$0.05 \quad 0.20$

Inspiring

0.15

0.47

Enabling

0.13

0.50

Modeling

$-0.28$

$-1.21$

Encouraging

0.09

0.41

Note. $N \mathrm{~s}=49-51$ because of listwise deletion; $R^{2}=.064 ; F(5,46)=0.63, p=.68$. ${ }^{*} p<.05 . * * p<.01 .{ }^{* * *} p<.001$. 


\section{Testing Hypothesis 2: Correlational Analysis}

Hypothesis 2 stated there would not be a positive relationship between principals' leadership behaviors (Challenging the Process, Inspiring a Shared Vision, Enabling Others to Act, Modeling the Way, Encouraging the Heart; Louzes \& Posner, 2007) and student achievement (FCAT Reading and Mathematics scores). Similar to the statistical procedures for Hypothesis 1, zero-order correlations were examined among the variables as the first step. The results indicated that none of the five leadership behaviors demonstrated a statistically significant relationship with the four student achievement variables (percentage passing reading, percentage passing mathematics, mean reading gain, mean mathematics gain).

Hypothesis 2 was tested subsequently using a series of multiple regressions to predict relationships among the five leadership behaviors and students' FCAT reading and mathematics scores and percentage passing for the 2009-2010 school year (Florida Office of Economic and Demographic Research [FOEDR], 2010; see Tables 10-13). The regression analyses revealed no significant relationships among the five leadership behaviors and the four dependent variables. These were conducted in the four separate regression models (i.e., percentage of students passing in reading, percentage of students passing mathematics, the mean scores for passing in reading, and the mean scores for passing in mathematics). Thus, the results of these statistical analyses supported Hypothesis 2. 
Table 10

Multiple Regression Analyses With Leadership Behaviors Predicting Percentage Passing in Reading ${ }^{a}$

Percentage Passing Reading

Leadership

Variable

$\beta \quad t$

Challenging

Inspiring

Enabling

.534

.181

.652

Modeling

.34

.507

Encouraging

$-.337$

$-1.449$

.110

.509

\section{Table 11}

Multiple Regression Analyses With Leadership Behaviors Predicting Percentage Passing in Mathematics ${ }^{\mathrm{a}}$

Percentage Passing Mathematics

Leadership

Variable

$\beta \quad t$

Challenging

Inspiring

Enabling

$-.393$

$-1.648$

Modeling

.115

.413

.184

.693

Encouraging

$-.088$

$-.378$

.109

.505

${ }^{\mathrm{a}}$ For both tables, $N=51$ because of listwise deletion; $R^{2}=.089 ; F(5,42)=0.93, p>.05$. 
Table 12

Multiple Regression Analyses With Leadership Behaviors Predicting Mean Passing in Reading ${ }^{\mathrm{a}}$

Mean Passing in Reading

Leadership

Variable

$\beta \quad t$

Challenging

Inspiring

Enabling

.227

.952

.168

.601

Modeling

.035

.132

Encouraging

$-.313$

$-.1 .342$

.045

$-.211$

\section{Table 13}

Multiple Regression Analyses With Leadership Behaviors Predicting Mean Passing in Mathematics

$\underline{\text { Mean Passing in Mathematics }}$

Leadership

Variable

$\beta \quad t$

Challenging

Inspiring

.319

1.311

Enabling

$-.026$

$-.093$

Modeling

$-.022$

$-.080$

Encouraging

$-.180$

$-.756$

$-.097$

$-.439$

${ }^{\mathrm{a}}$ For both tables, $N=51$ because of listwise deletion; $R^{2}=.063 ; F(5,42)=0.70, p>.05$. 


\section{Testing Hypothesis 3: Group Differences}

Hypothesis 3 stated that, after controlling for gender, years at current school, and years in the district, there would not be positive relationships among principals' leadership behaviors, school climate, and student achievement. First, the data were examined for evidence of possible group differences among the research variables. This step was taken for the purpose of finding empirical support for using demographic variables as statistical controls in the partial correlation analyses. Thus, a series of oneway ANOVAs with Bonferroni and Scheffé post hoc analysis were run. An ANOVA can determine whether the set of group mean differences in the research variables are statistically significant (Holcomb, 2006).

Years as principal in current school was the sole demographic variable that demonstrated a significant mean difference in percentage passed in reading $F(2,45)=$ $3.184, p=.025$ and mathematics $F(2,45)=3.391, p=.02($ see Tables 14 and 15$)$. Both Bonferroni and Scheffé post hoc analysis $(p \mathrm{~s}<.01)$ revealed schools with the most experienced principals (11-15 years) had greater percentages of students passing the reading and mathematics portions of the FCAT than those with principals with 10 years or less experience at the current school.

Years worked in school district was the only demographic variable demonstrating a significant group difference in mean gain in reading $F(2,45)=2.722, p=.038$ and in mathematics $F(2,45)=3.538, p=.018$ (see Tables 16 and 17). Both Bonferroni and Scheffé post hoc analysis $(p \mathrm{~s}<.01)$ revealed that schools with principals who had 11-15 years in the school district had greater reading and mathematics gains on the FCAT than 
those with principals who had 21 or more years at the current school in the school district.

Table 14

Demographic Group Mean Differences: Student Percentage Passed in Reading

\begin{tabular}{lcccc}
\hline Characteristic & $F$ & $d f$ & $p$ & $\eta^{2}$ \\
\hline Gender & .001 & 1,46 & .489 & .000 \\
Age & 1.286 & 3,44 & .146 & .081 \\
Ethnicity & 1.196 & 3,44 & .161 & .075 \\
$\begin{array}{l}\text { Education } \\
\text { Years in the }\end{array}$ & .966 & 2,45 & .195 & .041 \\
$\begin{array}{l}\text { District } \\
\text { Number of } \\
\text { Years as } \\
\text { Principal }\end{array}$ & .128 & 2,45 & .440 & .037 \\
$\begin{array}{l}\text { Years in } \\
\text { Current School }\end{array}$ & .560 & 3,44 & .322 & .124 \\
$\begin{array}{l}\text { Number of } \\
\text { Education } \\
\text { Courses }\end{array}$ & .198 & & .025 & \\
\hline & & & & \\
\end{tabular}


Table 15

Demographic Group Mean Differences: Student Percentage Passed in Mathematics

\begin{tabular}{lcccc}
\hline Characteristic & $F$ & $d f$ & $p$ & $\eta^{2}$ \\
\hline Gender & .274 & 1,46 & .302 & .006 \\
Age & 1.456 & 3,44 & .120 & .090 \\
Ethnicity & 2.291 & 3,44 & .059 & .124 \\
Education & 2.291 & 2,45 & .056 & .092 \\
$\begin{array}{l}\text { Years in the } \\
\text { District }\end{array}$ & 1.043 & 2,45 & .181 & .001 \\
$\begin{array}{l}\text { Number of } \\
\text { Years as } \\
\text { Principal }\end{array}$ & .010 & 3,44 & .500 & \\
$\begin{array}{l}\text { Years in Current } \\
\text { School }\end{array}$ & 3.391 & & & .024 \\
$\begin{array}{l}\text { Number of } \\
\text { Education } \\
\text { Courses }\end{array}$ & .367 & 2,45 & .389 & \\
\hline & & 3,44 & & \\
\hline
\end{tabular}


Table 16

Demographic Group Mean Differences: Student Mean Gains in Reading

\begin{tabular}{lcccc}
\hline Characteristic & $F$ & $d f$ & $p$ & $\eta^{2}$ \\
\hline Gender & .060 & 1,46 & .404 & .001 \\
Age & 1.321 & 3,44 & .139 & .068 \\
Ethnicity & 1.317 & 3,44 & .139 & .068 \\
$\begin{array}{l}\text { Education } \\
\text { Years in the } \\
\text { District }\end{array}$ & 1.239 & 2,45 & .149 & .043 \\
$\begin{array}{l}\text { Number of } \\
\text { Years as } \\
\text { Principal }\end{array}$ & 2.722 & 2,45 & .038 & .069 \\
$\begin{array}{l}\text { Years in } \\
\text { Current School }\end{array}$ & 1.340 & 3,44 & .136 & \\
$\begin{array}{l}\text { Number of } \\
\text { Education } \\
\text { Courses }\end{array}$ & .348 & 2,45 & .385 & .009 \\
\hline & & & & \\
\hline
\end{tabular}


Table 17

Demographic Group Mean Differences: Student Mean Gains in Mathematics

\begin{tabular}{lcccc}
\hline Characteristic & $F$ & $d f$ & $p$ & $\eta^{2}$ \\
\hline Gender & .010 & 1,46 & .460 & .000 \\
Age & .989 & 3.44 & .204 & .063 \\
Ethnicity & 1.208 & 3,44 & .159 & .076 \\
Education & 2.291 & 2,45 & .056 & .092 \\
$\begin{array}{l}\text { Years in the } \\
\text { District }\end{array}$ & 3.538 & 2,45 & .018 & .029 \\
$\begin{array}{l}\text { Number of } \\
\text { Years as } \\
\text { Principal }\end{array}$ & .431 & 3,44 & .366 & \\
$\begin{array}{l}\text { Years in } \\
\text { Current School }\end{array}$ & .540 & & & .023 \\
$\begin{array}{l}\text { Number of } \\
\text { Education } \\
\text { Courses }\end{array}$ & .678 & 2,45 & .294 & \\
\hline
\end{tabular}


Demographic group differences were also examined for each of the five leadership behaviors (see Tables 18-25) and seven climate variables (see Tables 26-33). First, statistically significant group differences were not found by demographic variable for any of the leadership behaviors. These were gender and five leadership behaviors $F$ s $(1,56)=.001-.569, p \mathrm{~s}>.05$; age and five leadership behaviors $F \mathrm{~s}(3,54)=.086-1.639$, $p \mathrm{~s}>.05$; ethnicity and five leadership behaviors $F_{\mathrm{s}}(3,54)=.317-.652, p \mathrm{~s}>.05$; education and five leadership behaviors $F \mathrm{~s}(2,55)=.052-1.201, p \mathrm{~s}>.05$; years in district and five leadership behaviors $F_{\mathrm{s}}(2,55)=.174-1.311, p \mathrm{~s}>.05$; years as principal and five leadership behaviors $F \mathrm{~s}(3,54)=.095-.262, p \mathrm{~s}>.05$; years in current school and five leadership behaviors $F_{\mathrm{s}}(3,54)=.386-1.157, p \mathrm{~s}>.05$; and, number of education courses and five leadership behaviors $F_{\mathrm{s}}(3,54)=.345-.597, p \mathrm{~s}>.05$. Thus, no statistically significant demographic group differences were indicated by leadership behavior variable.

Second, marginally significant demographic group differences were found on several of the climate variables: age and Expectation climate $F(3,54)=1.199, p=.064$; education and involvement climate $F(2,55)=2.041, p=.070$; and, number of leadership courses and Involvement climate $F(2,55)=2.041, p=.070$. Bonferroni and Scheffé post hoc analyses revealed that the 31-40 age group had higher Expectation means than the 61 and over age group. The master's degree group had greater group scores in Involvement climate than both the group with doctoral degrees and other (specialists). The group taking 6-10 courses had significantly lower Involvement climate scores than the other three groups. 
There was no evidence of significant differences for three variables. These were gender $F_{\mathrm{s}}(1,56)=.001-.634, p \mathrm{~s}>.05$; years as principal $F_{\mathrm{s}}(3,54)=.153-1.288, p \mathrm{~s}>$ .05 ; and number of leadership courses $F \mathrm{~s}(2,55)=.054-.781, p \mathrm{~s}>.05$. In sum, the statistically significant results were marginal and thus tentative.

Overall, because of demographic group differences in the student achievement variables, years as principal in current school and years worked in district were included as control variables in the partial correlation analyses. In addition, gender was retained because of its theoretical and empirical importance. Thus, there were three statistical controls: these were gender, years as principal in current school, and years worked in district.

Table 18

Demographic Group Mean Differences: Leadership and Gender

\begin{tabular}{lcccc}
$\begin{array}{l}\text { Leadership Behavior } \\
\text { Variables }\end{array}$ & $F$ & $d f$ & $p$ & $\eta^{2}$ \\
\hline Challenging the Process & .569 & 1,56 & .227 & .010 \\
Inspiring a Shared Vision & .126 & 1,56 & .362 & .002 \\
Enabling Others to Act & .081 & 1,56 & .389 & .001 \\
Modeling the Way & .001 & 1,56 & .488 & .000 \\
Encouraging the Heart & .446 & 1,56 & .254 & .008 \\
\hline
\end{tabular}


Table 19

Demographic Group Mean Differences: Leadership and Age

Leadership Behavior

Variables

$F \quad d f \quad p \quad \eta^{2}$

\begin{tabular}{lcccc}
\hline Challenging the Process & 1.096 & 3,54 & .180 & .057 \\
Inspiring a Shared Vision & .283 & 3,54 & .419 & .015 \\
Enabling Others to Act & .086 & 3,54 & .484 & .005 \\
Modeling the Way & 1.639 & 3,54 & .377 & .022 \\
Encouraging the Heart & .654 & 3,54 & .292 & .035 \\
\hline
\end{tabular}

Table 20

Demographic Group Mean Differences: Leadership and Ethnicity

\begin{tabular}{lcccc}
$\begin{array}{l}\text { Leadership Behavior } \\
\text { Variables }\end{array}$ & $F$ & $d f$ & $p$ & $\eta^{2}$ \\
\hline Challenging the Process & .652 & 3,54 & .293 & .035 \\
Inspiring a Shared Vision & .564 & 3,54 & .321 & .030 \\
Enabling Others to Act & .317 & 3,54 & .407 & .017 \\
Modeling the Way & .401 & 3,54 & .377 & .022 \\
Encouraging the Heart & .331 & 3,54 & .402 & .018 \\
\hline
\end{tabular}


Table 21

Demographic Group Mean Differences: Leadership and Education

\begin{tabular}{lcccc}
\hline $\begin{array}{l}\text { Leadership Behavior } \\
\text { Variables }\end{array}$ & $F$ & $d f$ & $p$ & $\eta^{2}$ \\
\hline Challenging the Process & 1.191 & 2,55 & .156 & .042 \\
Inspiring a Shared Vision & .469 & 2,55 & .314 & .017 \\
Enabling Others to Act & .860 & 2,55 & .215 & .030 \\
Modeling the Way & 1.201 & 2,55 & .155 & .042 \\
Encouraging the Heart & .052 & 2,55 & .475 & .002 \\
\hline
\end{tabular}

Table 22

Demographic Group Mean Differences: Leadership and Years in District

\begin{tabular}{lcccc}
\hline $\begin{array}{l}\text { Leadership Behavior } \\
\text { Variables }\end{array}$ & $F$ & $d f$ & $p$ & $\eta^{2}$ \\
\hline Challenging the Process & .174 & 2,55 & .421 & .006 \\
Inspiring a Shared Vision & 1.311 & 2,55 & .139 & .046 \\
Enabling Others to Act & .349 & 2,55 & .354 & .013 \\
Modeling the Way & .784 & 2,55 & .231 & .028 \\
Encouraging the Heart & .200 & 2,55 & .410 & .007 \\
\hline
\end{tabular}


Table 23

Demographic Group Mean Differences: Leadership and Years as Principal

Leadership Behavior

Variables

$F \quad d f \quad p \quad \eta^{2}$

Challenging the Process

.190

3,54

.452

.010

Inspiring a Shared Vision

.095

3,54

.481

.005

Enabling Others to Act

.208

3,54

.445

.011

Modeling the Way

.262

3,54

.426

.014

Encouraging the Heart

.107

3,54

.478

.006

Table 24

Demographic Group Mean Differences: Leadership and Years in Current School

Leadership Behavior

Variables

F $\quad d f$

$p$

$\eta^{2}$

Challenging the Process

.610

3,54

.274

.022

Inspiring a Shared Vision

.518

3,54

.300

.018

Enabling Others to Act

1.157

3,54

.161

.040

Modeling the Way

.386

3,54

.341

.014

Encouraging the Heart

1.125

3,54

.166

.039 
Table 25

Demographic Group Mean Differences: Leadership and Number of Leadership Courses

Leadership Behavior

Variables

$F \quad d f \quad \eta^{2}$

\begin{tabular}{lllll}
\hline Challenging the Process & .500 & 3,54 & .342 & .027 \\
Inspiring a Shared Vision & .345 & 3,54 & .387 & .019 \\
Enabling Others to Act & .508 & 3,54 & .339 & .027 \\
Modeling the Way & .597 & 3,54 & .310 & .032 \\
Encouraging the Heart & .376 & 3,54 & .386 & .020 \\
\hline
\end{tabular}

Table 26

Demographic Group Mean Differences: Climate and Gender

\begin{tabular}{lcccc}
\hline $\begin{array}{l}\text { School Climate } \\
\text { Variables }\end{array}$ & $F$ & $d f$ & $p$ & $\eta^{2}$ \\
\hline Order & .060 & 1,56 & .404 & .001 \\
Leadership & .001 & 1,56 & .491 & .000 \\
Environment & .004 & 1,56 & .475 & .000 \\
Involvement & .071 & 1,56 & .396 & .001 \\
Instruction & .492 & 1,56 & .243 & .009 \\
Expectation & .000 & 1,56 & .499 & .000 \\
Collaboration & .634 & 1,56 & .215 & .011 \\
\hline
\end{tabular}


Table 27

Demographic Group Mean Differences: Climate and Age

School Climate

Variables

F

$d f$

$\quad \eta^{2}$

\begin{tabular}{lcccc}
\hline Order & .713 & 3.54 & .274 & .038 \\
Leadership & 1.057 & 3,54 & .188 & .055 \\
Environment & .605 & 3,54 & .308 & .032 \\
Involvement & .302 & 3,54 & .412 & .017 \\
Instruction & .120 & 3,54 & .474 & .007 \\
Expectation & 1.199 & 3,54 & .064 & .099 \\
Collaboration & 1.148 & 3,54 & .169 & .060 \\
& & & & \\
\hline
\end{tabular}

Table 28

Demographic Group Mean Differences: Climate and Ethnicity

School Climate

Variables

F

$d f$

$p \quad \eta^{2}$

Order

1.407

3.54

.126

.073

Leadership

1.625

3,54

.097

.083

Environment

.962

3,54

.209

.051

Involvement

.061

3,54

.490

.003

Instruction

.481

3,54

.349

.026

Expectation

.446

3,54

.311

.208

Collaboration

.1420

3,54

.124

.073 
Table 29

Demographic Group Mean Differences: Climate and Education

School Climate

Variables

F

$d f$

$\quad \eta^{2}$

\begin{tabular}{lcccc}
\hline & & & & \\
Order & .133 & 2,55 & .438 & .005 \\
Leadership & .453 & 2,55 & .319 & .016 \\
Environment & .382 & 2,55 & .342 & .014 \\
Involvement & 2.041 & 2,55 & .070 & .069 \\
Instruction & .010 & 2,55 & .495 & .000 \\
Expectation & .262 & 2,55 & .386 & .009 \\
Collaboration & .154 & 2,55 & .429 & .006 \\
& & & & \\
\hline
\end{tabular}

Table 30

Demographic Group Mean Differences: Climate and Years in District

School Climate

Variables

$F$

$d f$

$\quad \eta^{2}$

\begin{tabular}{lcccc}
\hline & & & & \\
Order & .583 & 2,55 & .281 & .021 \\
Leadership & .842 & 2,55 & .218 & .017 \\
Environment & .159 & 2,55 & .427 & .011 \\
Involvement & .237 & 2,55 & .395 & .015 \\
Instruction & .453 & 2,55 & .319 & .019 \\
Expectation & .321 & 2,55 & .364 & .025 \\
Collaboration & .935 & 2,55 & .196 & .012 \\
& & & & \\
\hline
\end{tabular}


Table 31

Demographic Group Mean Differences: Climate and Years as Principal

\begin{tabular}{|c|c|c|c|c|}
\hline $\begin{array}{l}\text { School Climate } \\
\text { Variables }\end{array}$ & $F$ & $d f$ & $p$ & $\eta^{2}$ \\
\hline Order & .952 & 3,54 & .211 & .050 \\
\hline Leadership & .493 & 3,54 & .344 & .027 \\
\hline Environment & .321 & 3,54 & .405 & .018 \\
\hline Involvement & 1.288 & 3,54 & .288 & .067 \\
\hline Instruction & .153 & 3,54 & .464 & .008 \\
\hline Expectation & .374 & 3,54 & .386 & .020 \\
\hline Collaboration & .726 & 3,54 & .271 & .039 \\
\hline \multicolumn{5}{|l|}{ Table 32} \\
\hline \multicolumn{5}{|c|}{ Demographic Group Mean Differences: Climate and Years at Current School } \\
\hline $\begin{array}{l}\text { School Climate } \\
\text { Variables }\end{array}$ & $F$ & $d f$ & $p$ & $\eta^{2}$ \\
\hline Order & .348 & 2,55 & .354 & .013 \\
\hline Leadership & .057 & 2,55 & .947 & .002 \\
\hline Environment & .222 & 2,55 & .401 & .010 \\
\hline Involvement & .781 & 2,55 & .232 & .007 \\
\hline Instruction & .613 & 2,55 & .072 & .022 \\
\hline Expectation & .420 & 2,55 & .330 & .014 \\
\hline Collaboration & .054 & 2,55 & .474 & .015 \\
\hline
\end{tabular}


Table 33

Demographic Group Mean Differences: Climate and Number of Leadership Courses

\begin{tabular}{lcccc}
\hline $\begin{array}{l}\text { School Climate } \\
\text { Variables }\end{array}$ & $F$ & $d f$ & $p$ & $\eta^{2}$ \\
\hline Order & 1.384 & 3,54 & .129 & .071 \\
Leadership & .251 & 3,54 & .430 & .014 \\
Environment & 1.333 & 3,54 &, 137 & .069 \\
Involvement & 2.115 & 3,54 & .055 & .105 \\
Instruction & .871 & 3,54 & .231 & .046 \\
Expectation & 1.266 & 3,54 & .148 & .066 \\
Collaboration & 1.332 & 3,54 & .137 & .069 \\
\hline
\end{tabular}

\section{Testing Hypothesis 3: Among Leadership Behaviors, Climate, and Achievement}

Hypothesis 3 stated that, after controlling for gender, years at current school, and years in the district, there would not be positive relationships among principals' leadership behaviors, school climate, and student achievement. A number of positive, statistically significant relationships were found among the climate and leadership variables: Order climate and Inspiring a Shared Vision leadership (partial $r=.264, p<$ .05 ) and Enabling Others to Act leadership (partial $r=.297, p<.05$ ); Leadership climate and Encouraging the Heart leadership (partial $r=.269, p<.05$ ); Instruction climate and Challenging the Process leadership (partial $r=.299, p<.05$ ) and Encouraging the Heart leadership (partial $r=.302, p<.05$ ); and finally, Expectation climate and Challenging the Process (partial $r=.27, p<.05$ ) and Enabling Others to Act (partial $r=.27, p<.05$ ). 
Thus, in partial rejection of Hypothesis 3, some leadership behavior and climate variables were positively linked.

As for the association among leadership behaviors and the four achievement dependent variables, Modeling the Way leadership was negatively associated with percentage passing reading (partial $r=-.35, p<.05$ ) and percentage passing mathematics (partial $r=-.28, p<.05$ ). Inspiring Shared Vision (partial $r=.31, p<.05$ ) and Enabling Others to Act (partial $r=.30, p<.05$ ) leadership behaviors were positively associated with mean gain in reading. None of the other leadership behaviors demonstrated a significant relationship with the achievement dependent variables.

The climate variables demonstrated significant relationships with the dependent variables as well. The climate variable of Order was significantly related to percentage passing reading (partial $r=.27, p<.05$ ), percentage passing mathematics (partial $r=.31$, $p<.05$ ), mean gain reading (partial $r=.33, p<.05$ ) and mean gain mathematics (partial $r$ $=.27, p<.05)$. Further, the Involvement climate variable was significantly related to mean gain reading (partial $r=.30, p<.05$ ) and mean gain mathematics (partial $r=.27$, $p<.05)$. Finally, the Expectation climate variable was significantly related to mean gain reading (partial $r=.34, p<.05$ ) and mean gain mathematics (partial $r=.30, p<.05$ ). None of the other climate variables demonstrated a significant relationship with the achievement dependent variables.

Inasmuch as the Inspiring a Shared Vision and Enabling Others to Act leadership behaviors were positively linked to mean gain in reading, there was partial rejection of Hypothesis 3. Further rejection of this hypothesis, albeit partial, was also demonstrated 
through positive relationships among the climate variables of Order, Involvement, and Expectation and the dependent variables for achievement (see Table 34).

Table 34

Partial Correlation Analysis of Relationships Among Leadership Behavior, Climate, and Student Achievement ${ }^{a}$

\begin{tabular}{|c|c|c|c|c|}
\hline $\begin{array}{l}\text { Leadership Behavior and School } \\
\text { Climate Variables }\end{array}$ & $\begin{array}{l}\% \text { Passing } \\
\text { Reading }\end{array}$ & $\begin{array}{l}\% \text { Passing } \\
\text { Math }\end{array}$ & $\begin{array}{l}\text { Mean Gain } \\
\text { Reading }\end{array}$ & $\begin{array}{l}\text { Mean Gain } \\
\text { Math }\end{array}$ \\
\hline Challenging process & -.16 & -.23 & .10 & .03 \\
\hline Inspiring vision & .01 & -.11 & $.31 *$ & .10 \\
\hline Enabling to act & .10 & -.03 & $.30 *$ & .15 \\
\hline Modeling the way & $-.35 *$ & $-.28 *$ & -.08 & -.05 \\
\hline Encouraging heart & -.14 & -.09 & -.08 & -.05 \\
\hline Order & $.27 *$ & $.31 *$ & $.33^{*}$ & $.27 *$ \\
\hline Leadership & .00 & .07 & -.07 & -.16 \\
\hline Environment & -.08 & -.11 & .00 & -.02 \\
\hline Involvement & .03 & -.06 & $.30 *$ & $.27 *$ \\
\hline Instruction & -.09 & -.13 & .02 & .02 \\
\hline Expectation & .02 & -.11 & $.34^{*}$ & $.30 *$ \\
\hline Collaboration & -.13 & -.07 & .01 & -.13 \\
\hline
\end{tabular}

${ }^{a} N \mathrm{~s}=49-51$ because of listwise deletion.

$* p<.05$. 


\section{Summary}

Results of this study partially supported and partially rejected two of the three hypotheses (one and three) proposed in this study. Rejecting the first hypothesis, the multiple regression results revealed that Encouraging the Heart leadership behavior was positively linked to Leadership (instructional), Involvement, and Expectation climate. However, Modeling the Way was negatively linked to Leadership, Involvement, and Expectation climate variables. The second hypothesis was supported in that leadership behavior did not make unique contributions to predicting percentage passing reading, percentage passing mathematics, mean reading gain, and mean mathematics gain. Finally, testing the third hypothesis via a series of partial correlation analyses in which gender, years at current school as principal, and years worked in the district, were used as statistical controls, the third hypothesis was partially rejected. This was demonstrated by positive relationships among some leadership behaviors and climate variables and at least one of the achievement dependent variables (percentage passing reading, percentage passing mathematics, mean reading gain, or mean mathematics gain).

In Chapter $\mathrm{V}$, the results and implications for theory, research, practice, and policy are discussed. In addition, limitations of the study are described. Finally, recommendations are made for further research. 


\section{CHAPTER V}

\section{DISCUSSION}

This chapter provides a brief summary of the study, including an overview of the problem and purpose statement. The results are presented next in terms of the major findings for the three hypotheses and relationships to the literature. Finally, implications for theory, research, practice, and policy are presented, followed by limitations of the study, recommendations for future research, and concluding observations.

\section{Summary of the Study}

\section{Overview of the Problem}

One of the great challenges facing American public schools is the improvement of urban education (Harvey \& Housman, 2004; Pingle \& Cox, 2007). The Nation's Report Card, a national measure of the effectiveness of reform efforts, showed that in 2005 the reading and mathematics scores of over 21,000 high school seniors from 900 schools across the country were lower than scores in 1992 (National Center for Education Statistics, 2007). To address the need for better student achievement and to ensure America's competitive edge in the future, significant secondary school reform is needed. These reform efforts should focus on what educators must do so that secondary schools graduate young people with the skills, habits, and convictions that are required in the rapidly changing American culture and the global workplace (Miami-Dade County Public Schools, 2005).

The No Child Left Behind Act (NCLB) of 2001 has increased pressures for school improvement and student achievement. Accountability pressures and ambitious educational goals have placed districts and schools in the position of requiring rapid 
change to meet the new demands of secondary school reform. Principals are at the center of this process, and their leadership is key to the successful implementation of change (Kelley et al., 2005).

\section{Purpose Statement}

The purpose of this nonexperimental ex post facto study was to test the relationships among secondary school principals' leadership behaviors, school climate, and student achievement. The three hypotheses tested were as follows:

1. There is not a positive relationship between principals' leadership behaviors and school climate.

2. There is not a positive relationship between principals' leadership behaviors and student achievement.

3. After controlling for gender, years at current school, and years in the district, there are not positive relationships among principals' leadership behaviors, school climate, and student achievement.

\section{Review of Methodology}

A nonexperimental ex post facto design was used to test the three hypotheses. Participants were administered the researcher-designed Demographic Questionnaire, Leadership Practice Inventory (LPI), and School Climate Inventory (SCI) by email. Data were collected by the researcher on the 2009-2010 reading and mathematics subtests for 8th- and 10th-grade students of the Florida Comprehensive Achievement Test (FCAT). The three hypotheses were examined using correlational and regression analyses to test the relationships among the variables. Zero-order correlation analyses were conducted to preliminarily examine the strength and direction of relationships among the research 
variables. Multiple regressions were employed to determine the degree to which the independent variables predicted the dependent variables in Hypotheses 1 and 2.

To test Hypothesis 3, a series of one-way ANOVAs were run to test for possible group differences between the demographic and research variables to support their use as statistical controls in the partial correlation analyses. Partial correlation analyses were used subsequently to determine the strength and direction of the relationships among the leadership, climate, and student achievement variables.

When group means between the descriptive variables of the Demographic Questionnaire and the LPI and SCI-R were tested through the ANOVAs, it was found that schools with the most experienced principals (11 to 15 years at current school) had a greater percentage of students passing reading and mathematics. Similarly, schools with principals with 11 to 15 years in their district had greater reading and mathematics gains.

The partial correlational analyses revealed positive associations among some of the leadership, climate, and student achievement variables. Encouraging the Heart leadership was positively related to Instruction and Leadership climate. Enabling Others to Act was positively related to Expectation and Order climates, while Challenging the Process was positively related to Expectation and Instruction climates. Last, Inspiring a Shared Vision was positively associated with Order climate.

After an examination of the links among leadership behaviors and the four dependent achievement variables through the partial correlation analyses, Inspiring a Shared Vision and Enabling Others to Act were found to be positively linked to mean gain in reading. In contrast, Modeling the Way leadership was found to be negatively associated with percentage passing reading and percentage passing mathematics. As for 
the association among climate and the four achievement dependent variables, a positive relationship was found between Order and percentage passing reading and mathematics. A positive relationship was also found between the Order and mean gains in reading and mathematics. Finally, Involvement showed a statistically significant positive link with mean gains in reading and mathematics.

\section{Discussion of the Results and Relationship to Previous Literature}

The overall purpose of this study was to determine if leadership behaviors in the study population were not positively associated with school climate and student achievement. Specifically, this study examined if the exemplary leadership behavior scores of the LPI (Kouzes \& Posner, 2007) were related to school climate scores, measured by the SCI (CREP, 2002) and student achievement in reading and mathematics, measured by the 2009-2010 FCAT scores of 8th- and 10th-grade students. In this section, the three hypotheses are examined and discussed in relation to the findings of previous studies.

\section{Hypothesis 1}

Hypothesis 1 stated there would not be a positive relationship between leadership behaviors and school climate. Results from the multiple regression analyses indicated that Encouraging the Heart was a positive predictor of the climate subscale of Leadership (Instructional, Involvement, and Expectation (see Table 7). However, no significant relationships were found among the leadership variables of Challenging the Process, Inspiring a Shared Vision, Enabling Others to Act, or Modeling the Way and the school climate subscales of Order, Instruction, and Collaboration. Conversely, Modeling the Way showed a strong negative correlation to the climate subscale of Leadership 
(Instructional), Involvement, and Expectation (see Table 8). The next sections discuss the results of the predictor variables and their relationships to the school climate subscales.

Encouraging the Heart and school climate. Findings from this study are congruent with the theory of Transformational Leadership by Burns (1978). In his groundbreaking book, Leadership, Burns defined a transformational leader as one who looks for potential motives in followers, seeks to satisfy higher needs, and engages the full potential of followers. Encouraging the Heart as a characteristic of transformational leadership involves recognizing individual contributions to every project's success and regularly celebrating team accomplishments. When leaders commend individuals for achieving the values and goals of the organization, they give them courage, inspiring them to experience their own ability to deliver positive change even during tough times (Kouzes \& Posner, 2007).

The four assumptions of the theory of Ecological Grounding (Sheridan \& Gutkin, 2000) are also consistent with the findings of this research. In Ecological Grounding, students are addressed and seen within the contexts of classrooms, schools, and communities. Four assumptions are made: (a) each student is "an inseparable part of a small social system"; (b) disturbance is viewed as discordance ("lack of balance") in the system rather than the individual student; (c) discordance is seen as a disparity between the student's abilities and the environmental demands or expectations; and, (d) "the goal of any intervention is to make the system work" (Sheridan \& Gutkin, p. 489). Ecological grounding was the second theory that guided this research.

As the findings of this study indicate, some principals' leadership variables were positively associated with school climate. This finding is consistent with McGuigan and 
Hoy (2006) who theorized that principals' positive leadership behaviors can improve school climate, specifically through the concept of academic optimism. The researchers found that in urban context, an orderly school environment with high expectations and involvement of the community produced a positive force for learning.

Modeling the Way and school climate variable of Leadership. Kouzes and Posner (2007) defined Modeling the Way as the manner in which the leader sets the example of exemplary leadership and true caring. The leader demonstrates Modeling the Way through behavior consistent with shared values. The leader also publicizes followers' small victories that promote consistent progress and build others' commitment. Modeling the Way was built upon Schein's (1997) strategies for leaders engaging in cultural changes. Schein stated leaders must constantly endeavor to model desired behavior through their actions. Deal and Kennedy (1982) viewed leaders as the "heroes" of the organization by their modeling a commitment to visionary goals and exemplary actions.

The negative relationship found in the present study between Modeling the Way and the school climate subscale of Leadership (Instructional) may be partially explained by principals' misunderstanding of Modeling the Way to mean that they modeled instructional strategies in the classroom. This negative relationship is in contrast to the findings of Kiper (2007). Kiper studied the correlation between transformational leadership behaviors of school leaders and student state-mandated proficiency scores in reading and mathematics in seven suburban Minnesota schools. Teachers used the LPI to rate their principals in the five exemplary leadership practices of Kouzes and Posner (2007). 
The results of Kiper's (2007) study showed that all five leadership practices of the LPI were positively correlated to mathematics scores on the Minnesota Comprehensive Assessment (MCA). In contrast to the present findings, Modeling the Way was of positive statistical significance. The findings of Kiper's (2007) study partially support the hypothesis that leadership behaviors are predictors of school climate variables, such as instructional leadership, although Kiper's (2007) results indicated positive correlations while the present study indicated negative correlation.

\section{Hypothesis 2}

Hypothesis 2 stated that there would not be a positive relationship between leadership behaviors and student achievement. Results from the zero-order correlations indicated that none of the five leadership behaviors had a statistically significant relationship to the four student achievement variables. Later, a series of multiple regressions were run to predict relationships among the five leadership behaviors and the percentage passing the FCAT reading and mathematics. The multiple regression analyses showed no significant relationships between the leadership behaviors and the four dependent achievement variables (see Tables 10-13).

Researchers in education have long recognized that educational leaders, especially school principals, influence school effectiveness (Levin \& Lezotte, 1990; Pashiardis, 2004; Reynolds \& Cuttance, 1992). Surprisingly, the multiple regression findings of the present study, which did not include statistical controls, did not agree with these earlier studies. However, findings of other studies were mixed concerning the effects of leadership on student achievement. Some found no influence and others identified some effects (Heck, 1992; Johnson, 1993; Witziers, Bosker, \& Kruger, 2003). These initial 
findings with regard to Hypothesis 2 were interesting and strongly indicate the need for further research.

\section{Hypothesis 3}

Hypothesis 3 stated that, after controlling for gender, years at current school, and years in the district, there would not be positive relationships among principals' leadership behaviors, school climate, and student achievement. Results from the partial correlation analyses indicated the leadership variables of Inspiring a Shared Vision, Enabling Others to Act, and Challenging the Process were associated with the climate variables of Order, Leadership (Instructional), and Expectation (see Tables 7-9). The next section discusses the results of relationships among the predictor variables, school climate, and student achievement.

Leadership and school climate. Positive partial correlations were found between the leadership variables of Inspiring a Shared Vision, Enabling Others to Act, Encouraging the Heart, and Challenging the Process and the climate variables of Order, Leadership (Instructional), Instruction, and Expectation (see Tables 7-8). These findings were consistent with previous research. Sugai et al. (2000) found that when school principals are explicit about behavioral expectations, provide support to help students meet expectations, monitor individual and school-wide behavior, and provide frequent positive reinforcement, student discipline can be reduced and instructional time recovered.

Leadership and student achievement. Inspiring a Shared Vision and Enabling Others to Act leadership variables both had a positive relationship with mean gain in reading. Inspiring a Shared Vision involves envisioning an uplifting and ennobling future 
and enlisting others in a common vision through appeal to their values, interest, hopes, and dreams. On the other hand, Enabling Others to Act involves fostering collaboration by promoting cooperative goals and building trust, as well as strengthening other by surrendering power, providing choices, developing competence, assigning crucial tasks, and offering visible support (Kouzes \& Posner, 2007). However, Modeling the Way, setting the example by consistent behavior, had a negative correlation with percentage passing in both reading and mathematics (see Tables 10-11).

Thirty years of research by Marzano (2004) and Waters et al. (2003) demonstrated a substantial association between leadership and achievement. Similarly, research at the Center for Comprehensive School Reform and Improvement (2005) found that principals who effectively formulated school goals, set and communicated expectations, allocated resources, supervised teacher performance, and promoted an orderly, positive environment of learning apparently had a positive effect on teaching in the classroom and student achievement. Higher reading scores on the Pennsylvania System of School Assessment were found when principals' behaviors were focused on student achievement (Center for Comprehensive School Reform and Improvement, 2005). Conversely, in the present study, Modeling the Way had a strong negative correlation to achievement (see Tables 10-11).

\section{Implications for Theory}

Because some of the leadership behaviors analyzed in this study were positive predictors of climate and achievement, educational theorists can use the results to support further testing of the strengths and weaknesses of Kouzes and Posner's (2007) five exemplary leadership behaviors, especially in examinations of leadership in an 
understudied context, urban high schools. Results could inform other theories by illuminating linkages among variables of leadership, school climate, and student achievement.

The theory of Ecological Grounding requires addressing student issues in the context of the classroom, school and community, and beyond the office of the principal. This theory aided the findings of the present study in the delineation of components of school climate. Ecological Grounding is less studied than exemplary leadership behaviors theory of Kouzes and Posner (2007). Thus, future studies on Ecological Grounding could be conducted in understudied contexts such as urban high schools as well. Such studies could extend knowledge about the theoretical grounding of the four assumptions regarding school climate and increase all stakeholders' understanding of how climate can be improved for the sake of enhancing student achievement.

\section{Implications for Research}

The purpose of this study was to explore the relationships among principals' leadership behaviors, school climate, and student achievement. Several significant relationships were discovered that showed a positive relationship between leadership behaviors and school climate, as well as student achievement in reading and mathematics. However, conflicting results of studies of the relationships among school leadership, school climate, and student achievement indicate the need for additional research in these areas.

The empirical findings derived from this study may add new information to development of a leadership model that promotes an organizational climate that fosters optimal academic and intellectual pursuits at the school. Furthermore, organizational 
researchers should test Kouzes and Posner's (2007) exemplary leadership behaviors for identifying successful and effective leaders for their organizations. Educational and HRD researchers could also examine other transformational leadership models, such as Covey's (1990) seven habits of highly effective people and "shared" and "distributed leadership" (Hallinger, 2003, p. 330) to support further examination of how leadership behaviors are linked to vital organizational outcomes.

\section{Implications for Practice}

The empirical data from this study provide principals in urban districts with preliminary insights into the critical elements needed for effective leadership. These are especially applicable toward the goal of school improvement and reform. Encouraging the Heart, for example, is one of those elements.

The No Child Left Behind Act of 2001 and other state and local legislations have placed increasing pressure on principals and teachers for improve school culture to maximize student achievement. This rising pressure may account for the moderate relationship found in the present study between Encouraging the Heart and school climate. It may also account for the negative link between Modeling the Way and school climate and student achievement. Many of the tasks principals are expected to perform are prescribed by district and state mandates.

In addition, Modeling the Way may not be a predictor of climate and achievement because secondary school students face complex and challenging material that requires sophisticated vocabulary and comprehension skills. These students need intensive, highquality literacy instruction implemented at the classroom level. The decision to provide the financial resources for this intensive literacy instruction is beyond the principal's 
purview and generally made at the state or district level. Likewise, providing resources to properly train teachers would be beyond the principal's authority (Alliance for Excellent Education, 2009).

Further, the school climate variable of Involvement was also important in this research. Leadership is viewed as critical component for school reform during these times of rapid change and increased accountability (Murphy, 2005). Therefore, it is imperative that leaders understand the processes that create conditions for involvement of all stakeholders in school improvement. School leaders must be able to assess and evaluate student data and, equally importantly, assess the teachers', parents', and students' perceptions of their own leadership style (Kelly et al., 2005). To achieve these goals, principals must continue to participate in leadership seminars emphasizing transformational leadership practices that create learning environments that involve community stakeholders and thereby facilitate improved student learning.

The present study findings may also aid human resources directors and boards of education in creating a set of transformational leadership characteristics for school principals to assist in their ongoing professional development and evaluation. This set of characteristics could enable human resources directors and boards to identify principal candidates for employment who have the most potential to act as transformational leaders.

With regard to school climate, the four assumptions of the Ecological Grounding theory (Sheridan \& Gutkin, 2000) may be precepts for principals and teachers to consider. This consideration would help educators gain insight into how to better meet the individual needs of students. 
The multifaceted and complex demands on principals to collect, analyze, and use data to improve school climate and student achievement have increased during the past two decades (Orr et al., 2005). The pace for principals is rapid, interruptions are frequent, and decisions are sometimes made without accurate or complete information (Greenfield, 1995). As the roles of principals have changed dramatically, the need for exemplary leadership has become more apparent (Pingle \& Cox, 2007).

In 2004, in the Miami-Dade County School District, then Superintendent Dr. Rudolph Crew recognized a shortfall of qualified principals in the Miami-Dade County School District. The Superintendent's Urban Principal Initiative was born out of Dr. Crew's effort to build leadership capacity of principals (Miami-Dade County Public Schools Superintendent's Urban Principal Initiative, 2006). The Superintendent's Initiative was a 3-year leadership development model involving 13 schools in the district. The initiative is now recognized as one of the nation's most multifaceted and comprehensive leadership training programs and is considered a model for other school leadership training programs (Miami-Dade County Public Schools, 2010).

Other large, urban school districts have implemented similar training programs as Miami-Dade County Public Schools. Chicago, New York, and Washington, DC, offered the noteworthy New Leaders for New Schools program (NGA Center for Best Practices, 2003). Springfield, Massachusetts, with its mixture of urban and suburban schools, developed The New Model for Principal Preparation program with support from the Massachusetts Department of Education. The Springfield Public Schools (SPS) developed a new "Leadership University" to house all training and professional 
development activities for principals and district staff (NGA Center for Best Practices, 2003).

Candidates in the SPS Leadership University were selected for the program through a rigorous application process managed by SPS. The Leadership University offered its own preparation and licensure programs. District staff members collaborated with seven local colleges and universities to teach the coursework. This 5-year program was planned for the training of 150 new administrators for SPS and other local districts (NGA Center for Best Practices, 2003).

As part of the SPS superintendent's strategic plan for 2009-2012, the Leadership University partnered with the Focus on Results Corporation to provide coaching and support for acceleration of the school improvement process. Support is provided in leadership development for both principals and teachers with the goals of improvement of student achievement and increased effectiveness of school-based leadership teams. Such initiatives are highly important for leadership training of school principals and can be implemented on a comprehensive basis in urban, semi-urban, and rural school districts (Institute for School Improvement, 2006).

\section{Implications for Policy}

Because the results of this study indicated principals' leadership behaviors are positive predictors of some climate and achievement variables, these results support school districts including leadership practices in leadership training, school climate improvement, and professional development programs. Such programs could be required of prospective principals and assistant principals. Provisions for ongoing mentorship could supplement these programs. 
The findings of this study could also lead to implementation of educational policy requiring the development of training and licensure programs in higher education, business, and industry to train and certify school leaders. Organizations such as the National Association of Secondary School Principals (NASSP), National Teacher Association, National Education Association (NEA), and U.S. State Departments of Education provide scholarly research-based data that inform practice and support datadriven decisions. This research also helps advance the performance of secondary schools. The findings of the research of these organizations provide a contemporary perspective on effective leadership behaviors to further the aims of these organizations and aid school leaders in many aspects of their duties and responsibilities.

NEA President Dennis Van Roekel (2011) stated in the organization's ThreePoint Plan for Reform that too many experts and policymakers who have proposed ideas to promote effective teaching have neither taught nor experienced firsthand the complexities, challenges, and rewards of teaching. As a result, too often such recommendations have led to policies that appeared unworkable for students or teachers and even threatened the quality of instruction and the education profession. The findings of this study are derived from the principals' perspectives, and therefore should be used to improve the quality of instruction and the profession.

\section{Limitations of the Study}

The following limitations should be considered when inferences are drawn from the results of this study. First, use of a cross-sectional survey design, although commonly employed, limits the inference of causation from observed empirical relationships (Johnson \& Christensen, 2007). Second, the population was comprised of principals from 
large urban school districts only. Use of this population limited the generalizability of study results possibly only to other urban districts. However, all secondary principals from the three counties were surveyed to compensate for nonresponses and missing information on the instruments (Israel, 1992). Nevertheless, the sample was smaller than anticipated due to one county's approval of data collection in only 5 of its 72 secondary schools.

Third, because the principals were from urban school districts only, results may not be generalizable to principals in smaller and/or rural districts (Johnson, 2001). Urban schools often face challenges such as high student poverty, mobility rates, large numbers of English language learners, and unsafe neighborhoods (Orr, Byrne-Jimenez, McFarlane, \& Brown, 2005). A composite of these factors may not be present in rural and suburban schools, limiting generalizability of results.

Fourth, the use of self-reports may have biased results because principals may have responded as they believed the researcher would wish them to or because of their self-images (Holtgraves, 2004), although self-reports have been used extensively and successfully to study leadership in a wide range of organizations, including schools. Finally, the response rate was less than optimal, but entirely consistent with prior webbased survey research (Crawford, Couper, \& Lamais, 2001; Dillman \& Bowker, 2001). The researcher followed test data management principles (Dillman 2007) to maximize responses, including distributing the surveys via SurveyMonkey, the U. S. mail, facsimile transmissions, and follow-up phone calls. Thus, study results may not be representative of the principals surveyed or reliably generalized to other similar sampling frames (Creswell, 2008). 


\section{Recommendations for Future Research}

In the future, it would be beneficial to recruit more participants to secure a larger sample size, thus improving the ability to detect significant differences between values (Israel, 1992). Furthermore, principals from rural, suburban, charter schools, and private schools should be recruited to improve validity and generalizability. Especially helpful could be testing the variables in other urban settings, such as cities in Texas (e.g., DallasFort Worth, Houston) and California (e.g., Los Angeles).

It may be desirable to administer the instruments to teachers as well to discern their perceptions of their principals' leadership behaviors and ascertain the relationship of their perceptions of principals' leadership to school climate and student achievement. Teachers' perceptions of principals' leadership behaviors and the relationship to school culture were studied by Stone (2003) in Mississippi public schools. Stone found statistically significant relationships among all principals' practices of all five of the exemplary leadership practices of the LPI and the schools' culture, as measured by the Instructional Climate Inventory (Braskamp \& Maehr, 1986).

In subsequent studies, it would also be advantageous to include principals of schools in counties with different socioeconomic statuses than those in Miami-Dade, Broward, and Palm Beach counties. In these counties, the proportions of residents living below the poverty line in 2008 were $18 \%, 11 \%$, and 10\% respectively (FOEDR, 2008). Studies of different counties could determine whether or to what extent socioeconomic status affects relationships among leadership behaviors, school climate, and student achievement. 
In future studies, the Demographic Questionnaire could be revised to include a separate question for the types of leadership courses and training of principals completed. If a principal responded "Yes" to item 8 ("Have you ever had leadership training?"), whether it was a college level or professional development course, and in item 9 indicated the number of courses, the next item could request descriptions of the types of courses completed. These descriptions could provide universities and training institutions insight into the effectiveness of these courses. Statistical analysis could then take place for possible relationships between the types of leadership courses and principals' leadership behaviors.

Future studies could also be introduced with definitions of the leadership behaviors of the LPI. Such introductions would help ensure that principals understand the import and substance of the specific behaviors. As noted above, misunderstanding by principals of the Modeling the Way leadership behavior may have resulted in the negative relationship found between this behavior and the school climate subscale of Leadership (Instructional).

Studies could also be conducted investigating links between organizational culture and leadership behaviors. Howell and Avolio (1993) found that transformational leadership measures had significantly positive association with performance in business units. Transactional leadership measures were negatively related to performance in business units. Thus, schools' performances as business units could be explored with regard to principals' leadership styles for significant positive and negative associations.

Future qualitative studies could also be beneficial. These could supplement quantitative investigations with insights and recommendations of principles, teachers, 
parents, and students on the barriers and necessary components of effective leadership implementation, improved school climate, and student achievement. Structured interviews with these stakeholders could determine which principal leadership behaviors were perceived to be transformational. Moscoso and Salgado (2001) found structured interviews to be a valid approach for assessing individuals' abilities and motivation to work. Such interview data would be enlightening because by definition transformational leaders organize their work and action from a-framework of sharing their vision with others. Qualitative studies could thus provide additional understanding of effective methods of administration and implementation that could be instituted for school and leadership improvement.

\section{Conclusion}

The national percentages of inadequate high schools and high school dropouts call for reform and improvement so that students can learn and complete a basic high school education in a supportive educational climate. Effective instructional leaders are needed to support this environment and to develop and encourage high-quality teaching and learning. This goal includes additional support for students who need it in terms of tutorials, mentoring, and special attention.

With these goals in mind, the findings of this study contribute to the current knowledge based on how principals' leadership behaviors are related to school culture and ultimately student achievement. The Encouraging the Heart leadership variable had a moderately significant positive correlation to the climate variables of Leadership (Instructional), Involvement, and Expectation. Surprisingly, the Modeling the Way leadership variable had a negative relation to both school climate and student 
achievement. Modeling the Way, therefore, should perhaps be de-emphasized by Boards of Education and policymakers in training and professional development programs for school leaders.

None of the leadership variables were significantly correlated to achievement when first examined with zero-order analyses. However, as partial correlation analyses were conducted in Hypothesis 3, a positive relation was found among some of the leadership and school climate variables and percentage passing reading and mathematics, as well as mean gains in reading and mathematics. These partial correlations were supported by the literature. These results should prove promising for reform of secondary schools in urban districts across the nation.

After controlling for gender, years at current school, and years in the district, partial positive correlations were found between leadership and school climate and student achievement. Inspiring a Shared Vision, Enabling Others to Act, Encouraging the Heart, and Challenging the Process leadership variables were partially correlated to the climate variables of Order, Leadership (Instructional), and Expectation. Thus, principals who consistently exhibited the leadership behaviors that were positive predictors of school climate and student achievement and possess the knowledge, skills, and judgment to make the improvements needed may make significant contributions to orderly and positive learning environments. 


\section{REFERENCES}

Adams, J. E., Jr., \& Kirst, M. W. (1999). New demands and concepts for educational accountability: Striving for results in an era of excellence. In J. Murphy \& K. S. Louis (Eds.). The handbook of research on educational administration (2nd ed., pp. 463-489). San Francisco, CA: Jossey-Bass.

Alliance for Excellent Education. (2009). High school dropout in America: FactSheet. Retrieved September 4, 2010, from http://www.all4ed.org/files/ GraduationRates_FactSheet.pdf

America's Promise. (2008). Promise 4: An effective education. Retrieved April 16, 2008, from http://www.americaspromise.org/APAPage.aspx? $\mathrm{id}=6378$

Anderson, C. (1982). The search for school climate: A review of the research. Review of Educational Research, 52, 368-420.

Avolio, B.. J. (1999). Full leadership development: Building the vital forces in organizations. Thousand Oaks, CA: Sage.

Avolio, B. J., \& Bass, B. M. (2002a). Developing potential across a full range of leadership. Human Resource Management, 41, 507-509.

Avolio, B. J., \& Bass, B. M. (2002b). Manual for the Multifactor Leadership Questionnaire (Form 5X). Redwood City, CA: Mindgarden.

Babbie, E. (2007). The basics of social research (4th ed.). Belmont, CA: Wadsworth.

Bass, B. M. (1998). Transformational leadership: Industrial, military and educational impact. Mahwah, NJ: Erlbaum.

Bass, B. M., \& Avolio, B. J. (1990). The implications of transactional and transformational leadership for individual, team, and organizational development. Research in Organizational Change and Development, 4, 231-272.

Bass. B. M., \& Avolio, B. J. (1997). Full-range leadership development: Manual for the Multifactor Leadership Questionnaire. Palo Alto, CA: Mindgarden.

Bass, B. M., Avolio, B. J., Jung, D. I., \& Berson Y. (2003). Predicting unit performance by assessing transformational and transactional leadership. Journal of Applied Psychology, 88, 207-218. doi: 10.1037/0021-9010.88.2.207

Bell, T. H. (1993). Reflections one decade after A Nation at Risk. Phi Delta Kappan, 74, 592-597. 
Bell-Roundtree, C. V. (2004). Does manager behavior influence knowledge worker job satisfaction and organizational commitment attitudes? A validation of Kouzes and Posner's transformational leadership theory. Unpublished doctoral dissertation, University of Alabama, Huntsville.

Berliner, D. C., \& Biddle, B. J. (1995). The manufactured crisis: Myths, fraud, and the attack on America's public schools. Reading. MA: Addison-Wesley.

Blanchard K., Hambleton, R. Zigarmi, D., \& Forsyth, D. (1991). Leadership behavior analysis: II other. Escondido, CA. Blanchard Training and Development.

Blatt, D. A. (2002). A study to determine the relationship between the leadership styles of career technical directors and school climate as perceived by teachers. Unpublished doctoral dissertation, Morgantown, West Virginia University.

Block, P. (1996). Stewardship: Choosing service over self-interest. San Francisco, CA: Berrett-Koehler.

Bolman, L. G., \& Deal, T. E. (2008). Reframing organizations: Artistry, choice, and leadership. San Francisco, CA: Jossey-Bass.

Borman, G. D, Hewes, G. M., Overman, L. T., \& Brown, S. (2002). Comprehensive school reform and student achievement: A meta-analysis. Baltimore, MD: CRESPAR/Johns Hopkins University, Retrieved August 28, 2007, from http://csos.jhu.edu/CRESPAR/techReports/Reports59.pdf.

Boyer, E. L. (1995). The basic school: A community for learning. San Francisco, CA: Jossey-Bass.

Brace, N., Kemp, R., \& Snelgar, R. (2006). SPSS for psychologists. Hillsdale, NY: Lawrence Erlbaum Associates.

Bracey, G. W. (2003). On the death of childhood and the destruction of public schools. Portsmouth, NH: Heinemann.

Branch, G. F., Hanushek, E. A., \& Rivkin, S. G. (2009). Estimating principal effectiveness. Calder Working Paper 32. Washington, DC: Union Institute.

Braskamp, L. A., \& Maehr, M. L. (1986). The motivation factor: A theory of personal investment. Lexington, MA: Lexington Books.

Brookover, W. (1979). School social systems and student achievement: Schools can make a difference. New York, NY: Praeger. 
Broward County Public Schools. (2010). Broward County public schools fact sheets. Retrieved June 21, 2010, from www.browardschools.com

Bruce, M. (2011, September 23). Obama: "No child left behind" changes will allow states to meet higher standards. Retrieved March 29, 2012, from http://abcnews.go.com/blogs/politics/2011/09/obama-no-child-left-behindchanges-will-allow-states-to-meet-higher-standards/

Bulach, C., Boothe, D., \& Pickett, W. (1998). "Should nots" for school principals: Teachers share their views. ERS [Educational Research Service] Spectrum: Journal of School Research and Information, 16(1), 16-20.

Bulach, C. Boothe, D., \& Pickett, W. (2006). Analyzing the leadership styles of school principals. Connexions Online Journal. Retrieved January 4, 2009, from http://www.cnx.org/content/m13813/latest/

Bulach, C., \& Malone, B. (1994). The relationship of school climate to the implementation of school reform. ERS Spectrum: Journal of School Research and Information, 12, 3-8.

Bulach, C., Malone, B., \& Castleman, C. (1995). An investigation of variables related to student achievement. Mid-Western Educational Researcher, 8(2), 23-29.

Burns, J. M. (1978). Leadership. New York, NY: Harper \& Row.

Burns, J. M. (2003). Transforming leadership: A new pursuit of happiness. New York, NY: Atlantic Monthly Press.

Butler, E. D., \& Alberg, M. J. (1991). The Tennessee School Climate Inventory: Resource manual. Memphis, TN: University of Memphis, Center for Research in Educational Policy.

Carless, S. A. (2001). Assessing the discriminant validity of the Leadership Practices Inventory. Journal of Occupational and Organizational Psychology, 74, 233-239.

Casavant, M. D., \& Cherkowski, S. (2001). Effective leadership: Bringing mentoring and creativity to the principalship. NASSP Bulletin, 85, 71-75.

Center for Comprehensive School Reform and Improvement (2005, September). The role of principal leadership in improving student achievement. Newsletter, pp. 1-4.

Center for Research in Educational Policy. (CREP). (2002). School Climate Inventory (SCI). Retrieved December 30, 2007, fromhttp://crep.memphis.edu/web /instruments/sci.php 
Chen, H.-C., \& Baron, M. (2007). Psychometric properties of the Chinese Leadership Practices Inventory. International Journal of Nursing Education Scholarship, 4(1), Article 12. Retrieved April 3, 2008, from http://www.bepress.com/ ijnes/vol4/iss 1/art23/

Chin, T. Y., Shaw, L. H., Dwyer, A. C., McCormick, C., \& Geisinger, K. F. (2010). Operational check of the 2010 FCAT 10th grade reading and 11th grade science equating results. Lincoln, NE: Buros Center for Testing. Retrieved July 7, 2010, from http://www.fldoe.org/pdf/2010FCATCalibrationEquatingGR10-11.pdf

Cho, Y. (2003, August). Influence of school principal's leadership and school climate on the productivity of transition system in vocational high school. Paper presented at the annual meeting of the American Sociological Association, Atlanta, GA.

Clark, D., Martorell, P., \& Rockoff, J. E. (2009). School principals and school performance. Calder Working Paper 38. Washington, DC: Union Institute.

Cohen, J. (2006). Social, emotional, ethical and academic education: Creating a climate for learning participation in democracy and well-being. Harvard Educational Review, 76, 201-237.

Cohen, J., \& Cohen, P. (1983). Applied multiple regression/correlation analysis for the behavioral sciences (2nd ed.). Hillsdale, NJ: Erlbaum.

Cook, R. G. (2003). The utility of DIBELS as a curriculum-based measurement in relation to reading proficiency of high stakes testing. Unpublished master's thesis, Marshall University, Huntington, WV.

Cotton, K. (2003). Principals and student achievement: What the research says. Alexandria, VA: Association for Supervision and Curriculum Development.

Covey, S. (1990). The seven habits of highly effective people. New York, NY: Free Press.

Crawford, S. D., Couper, M. P., \& Lamias, M. J. (2001). Web surveys: Perceptions of burden. Social Science Computer Review, 19, 146-162.

Creemers, B. P. M., \& Reezigt, G. J. (1999). The role of school and classroom climate in elementary school learning environments. In H. J. Freiberg (Ed.), School climate: Measuring improving and sustaining healthy environments (pp. 30-47).

Philadelphia, PA: Falmer Press. 
Creswell, J. W. (2008). Educational research: Planning, conducting, and evaluating quantitative and qualitative research (3rd ed.). Upper Saddle River, NJ: Pearson Merrill Prentice Hall.

Cunningham, B.C.A. (2003). A study of the relationship between school culture and student achievement. Unpublished doctoral dissertation, University of Central Florida, Orlando.

Deal, T. E., \& Kennedy, A. A. (1982). Corporate cultures. New York, NY: AddisonWesley.

Deal, T. E., \& Peterson, K. (1990). The principal's role in shaping school culture. Washington, DC: U. S. Department of Education.

Devereaux, L. (2000). Principal training: The missing link for successful school councils. International Electronic Journal for Leadership in Learning, 4(9). Retrieved May 3, 2008, from http://www.acs.ucalgary.ca/ iejll/volume4/devereaux_vrn9.html

Dillman, D. A. (2007). Mail and internet surveys: The tailored design method (2nd ed.). Hoboken, NJ: John Wiley.

Dillman, D. A., \& Bowker, D.K. (2001). The web questionnaire challenge to survey methodologists. Retrieved May 29, 2008, from

http://www.survey.sesrc.wsu.edu/dillman/zuma_paper_dillman_bowker.pdf

Dillman, D. A., Smythe, J., \& Christian, L. M. (2008). Internet, mail and mixed-mode surveys: The tailored design method (3rd ed.). Hoboken, NJ: John Wiley.

Edmonds, R. (1979). Effective schools for the urban poor. Educational Leadership, $37(1), 15-18,20-24$.

Edmonds, R. (1982, February). Programs of school improvement: An overview. Paper presented at National Institute of Education conference, The Implications of Research for Practice, Warrenton, VA.

Elmore, R. (2003). Knowing the right things to do: School improvement and performance-based accountability Washington, DC: National Governors' Association, Center for Best Practices.

Faul, F., Erdfelder, E., Lang, A.-G., \& Buchner, A. (2007). G*Power 3: A flexible statistical power analysis for the social, behavioral, and biomedical sciences. Behavior Research Methods, 39, 175-191. 
Herold, D. M., Fields, D. L., \& Hyatt, C. W. (1993, August). Using leadership instruments in a management development context: What are we measuring? Paper presented at the Academy of Management Annual Meeting, Atlanta, GA.

Fields, D. L., \& Herold, D. M. (1997). Using the leadership practices inventory to measure transformational and transactional leadership. Educational and Psychological Measurement, 57, 569-579.

Finnan C., Schnepel, K., \& Anderson, L. (2003). Powerful learning environments: The critical link between school and classroom cultures. Journal of Education for Students Placed At Risk, 8, 391-418.

Florida Department of Education. (2007). Accountability, research measurement: Florida comprehensive assessment. Retrieved August 25, 2007, from http://fcat.fldoe.org/results

Florida Department of Education. (2008a). FCAT. Retrieved April 16, 2008, from http://www.fldoe.org/

Florida Department of Education. (2008b). 2008 FCAT results. Retrieved May 22, 2008, from http://fcat.fldoe.org/results

Florida Department of Education. (FLDOE). (2010a). FCAT. Retrieved April 16, 2010, from http://www.fldoe.org/

Florida Department of Education. (FLDOE). (2010b). Scoring the FCAT. Retrieved July 7, 2010, from http://www.fldoe.org/fcat.asp

Florida International University. (2007). Regulations for thesis and dissertation preparation manual. Miami, FL: Author.

Florida Office of Economic and Demographic Research. (FOEDR). (2008). County profiles. Retrieved April 10, 2008, from http://edr.state.fl.us /county\%20profiles.htm

Florida Office of Economic and Demographic Research. (FOEDR). (2010). FCAT statistics. Retrieved June 28, 2010, from http://www.fldoe.org/fcat.asp

Freiberg, H. J. (1998). Measuring school climate: Let me count the ways. Educational Leadership, 56(1), 22-26.

Fullan, M. (2002). The change leader. Educational Leadership, 59(2), 16-20.

Gall, M. D., Gall, J. P., \& Borg, W. R. (2005). Educational research: An introduction (7th ed,). Boston, MA: Allyn \& Bacon. 
Ghaith, G. M. (2004). The relationship between forms of instruction, achievement, and classroom climate. Educational Research, 45(1), 107-117

Glover, D., \& Coleman, M. (2005). School culture, climate and ethos: Interchangeable or distinctive concepts? Journal of In-Service Education, 31(2), 251-272.

Goodlad, J. I. (2003). A nation in wait. Retrieved September 5, 2010, from http://www,edweek.org/ew/issues/a-nation-at-risk/

Goldstein, A. P., \& Soriano, F. I. (1994). Juvenile gangs. In L. D. Eron, J. H. Gentry, \& P. Schlegel (Eds.), Reason to hope (pp. 315-333). Washington, DC: American Psychological Association.

Greenfield, W. D. (1995). Toward a theory of school administration: The centrality of leadership. Educational Administration Quarterly, 31(1), 61-85.

Gruenert, S., \& Valentine, J. (1998). School climate survey. Columbia, MO: Middle Level Leadership Center, University of Missouri.

Hallinger, P. (2003). Leading educational change: Reflecting on the practice of instructional and transformational leadership. Cambridge Journal of Education, 33(3), 321-351.

Hallinger, P., Bickman, L. \& Davis, K. (1996). School context, principal leadership, and student reading achievement. Elementary School Journal, 96(5), 527-549.

Hallinger, P., \& Heck, R. (1996). The principal's role in school effectiveness: An assessment of methodological progress, 1980-1995. In K. Leithwood, J. Chapman, D. Corson, P. Hallinger, \& A. Hart (Eds.),. International handbook of educational leadership and administration, part 2 (pp. 723-783). Amsterdam, Netherlands: Kluwer Academic Publishers.

Hallinger, P., \& Heck, R. (1998). Exploring the principal's contribution to school effectiveness: 1980-1995. School Effectiveness and School Improvement: An International Journal of Research, Policy and Practice, 9(2), 157-191. doi: 10.1080/0924345980090203

Hallinger, P., \& Murphy, J. (1987). Assessing and developing principal instructional leadership. Educational Leadership, 45(1), 54-61.

Halpin, A. W., \& Croft, D. B. (1962). The organizational climate of Paraguayan elementary schools: Rural-urban differentials. Education and Urban Society. 3(3), 333-345. 
Harvey, J., \& Housman, N. (2004). Crisis or possibility: Conversation about the American high school. Washington, DC: National High School Alliance.

Heck, R. H. (1992). Principal assessment: Conceptual problem, methodological problem or both? Peabody Journal of Education, 68(1), 124-144.

Heck, R., \& Hallinger, P. (1999). Conceptual model, methodology, and methods for studying school leadership. In J. Murphy \& K. Seashore-Louis (Eds.), The 2nd handbook of research in educational administration. (pp. 141-162). San Francisco, CA: McCutchan Publishing.

Hill, L. A. (2007). Becoming the boss. Harvard Business Review, 85(1), 48-57.

Hinkle, D. E., Wiersma, W., \& Jurs, S. G. (2003). Applied statistics for the behavioral sciences. New York, NY: Houghton Mifflin.

Holcomb, Z. C. (2006). SPSS basic techniques for a first course in statistics. Glendale, CA: Pyrczak Publishing.

Holtgraves, T. (2004). Social desirability and self-reports: Testing models of socially desirable responding. Personality and Social Psychology Bulletin, 30(2), 161-172.

Howard, M. P. (2004). A study of the relationship between transformational leadership and organizational culture. Unpublished doctoral dissertation, Western Michigan University, Kalamazoo.

Howell, J. M., \& Avolio, B. J. (1993). Transformational leadership, transactional leadership, locus of control, and support for innovation: Key predictors of consolidated-business-unit performance. Journal of Applied Psychology, 78(6), 891-903. doi:10.1037/0021-9010.78.6.891

Hoy, W., \& Miskel, C. (2005). Education administration: Theory, research, and practice (7th ed.). New York, NY: McGraw-Hill.

Hoy, W., Tarter, C., \& Bliss, F. (1990). School characteristics and faculty trust in secondary schools. Educational Administration Quarterly, 25, 294-309.

Huber, S., \& West, M. (2002). Developing school leaders: A critical review of current practices, approaches, issues, and some directions for the future. In K. Leithwood \& D. Hallinger (Eds.), Second international handbook of educational leadership and administration. Part 2 (pp. 1071-1099). Dordrecht, The Netherlands: Kluver.

IBM SPSS. (2010). IBM SPSS 19. Chicago, IL: SPSS, Inc. 
Institute for School Improvement. (2006). Research brief: Examining the relationship between school climate and student achievement. Springfield, MO: Missouri State University. Retrieved March 4, 2009, from http://education.missouristate.edu/assets/isi/SchoolClimateBrief.pdf

Israel, G. D. (1992). Determining sample size. Retrieved June 22, 2010, from http//eds. ufl.edu/pd/006

Janc, H., \& Appelbaum, D. (2004). Comprehensive school reform at the helm of the North Carolina instructional leadership reform program. National Clearinghouse for Comprehensive Reform Benchmark Newsletter, 5(4), 1-11.

Jantzi, K., \& Leithwood, D. (1997). Explaining variation in teachers' perceptions of principals' leadership: A replication. Journal of Educational Administration. 35(4), 312-331.

Johnson, R. B. (2001). Toward a new classification of nonexperimental quantitative research. Educational Research, 30(2), 3-13.

Johnson, B., \& Christensen, L. B. (2007). Educational research: Quantitative, qualitative, and mixed approaches (2nd ed.). Boston, MA: Pearson Educational.

Kelley, R. C., Thorton, B., \& Daugherty, R. (2005). Relationships between measures of leadership and school climate, Education, 126(1), 17-25.

Kiper, R. S. (2007). Teachers' perceptions of principals as transformational leaders and AYP testing mandates for No Child Left Behind Act of 2001: A correlational study using Minnesota Comprehensive Assessment. Unpublished doctoral dissertation, St. Mary's University of Minnesota, Minneapolis.

Kolb, D. (1984). Experiential learning: Experience as the source of learning and development. Englewood Cliffs, NJ: Prentice Hall.

Kottkamp, R. (1984). The principal as cultural leaders. Planning and Changing, 15, 152-159.

Kouzes, J. M., \& Posner, B. Z. (2000). Leadership Practices Inventory: Psychometric properties. Retrieved February 5, 2008, from www.leadershipchallenge.com

Kouzes, J. M., \& Posner, B. Z. (2002). The Leadership Practices Inventory: Theory and evidence behind the five practices of exemplary leaders. Retrieved January 4, 2008, from www.leadershiphchallenge.com 
Kouzes, J. M., \& Posner, B. Z. (2003). The Jossey-Bass academic administrator's guide to exemplary leadership. San Francisco, CA: Jossey-Bass.

Kouzes, J. M., \& Posner, B. Z. (2007). The leadership challenge (4th ed.). New York, NY: John Wiley.

Kuhnert, K. W. (1994). Transforming leadership: Developing people through delegation. In B. M. Bass \& B. J. Aviolo (Eds.), Improving organizational effectiveness through transformational leadership (pp. 10-25). Thousand Oaks, CA: Sage.

Leadership Challenge. (2007). Research. Retrieved November 2, 2007, from http://www.leadershipchallenge.com/WileyCDA/Section/id-131053.html

Leadership Practices Inventory (2003, 3rd ed.). Retrieved November 2, 2007, from http://www.leadershipchallenge.com/ WileyCDA/Section/id-131053.html

Leece, P., Bhandari, M., Sprague, M., Swiontkowski, M. F., Schemitsch, E. H., Tornetta, P., et al. (2004). Internet versus mailed questionnaires: A randomized comparison. Journal of Medical Internet Research, 6(3). Retrieved May 24, 2008, from http://www.pubmedcentrla.hh.gov/rticlerender.fcgi?artid=1550617

Leithwood, K. (1992). The move toward transformational leadership. Educational Leadership, 49(5), 8-12.

Leithwood, K., Aitken, R., \& Jantzi, D. (2006). Making schools smarter: Leading with evidence. Thousand Oaks, CA: Corwin.

Leithwood, K. \& Jantzi, D. (1999). Transformational leadership. In B. Davies (Ed.), The essentials of school leadership, Part 2 (pp. 31-43). London, UK: Paul Chapman Publishing.

Leithwood, K., Jantzi, D., \& Steinbach, R. (1999). Changing leadership for changing times. Buckingham, UK: Open University Press.

Leithwood, K., \& Harris, A. (2010). Leading school turnaround: How successful leaders transform low performing schools. San Francisco, CA: Jossey-Bass.

Leithwood, K., Seashore-Louis, K., Anderson, S., \& Wahlstrom, K. (2004). How leadership influences student learning. New York, NY: Wallace Foundation. Retrieved August 13, 2007, from http://www.wallacefoundation.org/WF /KnowledgeCenter/KnowledgeTopics/Educationleadership /HowLeadershipInfluences StudentLearning.htm. 
Levine, D. U., \& Lezotte, L. W. (1990). Unusually effective schools: A review and analysis of research and practice. Madison, WI: National Center for Effective Schools.

Lezotte, L. W., \& Pepperl, J. C. (1999). The effective schools: A proven path to learning for all. Okemos, MI: National Center for Effective Schools Research.

Lifson, L. (2008, March 9). FCAT again: Home life holds key to achievement. Fort Lauderdale Sun-Sentinel, p. 5F.

Lusk, C., Delclos, G. L., Burau, K., Drawhorn, D. D., \& Aday, L. A. (2007). Mail versus internet surveys. Evaluation and the Health Professions, 30, 186-201.

Masden-Copas, P., \& Wagner, C. (2002). An audit of the culture starts with two handy tools. Journal of Staff Development, 23(3), 42-53.

Maehr, M. (1990). The "psychological environment" of the school: A focus for school leadership. (Project report). Champaign, IL: National Center for School Leadership.

Manfreda, K.L., Batagelj, Z., \& Vehovar, V. (2002). Design of web survey questionnaires: Three basic experiments. Journal of Computer-Mediated Communications, 7(3). [Online]. Retrieved May 21, 2008, from http://www.ascusc.org/jcmc/vol7/issie3/vehovar.html.

Marzano, R. J., \& McNulty, B. (2004, June). A tool for selecting the "right work" in your school. Paper presented at the ACSA Conference. Retrieved February 22, 2009, from

http://www.marzanoresearch.com/archive/2009_selected_research_archive.aspx

McGuigan, L., \& Hoy, W. K. (2006). Principal leadership: Creating a culture of academic optimism to improve achievement for all students. Leadership and Policy in Schools, 5, 203-229.

McMillan, J. N., \& Schumacher, S. (2009). Research in education: Evidencebased inquiry (7th ed.). New York, NY: Addison Wesley.

McNeely, C. A., Nonnemaker, J. M., \& Blum, R. W. (2002). Promoting school connectedness. Journal of School Health, 72, 138-146.

Mees, G. W. (2008). The relationship among principal leadership, school culture, and student achievement in Missouri middle schools. Unpublished doctoral dissertation, University of Missouri, Columbia, MO.

Miami-Dade County Public Schools (2005). Secondary school reform plan. Miami, FL. Retrieved August 25, 2007, from http://choice.dadeschools.net 
Miami-Dade County Public Schools. (2010). Schools: Middle and high schools.

Retrieved June 21, 2010, from www.dadeschools.net

Miami-Dade County Public Schools Superintendent's Urban Principal Initiative. (2006). Developing leaders of the future. Retrieved May 22, 2008, from http://www.miamisci.org/supi/docs/2006_SUPI_Booklet.pdf

Miller, S, I. ,\& Fredricks, J. (1990). The false ontology of school climate effects. Educational Theory, 40(3), 333-342.

Moscoso, S., \& Salgado, J. F. (2001). Psychometric properties of a structured behavorial interview to hire private security personnel. Journal of Business and Psychology, 16, 51-59.

Mulford, W., Silins, H., \& Leithwood, K. A. (2005). Educational leadership for organisational learning and improved student outcomes. New York, NY: Springer.

Murphy, J. (2005). Connecting teacher leadership and school improvement. Thousand Oaks, CA: Corwin Press.

National Center for Education Statistics. (2007). The nation's report card: $12^{\text {th }}$ grade reading and mathematics, 2005. Washington, DC: U. S. Department of Education.

National Center for Education Statistics. (2010). Fast facts. Retrieved from http://nces.ed.gov/fastFacts/display.asp?id $=98$

National Governors Association Center for Best Practices, (2003). New leaders for new schools. Retrieved September 9, 2011, from www.nga.org/cms/center/publications

National School Climate Center. (2007). The school climate challenge. New York: Center for Social and Emotional Education. Retrieved February 20, 2008, from http://ecs.org/html/projectsPartners/nclc/docs/schoo-climate-challenge-web.pdf

No Child Left Behind Act of 2001. (2002). Pub. L. No. 107-110. (2002).

Northouse, P. (2007). Leadership: Theory and practice (4th ed.). Thousand Oaks, CA: Sage.

O’Donnell, R. J., \& White, G. P. (2005). Within the accountability era: Principals' instructional leadership behaviors and student achievement. NASSP Bulletin, 89(645), 56-71. 
Orr, M. T., Byrne-Jimenez, M., McFarlane, P.. \& Brown, B. (2005). Leading out from low-performing schools: The urban principal experience. Leadership and Policy in Schools, 4, 23-54.

Osher, D., \& Dwyer, K. (2005). Research matters/Positive culture in urban schools. Educational Leadership, 62(6), 84-85.

Osher, D., \& Fleischman, S., (2005). Research matters/positive culture in urban schools. Educational leadership, 62(6), 84-85.

Palm Beach County Public Schools. (2010). District information. Retrieved June 21, 2010, from www.palmbeach.k12.fl.us/.

Pashiardis, P. (2004). Democracy and leadership in the educational system in Cyprus. Journal of Educational Administration, 42(6), 656-668.

Pennings, R. (2007, March). Transformational leadership: How do we get there? Paper presented at Leadership Conference, Maricopa Community College, Phoenix, AZ. Retrieved May 19, 2008, from http://www.mc.maricopa.edu/community/chair /conference /2007/papers/transformational_leadership.pdf

Peterson, P. E. (2003). Our schools and our future. Retrieved September 5, 2010, from http://www.edweek.org/ew/isssues/a-nation-at-rsik/

Pingle, T., \& Cox E. (2007). Leadership practices of elementary school principals. Academic Leadership Online Journal, 4(2). Retrieved August 13, 2007, from http://www.academicleadership.or/empirical_research

Phillips, G., \& Wagner, C. (2003). School culture assessment: A manual for assessing and transforming school and classroom culture. Vancouver, BC, Canada:

Eduserv, British Columbia School of Trustees Publishing.

Podsakoff, P. M., Todor, W. D., \& Skov, R. (1982). Effect of leader contingent and non contingent reward and punishment behaviors on subordinate performance and satisfaction. Academy of Management Journal, 25, 810-821.

Pont, B., Nusche, D., \& Mooran, H. (2008). Improving school leadership. Policy and Practice, Vol. 1. Paris, France: Organization for Economic Cooperation and Development.

Pursley, N. P. (2002). Reflections on leadership. Public Policy and Practice, 2(1), 24-28.

Reeves, D. (2004). Excerpts from a presentation to Kentucky educators attending the Fall 2004 Conference: Transforming leadership for learning. Bowling Green, KY: Green River Educational Cooperative. 
Remondini, B. (2001). Leadership style and school climate: A comparison between Hispanic and Non-Hispanic women principals in Southern New Mexico. Unpublished doctoral dissertation, New Mexico State University, Las Cruces.

Reynolds, H. T. (1984). Analysis of nominal data. Beverly Hills, CA: Sage.

Reynolds, D., \& Cuttance, P. (1992). School effectiveness: Research, policy, and practice. New York, NY: Wellington House.

Roach, A. T., \& Kratochwill, T. R. (2004). Evaluating school climate and school culture. Teaching Exceptional Children, 37, 9-17.

Ross, S. M., McDonald, A. J., Alberg, M., McSparrin-Gallagher, B., \& Calloway, F. (2005, April). Urban school reform: Achievement and school climate outcomes for the Knowledge Is Power program. Paper presented at the annual meeting of the American Educational Research Association, Montreal, Canada. Retrieved April 4, 2008, from http://crep.memphis.edu/web/research/ pubAERA\%2005\%20KIPP.pdf

Ross, J. M., \& Nunnery, (2005). The effect of school renaissance on student achievement in two Mississippi school district. Center for Research in Educational Policy: Research initiatives. Retrieved May 20, 2008, from http://crep/memphis/edu/ web/research/pub/Mississippi_School_Renaissance_FINAL_4.pdf

Rutter, M., Maughan, B., Mortimore, P., \& Ouston, J. (1979). Fifteen thousand hours: Secondary schools and their effects on children. Cambridge, MA: Harvard University Press.

Sandbakken, D. (2004). An investigation into leadership practices and organizational performance in a Norwegian context. Unpublished D.B.A. dissertation, Henley Management College, Henley-on-Thames, England. Retrieved May 3, 2008, from http://www.heleymc.ac.uk/elibrary/theses02.nsf/17a0dc1195968301180256bdb00 $537 \mathrm{~d} 54 /$

Santos, J.R.A. (1999). Cronbach's alpha: A tool for assessing the reliability of scales. Journal of Extension, 37(2), 1-6. Retrieved January 3, 2008, from http://www.joe.org/joe/1999april/tt3.html

Schein, E. H. (1997). Organizational culture and leadership. San Francisco, CA: Jossey-Bass.

Schmidt, F., \& Hunter, J. (2004). General mental ability in the world of work: Occupational attainment and job performance. Journal of Personality and Social Psychology, 86(1), 162-173. 
Sergiovanni, T. J. (1991). The principalship: A reflective practice perspective. Needham Heights, MA: Simon \& Schuster.

Sergiovanni, T., \& Starratt, R. (1998). Supervision: A redefinition. Boston, MA: McGraw-Hill.

Sheehan, K. B., \& Hoy, M. G. (1999). Using e-mail to survey Internet users in the United States: Methodology and assessment. Journal of Computer-Mediated Communication, 4(3). Retrieved May 24, 2008, from http://www.blackwellsynergy.com/doi/abs/10.1111/j.1083-6101.1999.tb00101.x

Sheridan, S. M., \& Gutkin, T. B. (2000). The ecology of school psychology: Examining and changing our paradigm for the 21st century. School Psychology Review, 29, 485-502.

Siegel, M. R. (1992). Theory and problems of probability and statistics. New York, NY: McGraw-Hill.

Sims, C. E. (2005). The effects of principals' leadership practices on school climate and student achievement in Title I elementary schools. Unpublished doctoral dissertation, Union University, Jackson, TN.

Simsek, Z., \& Veiga, J. F. (2000). The electronic survey technique: An integration and assessment. Organizational Research Methods, 3, 93-115.

Sizer, T. J. (2000). A visit to an "essential" school. School Administrator, 45(10), 18-19.

Solomon, D., Battistich, V., Watson, M., Schaps, E., \& Lewis, C. (2000). A six-district study of educational change. Social Psychology of Education, 4, 3-51.

Spellings, M. (2007). Building on results: A blueprint for strengthening the "No Child Left Behind Act." Washington, DC: U.S. Department of Education. Retrieved August 13, 2007, from www.edupubs.org

Stewart, J. (2006). Transformational leadership: An evolving concept examined through the works of Burns, Bass, Avolio, and Leithwood. Canadian Journal of Educational Administration and Policy, 54, 1-29.

Stone, C.M. (2003). A study of the relationship between principals' leadership behaviors and the school culture as perceived by teachers. Unpublished doctoral dissertation, University of Mississippi, Oxford.

Sue, V. M., \& Ritter, L. A. (2007). Conducting online surveys. Thousand Oaks, CA: Sage. 
Sugai, G., Horner, R. H., Dunlap, G., Hieneman, M., Lewis, T. J., Nelson, C. M., et al. (2000). Applying positive behavioral support and functional behavioral assessment in schools. Journal of Positive Behavioral Interventions, 2, 131-143.

Survey Monkey. (2008). Privacy policy. Retrieved May 19, 2008, from http://www.surveymonkey.com/

Tabachnick, B. G., \& Fidell, L. S. (2007). Using multivariate statistics (5th ed.). Boston, MA: Allyn \& Bacon.

Urban, V. (1999). Eugene's story: A case for caring. Educational Leadership, 56(6), 69 70.

U.S. Census Bureau. (2006). 2006 American community survey. Retrieved January 22, 2008, from http://factfinder.census.gov/servlet /ACSSAFFFacts?_event= Search\&geo_id $=\&$

U.S. Department of Education. (2007). Elementary/secondary schools. Retrieved from http://nces.ed.gov/fastfacts/.

Wagner, C., \& Masden-Copas, P. (2002). School Culture Triage Survey. Bowling Green, KY: Center for Improving School Culture.

Waters, T., Marzano, R., \& McNulty, B. (2004). Leadership that sparks learning. Educational Leadership, 61(7), 48-52.

Wentzel, K. R., \& Watkins, D. E. (2002). Peer relationships and collaborative learning as contexts for academic enablers. School Psychology Review, 31, 366-367.

Wis, B., Bosker, R. J., \& Kruger, M. L. (2003). Educational leadership and student achievement: The elusive search for an association. Educational Administration Quarterly, 39, 398-425.

Wright, K. B. (2005). Researching Internet-based populations: Advantages and disadvantages of online survey research, online questionnaire authoring software packages, and Web survey services. Journal of Computer-Mediated Communication, 10(3). Retrieved May 24, 2008, from http:www.blackwellsynergy.com/doi/abs/10.1111/j.1083-6101.2005.tb00259.x

Zepeda, S. J. (2007). The principal as instructional leader: A handbook for supervisors (2nd ed.). Larchmont, NY: Eye on Education.

Zigarmi, D., \& Edeburn, C. (1980). Organizational climate and I.G.E.: An assessment and implications. AIGE Forum, 3(1), 30-32. 
Zigarmi, D., Edeburn, C., \& Blanchard, K. (1995). Getting to know the LBII: Research, validity and reliability of the self and other forms. Escondido, CA: Blanchard Training and Development. 


\section{APPENDIX A \\ SCHOOL CLIMATE INVENTORY-REVISED INSTRUMENT USAGE AGREEMENT STATEMENT}

\section{School Climate Inventory-Revised (SCI-R)}

\section{Instrument Usage Agreement Statement}

Center for Research in Educational Policy (CREP)

The University of Memphis

325 Browning Hall

Memphis, TN. 38152

By using the School Climate Inventory - Revised (SCI-R) evaluation instrument developed and wholly owned by the Center for Research in Educational Policy (CREP) at The University of Memphis, I understand and agree to the following conditions and statements:

- The instrument is protected under copyright and intellectual property laws. The instrument remains the property of the Center for Research in Educational Policy

- This is a one-time permission for the agreed upon study. Further uses of this instrument would require similar permission

- CREP will be cited as the instrument developers in any publication associated with the agreed upon study

- CREP will not administer the instruments or provide data analysis unless agreed upon

- A copy of the publication (e.g., thesis, dissertation, report) associated with this one-time instrument use will be provided to CREP upon request

I understand and agree to the above terms.

Printed Name 


\section{APPENDIX B}

\section{DEMOGRAPHIC QUESTIONNAIRE}

For each item, please circle the choice that applies.

1. What is your gender?

1. Male

2. Female

2. What is your age?

1. Under 26

2. $26-30$

3. $31-40$

4. $41-50$

5. $51-60$

6. 61 - and over

3. What is your race/ethnicity?

1. African American

2. Asian

3. Hispanic

4. White

5. Other (please specify)

4. What is the highest degree you have earned?

1. BA or BS

2. Master's

3. Doctorate

4. Professional (MD, JD)

5. Other (please specify)

5. How many years have you worked in your school district?

1. Less than 5 years

2. $5-10$

3. $11-15$

1. $16-20$

2. 21 or more 
6. How many years have you been a school principal, at this or another school?

1. Less than 5 years

2. $5-10$

3. $11-15$

4. $16-20$

5. 21 or more

7. How many years have you been principal of your current school?

1. Less than 5 years

2. $5-10$

$3 \quad 11-15$

4. $16-20$

5. 21 or more

8. Have you ever had leadership training?

1. Yes

2. No

If the answer is yes, please indicate whether college level or professional (career) development program.

1. College level

2. Professional (career) development

9. If Yes to Item 8 , how many courses?

1. 1

2. $2-5$

3. $6-10$

4. Over 10

10. What is your most current school grade?
1. A
2. B
3. C
4. D
5. F 
11. Did your school meet AYP this year?

1. Yes

2. No

12. How many teachers are in your school?
1. $1-50$
2. $51-100$
3. $101-149$
4. $150-200$
5. Over 200

13. What percentage of your students are on free or reduced lunch?
1. $0-10 \%$
2. $11-21 \%$
3. $22-32 \%$
4. $33-43 \%$
5. $50 \%$ or more

14. Is your school a middle school or high school?

1. Middle school

2. High school 


\section{APPENDIX C}

\section{LEADERSHIP PRACTICES INVENTORY (LPI)}

Below your name, you will find thirty statements describing various leadership behaviors. Please read each statement carefully, and using the RATING

SCALE on the right, ask yourself: "How frequently do I engage in the behavior described?"

- Be realistic about the extent to which you actually engage in the behavior.

- Be as honest and accurate as you can be.

- DO NOT answer in terms of how you would like to behave or in terms of how you think you should behave.

- DO answer in terms of how you typically behave on most days, on most projects, and with most people.

- Be thoughtful about your responses. For example, giving yourself 10 s on all items is most likely not an accurate description of your behavior. Similarly, giving yourself all $1 \mathrm{~s}$ or all $5 \mathrm{~s}$ is most likely not an accurate description either. Most people will do some things more or less often than they do other things.

- If you feel that a statement does not apply to you, it's probably because you don't frequently engage in the behavior. In that case, assign a rating of 3 or lower.

For each statement, decide on a response and then record the corresponding number in the box to the right of the statement. After you have responded to all thirty statements, go back through the LPI one more time to make sure you have responded to each statement. Every statement should have a rating.

$\begin{array}{ll}1 & \text { Almost never } \\ 2 & \text { Rarely } \\ 3 & \text { Seldom } \\ 4 & \text { Once in a while } \\ 5 & \text { Occasionally } \\ 6 & \text { Sometimes } \\ 7 & \text { Fairly often } \\ 8 & \text { Usually } \\ 9 & \text { Very frequently } \\ 10 & \text { Almost always }\end{array}$


1. I set a personal example of what I expect of others.

2. I talk about future trends that will influence how our work gets 12345678910 done.

3. I seek out challenging opportunities that test my own skills and abilities.

4. I develop cooperative relationships among the people I work with.

12345678910

5. I praise people for a job well done.

12345678910

6. I spend time and energy making certain that the people I work with adhere to the principles and standards we have agreed on.

12345678910

7. I describe a compelling image of what our future could be like.

12345678910

8. I challenge people to try out new and innovative ways to do their work.

12345678910

9. I actively listen to diverse points of view.

12345678910

10. I make it a point to let people know about my confidence in their abilities.

12345678910

11. I follow through on the promises and commitments that I make.

12345678910

12. I appeal to others to share an exciting dream of the future.

12345678910

13. I search outside the formal boundaries of my organization for innovative ways to improve what we do.

12345678910

14. I treat others with dignity and respect.

12345678910

15. I make sure that people are creatively rewarded for their contributions to the success of our projects.

12345678910

16. I ask for feedback on how my actions affect other people's performance.

12345678910

17. I show others how their long-term interests can be realized by enlisting in a common vision.

12345678910 
18. I ask "What can we learn?" when things don't go as expected. $\quad 12345678910$

19. I support the decisions that people make on their own.

12345678910

20. I publicly recognize people who exemplify commitment to shared values.

12345678910

21. I build consensus around a common set of values for running our organization.

12345678910

22. I paint the "big picture" of what we aspire to accomplish.

12345678910

23. I make certain that we set achievable goals, make concrete plans, and establish measurable milestones for the projects and programs that we work on.

24. I give people a great deal of freedom and choice in deciding how to do their work.

12345678910

25. I find ways to celebrate accomplishments.

12345678910

26. I am clear about my philosophy of leadership.

12345678910

27. I speak with genuine conviction about the higher meaning and purpose of our work.

12345678910

28. I experiment and take risks, even when there is a chance of failure.

12345678910

29. I ensure that people grow in their jobs by learning new skills and developing themselves.

12345678910

30. I give the members of the team lots of appreciation and support for their contributions. 


\section{APPENDIX D \\ SCHOOL CLIMATE INVENTORY-REVISED (SCI-R)}

Indicate the extent to which you agree with each of the following items as they are currently reflected in your school. If you have no basis on which to respond, leave the item blank.

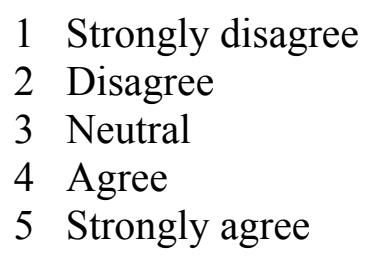

1. The faculty and staff share a sense of commitment to the school goals. 12345

2. Low achieving students are given opportunity for success in this school. 12345

3. School rules and expectations are clearly communicated. 12345

4. Teachers use a variety of teaching strategies.

5. Community businesses are active in this school.

6. Students are encouraged to help others with problems.

7. Faculty and staff feel that they make important contributions to this school. 12345

8. The administration communicates the belief that all students can learn. $\quad 12345$

9. Varied learning environments are provided to accommodate diverse teaching and learning styles.

10. The school building is neat, bright, clean, and comfortable.

11. Parents actively support school activities.

12. Parents are treated courteously when they call or visit the school.

13. Rules for student behavior are consistently enforced. 
14. School employees and students show respect for each others' individual differences.

15. Teachers at each grade (course) level design learning activities to support both curriculum and student needs. 5

16. Teachers are encouraged to communicate concerns, questions, and constructive ideas.

17. Students share the responsibility for keeping the school environment attractive and clean.

18. Parents are invited to serve on school advisory committees.

19. Parent volunteers are used wherever possible.

20. The administration encourages teachers to be creative and to try new methods.

21. Students are held responsible for their actions.

22. All students in this school are expected to master basic skills at each grade level.

23. Student discipline is administered fairly and appropriately.

24. Teachers often provide opportunities for students to develop higherorder skills.

25. Student misbehavior in this school does not interfere with the teaching process.

26. Students participate in solving school-related problems.

27. Students participate in classroom activities regardless of their sex, ethnicity, religion, socioeconomic status, or academic ability.

28. Faculty and staff cooperate a great deal in trying to achieve school goals.

29. An atmosphere of trust exists among the administration, faculty, staff, students, and parents.

30. Student tardiness or absence from school is not a major problem. 
31. Teachers are active participants in the decision making at this school.

32. Information about school activities is communicated to parents on a consistent basis.

33. Teachers use curriculum guides to ensure that similar subject content is covered within each grade.

34. The principal (or administration) provide useful feedback on staff performance.

35. Teachers use appropriate evaluation methods to determine student achievement.

36. The administration does a good job of protecting instructional time.

37. Parents are often invited to visit classrooms.

38. Teachers are proud of this school and its students.

39. This school is a safe place in which to work.

40. Most problems facing this school can be solved by the principal and faculty.

41. Pull-out programs do not interfere with basic skills instruction.

42. The principal is an effective instructional leader.

43. Teachers have high expectations for all students.

44. Teachers, administrators, and parents assume joint responsibility for student discipline.

45. The goals of this school are reviewed and updated regularly.

46. Student behavior is generally positive in this school.

12345

47. The principal is highly visible throughout the school.

48. Teachers use a wide range of teaching materials and media.

12345

49. People in this school really care about each other.

12345 
LETTERS OF PERMISSION TO CONTACT PRINCIPALS

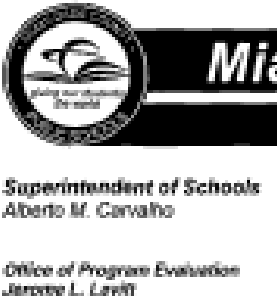

Onice of Progine $L$
EXECITE - IFPQNU giving our students the worid

Javar 25 aII

Mrami-Onde County School Board Ponte nouros Hastwin, Chay Q. Linovince S Fativiso, Wor Choir Dr Darctly Anodoso Mndivis Corlas L. Cantelo Rasier Dhe de is Portls Or. Whort "Toe" Holloway De Masin Kap Dr, Marta Aaver
Asoser A. Asosisoo

Ya. Valruxie Atecten

man $\times$ W. $5^{\mathrm{H}}$ Pase

Yiani. Farda 338t5-49

Dayr Ms. Whads:

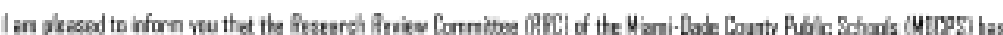

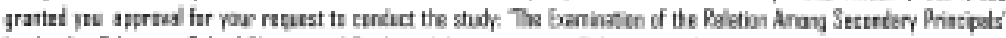

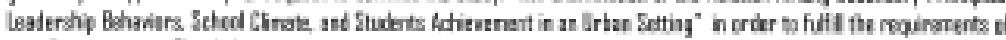

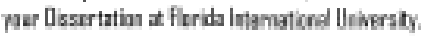

Tha epprod is grated with the filtivin condiers:

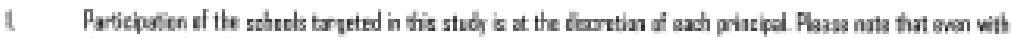

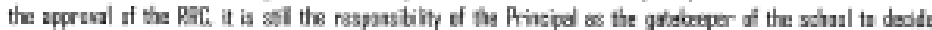

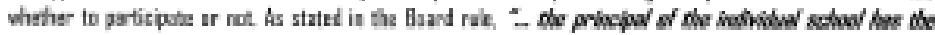

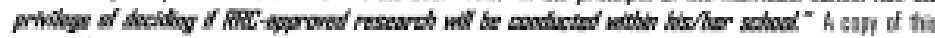
appreal letter nust be urasantad ta ech oritcija!

2. The participaten of all suljosts fuch as studerts faojty. ar steff) is valurtary

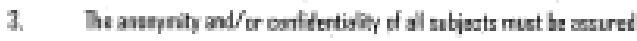

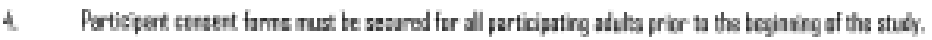

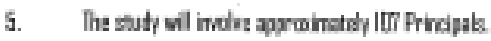

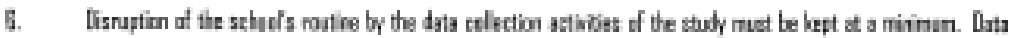

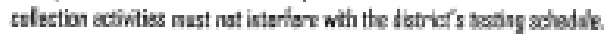

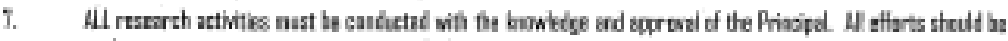
nata to ririniza any azgative inpact an tha laving uninunant.

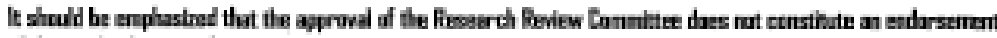

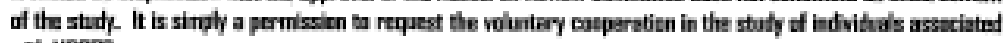
wath MOCPS.

Once of Program Evalusion * 1000 Blecayne Boubvard - Sute 224 * Man', R. 39132 305-995-7529 - 305-995-2691 $(F / N X) \cdot$ www dodeschools.net 


\section{THE SCHOOL BOARD OF BROWARD COUNTY, FLORIDA}

\section{RESEARCH SERVICES}

600 SOUTHEAST THIRD AVENUE • FORT LAUDERDALE, FLORIDA 33301-3125 • TEL 754-321-2500 • FAX 754-321-2520

MARIA R. LIGAS, Ph.D.

Institutional Review Board (IRB) Chai

marialigas@browardschools.com

June 9, 2011
SCHOOL BOARD

Chair BENJAMIN I. WILLIAMS

ANN MURRAY

ROBIN BARTLEMAN MAUREENS. DINNEN JENNIFER LEONARD GOTTLIEB LAURIE RICH LEVINSON NORA RUPERT DAVID THOMAS, NBCT

JAMES F. NOTTER Superinterdent of Schools

Dear Ms. Rhoden:

Thank you for submitting your research proposal, \#637 - The Examination of the Relation Among Secondary Principals' Leadership Behaviors, School Climate, and Student Achievement in an Urban Setting, for consideration by the Broward County Public Schools (BCPS). Staff has reviewed your research proposal and approval has been granted to contact the Principals at the following Middle and High Schools only:

Arthur Ash Middle School Lyons Creek Middle School Pioneer Middle School Piper High School Northeast High School South Broward High School

This approval means that we have found your proposed research methods to be compatible with a public school setting and your research questions of interest to the school District. The expiration date on your proposal is Friday, June 8, 2012. If you are unable to complete your research by the expiration date, you must submit an Annual Report/Request for Renewal, (http://www.broward.k12.fl.us/research_evaluation/IRB.Pdf), to the Research Services Department four weeks prior to the expiration date. If a renewal is granted, a Renewal Approval Letter and Memorandum will be issued.

Implementing your research, however, is a decision to be reached by the affected school-based staff on a strictly voluntary basis. To assist the school-based staff in their decision to participate, please outline the operational steps to be performed by staff at their school. Based upon this information, each school-based staff would then be asked to make a decision to participate or not and inform you or the requesting research parties of their decision at the time of your/their request. School-based staff have been instructed not to cooperate unless you provide both pieces of Approval Documentation.

The anticipated date for submitting an electronic copy of your research findings is Tuesday, October 9, 2012. If additional assistance is needed from our staff, please contact me at 754-321-2500.

$$
\begin{aligned}
& \text { Sincerely, } \\
& \text { c/ciciakasafoifantt } \\
& \text { Maria R. Ligas, Ph.D. }
\end{aligned}
$$

MRL/MAL:bt

Attachments 


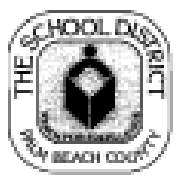

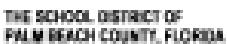

Wesk Hownad

warc avach Ft. D

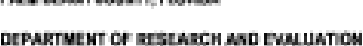

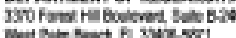

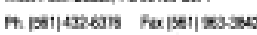

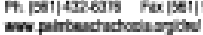

March 29, 2011

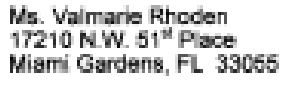

Dear Ms. Rhoden:

The Superintendent's Research Review Committee has approved your request to conduct the researeh study entled The Examination of the Reiation Amang Secondary Princiaals' Leadership Behawiova. Schod Civnate, and Student Achieverment in Chban Setting in the School District of Paim Beach County (the District). The purpcse of your study as indicated in your application is to test the relationship between principals' leadership behaviors, school cimate and studert achievement. Your study's focas will be firected at midde and high school principals in a comparisan of 30 schects

Accerding to our Datrict's precedures, schoal participatian is voluntary and subject to the authority of the school admiristration. To administer your research study, you require the parocipabon of the gencel prncipats to compene inree cinecent questionnaires. Your request to canduct research has been appraved at the folowing elgble schools.

\section{Middle Schools:}

BAK Midde School of the Arts

Christa MeAuime Middls Schoel

Congress Midde School

Crestwood Middle Scheo

Den Estridge High Tech Middle School

Eagles Landing Middle Schoc

Emersid Cove Middle Scheol

Independence Middle School

Jupiner Middle Schect

Logeers Run Midele School

Omni Middie Schoal

Osceda Creek Middle Schoo

Poia Park Middele Scheol

Rocesevelt Middle School

Welington Landings Mddle Scheel

Western Pines Midde Schoo

Wocelanda Midele School

\section{High Scheols:}

Alerander W. Dreytoos Jr. School of the Arts

Boca Raton Community High

Forest Hill Communty $\mathrm{High}$

Jupiter Communty High

Olymoic Heights Community High

Palm Beach Central High

Park Vista Community High

Royal Palm Beach Community Hgh

Semincle Ridge Community High

Spanish Rover Community High

Suncoesst High

West Boca Raton Community High

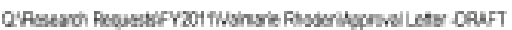

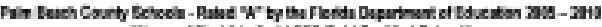

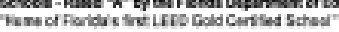

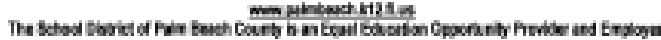




\section{APPENDIX F}

\section{PRENOTIFICATION LETTER TO PARTICIPANTS}

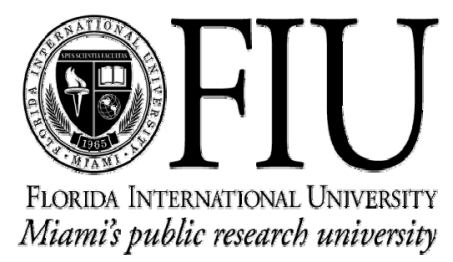

Good Morning, Principal:

The style of leadership you employ in your school today has the potential to significantly affect the school climate and achievement of your students. My name is Valmarie Rhoden, and I am doctoral candidate at Florida International University conducting research on the relationships between secondary school principals' leadership behaviors, school climate, and student achievement.

Previous research suggests that students' positive learning in urban schools is related to school climate through caring connections, behavioral support, and social and emotional learning, and that principals' leadership practices may affect school climate and student achievement.

Next week, you will be receiving an e-mail from me with a survey link asking you to provide your opinions in brief survey so that we may better understand this phenomenon. As a result of this research, I hope to provide you with valuable information about the critical elements needed for effective leadership toward the goal of school reform, resulting in a more positive school climate and greater achievement of your students.

Your participation in this research project will be strictly voluntary and no personally identifiable information will ever be associated with your responses in any way. I am hoping for a large response and, with your partnership, I will be able to better understand your views on your school climate and your leadership practices. If you have any questions or comments regarding this research project, please contact me by e-mail at valmarier@bellsouth.net or by phone at (786) 925-0104. You may also contact Dr. Thomas G. Reio, Jr., Department Chair, Educational Leadership and Policy Studies at Florida International University by e-mail at reiot@fiu.edu or Dr. Patricia Price, Chairperson of the Institutional Review Board by phone at 305-348-2618 or 305-3482494.

Please watch for the survey e-mail from Valmarie Rhoden early next week. Thank you for your help with this important project and for your collaboration.

Many thanks,

Valmarie Rhoden 


\section{SURVEY LAUNCH LETTER}

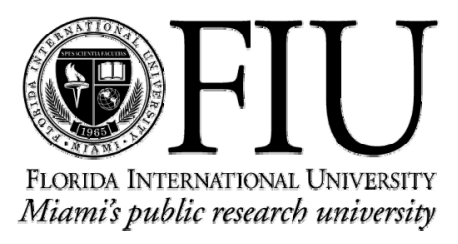

Good Morning/Afternoon:

I write today to ask for your participation in a survey being conducted by Florida International University with the support of your school district to better understand the relationship between principals' leadership styles, school climate, and student achievement. I am asking principals in the tri-county area of Miami-Dade, Broward, and Palm Beach Counties, just like you, to share your leadership practices and views on your school climate with us by answering just a few questions in the survey link below.

Your responses to this survey will help me advance my understanding of principals' leadership practices and their influence on school climate and student achievement.

This survey is comprised of a demographic questionnaire, a leadership practices inventory, and a school climate survey, that should take no more than 30 minutes of your time. Please click on the link below to go to the survey website (or copy and paste the survey link into your Internet browser) to begin this brief survey. Your participation constitutes your informed consent.

Survey link: http://www.surveymonkey.com/s/employee_engagement.

Your participation in this research study is entirely voluntary. All of your responses will be kept completely confidential. I will not ask for any private information, and no personally identifiable information will ever be associated with your responses in any way. In addition, to further assure your anonymity, all results will be reported in group form only.

Additionally, there are no known risks or benefits to you for helping with the survey. If you choose not to complete the survey, no other action is needed. Should you have any questions or comments regarding this research, please contact Valmarie Rhoden by email at valmarier@bellsouth.net or by phone at (786) 925-0104. You may also contact Dr. Thomas G. Reio, Jr., Department Chair, Educational Leadership and Policy Studies at Florida International University by e-mail at reiot@fiu.edu or Dr. Patricia Price, Chairperson of the Institutional Review Board by phone at 305-348-2618 or 305-3482494. 
I appreciate your time and consideration for taking this survey. Thank you for your participation in our study and for helping us better understand principals' leadership and its influence on school climate and student achievement.

Many thanks,

Valmarie Rhoden 
VITA

\section{VALMARIE RHODEN}

September 22, 1952

1969-1973

1984-1986

1989-1991

1973-1995

1996-2009
Born, Ft. Lauderdale, Florida

B.S., Business Education

Florida State University

Tallahassee, Florida

M.S., Reading

Nova University

Ft. Lauderdale, Florida

Certification, Area Vocational Director

Florida International University

Miami, Florida

Business Education Teacher

Miami-Dade County Public Schools

Miami, Florida

Principal

William H. Turner Technical Arts High School

Miami, Florida

\section{PUBLICATIONS AND PRESENTATIONS}

Rhoden, V. (2005, Month). Best practices in urban education. Paper presented at the meeting of the Connecticut Learn and Serve Annual Spring Conference, Westbrook, Connecticut.

Rhoden, V. (2007, Month). The senior capstone project. Paper presented at the meeting of the Connecticut Learn and Serve Annual Spring Conference, Westbrook, Connecticut.

Rhoden, V., Posey, E. R., Archie, S. L., \& Anim, E. (2008, Month). Implementing the career academy model. Paper presented at the meeting of the National Alliance of Black School Educators Conference, Atlanta, Georgia.

Rhoden, V., Boykin, W., Williams, B., et al. (2009, Month). Keeping Asa Hillard's vision alive: The 2009 Egyptian Symposium and Tour. Paper presented at the meeting of the National Alliance of Black School Educators Conference, Indianapolis, Indiana. 
Rhoden, V., Williams, A., \& Dixon, J. (2011, Month). Teen court/Student court: Intervention strategies for youthful offenders. Paper presented at the meeting of the National Alliance of Black School Educators Conference, New Orleans, Louisiana. 